\title{
NATIONAL SPACE BIOMEDICAL RESEARCH INSTITUTE
}

\author{
Annual Report \\ October 1, 1997 - September 30, 1998 \\ $\frac{1 N-52}{417980}$
}

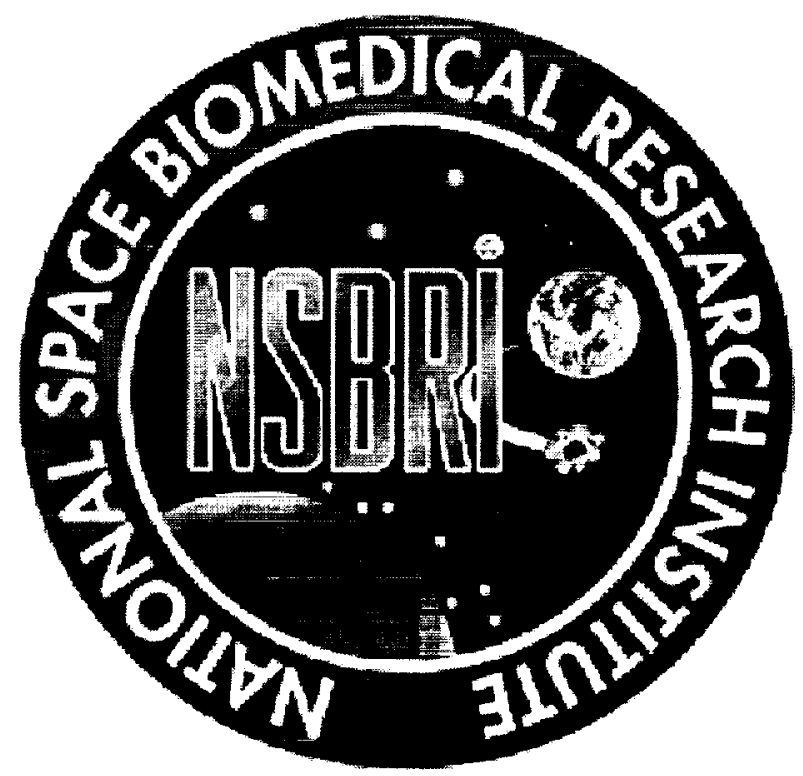

Cooperative Agreement NCC 9-58

with the

National Aeronautics and Space Administration

Lyndon B. Johnson Space Center

Houston, Texas

September 30, 1998 


\title{
NATIONAL SPACE BIOMEDICAL RESEARCH INSTITUTE
}

\author{
ANNUAL REPORT \\ OCTOBER 1, 1997 - SEPTEMBER 30, 1998 \\ (Cooperative Agreement NCC 9-58) \\ TABLE OF CONTENTS
}

1.0 INTRODUCTION............................................................................................................

2.0 RESEARCH PLAN ....................................................................................................

2.1 Development and Implementation of the Plan .....................................................

2.2 Research Highlights......................................................................................................

3.0 KEY PERSONNEL …....................................................................................................13

4.0 MANAGEMENT PLAN …….......................................................................................14

5.0 COMMERCIALIZATION, EDUCATION AND PUBLIC OUTREACH..............20

INSTITUTE DIVERSITY AND SCIENTIFIC COMMUNITY

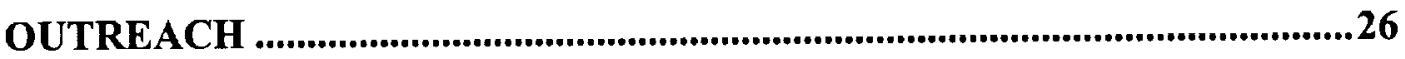

7.0 SPECIAL PROJECTS ......................................................................................................26

$\underline{\text { Tables }}$

1. Schedule of NSBRI/NASA team meetings held at Johnson Space Center .................4

2. Schedule of activities concerned with peer review and selection of initial set of NSBRI research proposals .................................................................................5

3. National Space Biomedical Research Institute BOARD OF DIRECTORS .............16

4. National Space Biomedical Research Institute EXTERNAL ADVISORY COUNCIL.

5. National Space Biomedical Research Institute BOARD OF SCIENTIFIC COUNSELORS

6. National Space Biomedical Research Institute USER PANEL 


\section{Tables (continued)}

7. Membership in the National Space Biomedical Research Institute INDUSTRY

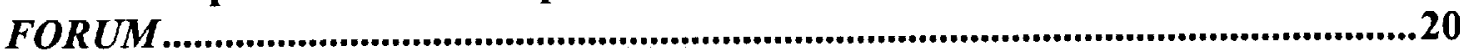

8. Outreach and public education partners and areas of concentration ......................24

9. First year accomplishments of the NSBRI education and public outreach team ..25

10. Life sciences scientific personnel transitions .28

\section{Figures}

1. Project review scores for the 58 initial NSBRI project candidates 7

2. Originally proposed NSBRI structure ..................................................................................15

3. Architecture planned for the Institute Data Archiving System (IDAS) ....................29

\section{$\underline{\text { Appendices }}$}

A. Peer review panels participating in the review of NSBRI's initial proposals

B. NSBRI Research Program - Year 1

C. Biographical Sketch - William T. Shearer, M.D., Ph.D.

D. Agreement of Affiliation between the Institute of Aerospace Medicine of the German Aerospace Center and the National Space Biomedical Research Institute

E. Agenda - NSBRI Retreat - June 8-11, 1998

F. NSBRI Industry Forum Materials

G. NSBRI Investigator List

H. Program Announcement for the NIDCD-NSBRI Program for the Support of Vestibular Research 


\title{
NATIONAL SPACE BIOMEDICAL RESEARCH INSTITUTE
}

\author{
ANNUAL REPORT \\ OCTOBER 1, 1997 - SEPTEMBER 30, 1998 \\ (Cooperative Agreement NCC 9-58)
}

\section{$1.0 \quad$ INTRODUCTION}

The National Space Biomedical Research Institute (NSBRI) sponsors and performs fundamental and applied space biomedical research with the mission of leading a world-class, national effort in integrated, critical path space biomedical research that supports NASA's Human Exploration and Development of Space (HEDS) Strategic Plan. It focuses on the enabling of long-term human presence in, development of, and exploration of space. This will be accomplished by:

- designing, implementing, and validating effective countermeasures to address the biological and environmental impediments to long-term human space flight;

- defining the molecular, cellular, organ-level, integrated responses and mechanistic relationships that ultimately determine these impediments, where such activity fosters the development of novel countermeasures;

- establishing biomedical support technologies to maximize human performance in space, reduce biomedical hazards to an acceptable level, and deliver quality medical care;

- transferring and disseminating the biomedical advances in knowledge and technology acquired through living and working in space to the benefit of mankind in space and on Earth, including the treatment of patients suffering from gravity- and radiation-related conditions on Earth; and

- ensuring open involvement of the scientific community, industry, and the public at large in the Institute's activities and fostering a robust collaboration with NASA, particularly through Johnson Space Center.

The National Space Biomedical Research Institute is a private, non-profit organization established in April 1997 following competitive selection by NASA to lead a national effort to carry out the research required to assure safe human exploration of space. It is governed by a consortium of educational institutions (including Baylor College of Medicine, Harvard Medical School, The Johns Hopkins University School of Medicine and the Applied Physics Laboratory, Massachusetts Institute of Technology, Morehouse School of Medicine, Rice University, and Texas A\&M University). The Institute's headquarters are in Houston at Baylor College of Medicine.

The NSBRI's research program is carried out at nineteen universities and government laboratories in addition to the consortium institutions. At these institutions, the NSBRI's research activities are built upon the considerable infrastructure already developed through existing Federal programs. Ten companies and non-profit organizations serve as industrial partners of the Institute. The management plan for the Institute is based on the model used by the National Institutes of Health. An independent Board of Scientific Counselors is responsible for assuring excellence in the Institute's intramural program through independent external peer review, and an External Advisory Council, consisting of leaders in the research fields central to the Institute's mission, is responsible for advising Institute management concerning programmatic effective- 
ness. In addition, the NSBRI has a User Panel of former and current astronauts and flight surgeons responsible for assuring that the research program is focussed squarely on astronaut health and safety, and an Industry Forum of representatives of space and biomedically-related industries that assists the Institute in developing industry participation in NSBRI and the timely transfer of technology.

The strategic research agenda of the NSBRI currently involves eight teams of research scientists focussed on:

- Bone Loss - Addressing the loss and weakening of bone during space flight with the inherent risks of fracture;

- Cardiovascular Alterations - Addressing the inflight increase of cardiac dysrhythmias and the postflight impairment of the cardiovascular response to orthostatic and exercise stress;

- Human Performance - Addressing maintenance of high cognitive performance and vigilance despite environmental or psychosocial stress and sleep disturbances;

- Immunology, Infection and Hematology - Addressing the potential for immune system impairment and altered susceptibility to infection, increased allergic response, decreased blood volume and postflight anemia;

- Muscle Alterations and Atrophy - Addressing the loss of skeletal muscle mass, strength and endurance that accompanies space flight;

- Neurovestibular Adaptation - Addressing the problems of space motion sickness and disorientation during flight and the postflight problems of balance and gaze disorders;

- Radiation Effects - Addressing the problem of increased cancer risk caused by the natural space radiation environment; and

- Technology Development - Developing instrumentation that will enhance the research of the other teams and transfer the technology to industry for the benefit of society.

The total current intramural research program, including all eight research areas, involves 41 projects, with an average funding per project of approximately $\$ 200,000$ (Direct + Indirect Costs).

In addition, the NSBRI has developed partnerships with both the National Science Foundation and one of the institutes of the National Institutes of Health (National Institute on Deafness and Other Communication Disorders, NIDCD) to jointly fund competitive extramural research grants focussing simultaneously on health on Earth and in space while complementing the NSBRI's intramural tasks. Peer reviews for these programs are managed by the partner, while the NSBRI's funds for these activities presently come from private sources.

The NSBRI also has signed an agreement of affiliation with the Institute of Aerospace Medicine of the German Aerospace Center (Deutsches Zentrum für Luft- und Raumfahrt e.V., DLR) enabling German-funded projects to become part of the NSBRI's intramural program

Finally, the NSBRI has developed a vital program of education and outreach, translating cuttingedge research from the laboratory to the classroom and home. This important program provides for: development of several types of classroom materials; a summer teacher training program; the preparation of a public documentary television program on space biomedical research; and a television series (Liftoff to Health, The Story of Medicine and Space) depicting the benefits medicine has received from the space program.

In summary, the NSBRI has established itself as the preeminent NASA-sponsored organization conducting the research necessary to understand the effects of the space environment on humans 
and using that information to develop countermeasures to the risks of space flight. In the short time that it has been in existence, the NSBRI has successfully implemented a sound management plan overseen by a unique consortium of some of the top medical and research universities in the country and has developed the infrastructure necessary to manage a complete biomedical research program. The NSBRI's current research program involves a core of strong biomedical researchers, selected through careful peer review and utilizing the modern tools of medical science. It has involved a number of investigators at NASA's Johnson Space Center in joint activities and reaps the fruit of their practical experience. In addition, the Institute has begun to invest in the education of school children and in raising public awareness of the benefits of space research. Finally, the NSBRI has established close connections and joint model programs with other Federal agencies, including the NIH and the NSF, and has developed good relations and partnerships with non-U.S. space agencies and the international biomedical science community, including a program that enables German-funded projects to be incorporated into the NSBRI's intramural teams.

\subsection{RESEARCH PLAN}

The original research plan for the NSBRI was conceived and developed by Institute management with the eight Research Team Leaders and the original investigators involved in the preparation of the proposal to NASA to establish the NSBRI (in mid-to-late 1996). In that winning proposal, the following statement was made concerning the steps to be taken to establish the Institute's research plan:

Upon award of the NSBRI, the individual investigators and teams will prepare fulllength, substantive scientific/technical proposals for formal independent peer-review by the Institute's Board of Scientific Counselors, an external group of scientists to be managed for the NSBRI by Information Dynamics, Inc. (IDI). No Institute Core research will be funded unless it meets appropriate standards of mission relevance, scientific excellence, and achievability. It should take four months or less to prepare and review the Institute task proposals and one month or less to prepare a detailed task funding plan and review this plan with the Institute's External Advisory Council. Thus, if NASA's stated selection schedule is maintained, the Institute Core research program will be implemented by September 1997.

In fact, even though the selection schedule was modified slightly, the plan, exactly as presented in the proposal, was carried out and the Institute's research program began on schedule in October 1997.

\subsection{Development and Implementation of the Plan}

The NSBRI was initiated with a Definition Phase lasting from April 1 to May 31, 1997. During this period, meetings were held between representatives of NASA and the NSBRI to discuss the approach to be taken for further interactions, to develop a mutual understanding of the strengths of and resources of each side, and to develop the appropriate management interfaces. These meetings resulted in the development of the Cooperative Agreement Management Plan for the Establishment of the National Space Biomedical Research Institute (CAMP), a controlled document that provides details through which NASA and the NSBRI will manage and conduct their joint activities. The CAMP and the Cooperative Agreement itself were signed at Johnson Space Center by senior representatives of NASA and the NSBRI on May 29, 1997. 
A ground-breaking activity during the Definition Phase was a series of working scientist meetings held at JSC to orient both NSBRI and NASA investigators to the function of the NSBRI within the NASA program, and to enable the scientists themselves to interact and develop collegial relationships. The full NSBRI management team and JSC senior management facilitated interactions between the two sides at each of the meetings. Table 1 presents the definition-period schedule of these working meetings.

Table 1. Schedule of NSBRI/NASA team meetings held at Johnson Space Center.

\begin{tabular}{|c|c|c|c|}
\hline $\begin{array}{l}\text { DATE } \\
(1997)\end{array}$ & TEAM & $\begin{array}{c}\text { NSBRI } \\
\text { COORDINATOR }\end{array}$ & $\begin{array}{c}\text { NASA } \\
\text { COORDINATOR }\end{array}$ \\
\hline April 16-17 & $\begin{array}{l}\text { Human Performance Factors, } \\
\text { Sleep, and Chronobiology }\end{array}$ & C. Czeisler & L. Putcha \\
\hline April 29-30 & Neurovestibular Adaptation & C. Oman & M. Reschke \\
\hline May 5-6 & $\begin{array}{l}\text { Muscle Alterations and } \\
\text { Atrophy }\end{array}$ & R. Schwartz & D. Feeback \\
\hline May 7-8 & $\begin{array}{l}\text { Hematology, Immunology, } \\
\text { and Infection }\end{array}$ & F. Rudolph & D. Pierson \\
\hline May 8-9 & $\begin{array}{l}\text { Bone Demineralization \& } \\
\text { Calcium Metabolism }\end{array}$ & J. Shapiro & L. Schakelford \\
\hline May 12-13 & Radiation Effects & J. Dicello & T. Yang \\
\hline May 13-14 & Technology Development & V. Pisacane & D. Feeback \\
\hline May 15 & Data Archive & V. Pisacane & J. Cox \\
\hline May 27-28 & Cardiovascular Alterations & R. Cohen & J. Yelle \\
\hline May 28 & Education \& Outreach & W. Thomson & D. Sickorez \\
\hline May 30 & Telemedicine & V. Pisacane & R. Billica \\
\hline
\end{tabular}

These meetings discussed the latest space research activity by NASA investigators and the research strategies proposed by NSBRI teams; they enabled the NSBRI research teams to develop even stronger sets of research projects for possible funding as part of the NSBRI core research program. During the months of April and May, significant effort was devoted to proposal preparation by all of the teams. Finally, during the Definition Period, the NSBRI implemented its proposed and accepted peer review plan by developing a contract with Information Dynamics, Inc. (IDI) to select and manage eight panels to review the detailed research proposals of the NSBRI Research Teams during July and August.

Table 2 presents the schedule of activities related to the peer review of the initial set of NSBRI research proposals. The members of the eight panels carrying out the reviews are provided in Appendix A of this report. 
Table 2. Schedule of activities concerned with peer review and selection of initial set of NSBRI research proposals.

\begin{tabular}{|l|l|}
\hline $\begin{array}{l}\text { DATE } \\
\text { (1997) }\end{array}$ & $\begin{array}{l}\text { Integrated Research Team Proposals Due at Peer Review Contractor } \\
\text { (IDI) Offices in Washington, DC }\end{array}$ \\
\hline June 20 & Cardiovascular Alterations Site Visit. MIT \\
\hline July 20-22 & Neurovestibular Adaptation Site Visit. MIT \\
\hline July 22-24 & Hematology, Immunology, and Infection Site Visit. Rice \\
\hline July 24-26 & Technology Development Site Visit. Johns Hopkins/APL \\
\hline July 30 - August 1 & Bone Demineralization/Calcium Metabolism Site Visit. Johns Hopkins \\
\hline August 3-5 & Muscle Alterations and Atrophy Site Visit. Baylor College of Medicine \\
\hline August 5-7 & $\begin{array}{l}\text { Human Performance Factors, Sleep, and Chronobiology Site Visit. } \\
\text { Harvard Medical School }\end{array}$ \\
\hline August 10-12 & Radiation Effects Site Visit. Johns Hopkins \\
\hline August 15 & $\begin{array}{l}\text { Latest Date for IDI to Provide Peer Review Scores and Critiques to } \\
\text { NSBRI }\end{array}$ \\
\hline September 2-3 & $\begin{array}{l}\text { Team Leaders Present Funding Recommendations to NSBRI } \\
\text { Management (Baltimore) }\end{array}$ \\
\hline September 5 & $\begin{array}{l}\text { Recommended Selection/Funding Plan Developed by NSBRI } \\
\text { Management and Sent to NSBRI Council }\end{array}$ \\
\hline September 15-16 & $\begin{array}{l}\text { NSBRI Council Meeting to Review FY 1998 Operational Plan; } \\
\text { Recommendation Forwarded to NSBRI Board (Houston) }\end{array}$ \\
\hline September 22-23 & $\begin{array}{l}\text { NSBRI Board of Directors Meeting to Determine FY 1998 Operational } \\
\text { Plan (Houston) }\end{array}$ \\
\hline September 30 & NSBRI Start-Up Phase Ends \\
\hline October 1 & $\begin{array}{l}\text { Rirst Operational Year (FY 1998) of NSBRI Begins } \\
\text { Research Team Funding Initiated for Approved Program }\end{array}$ \\
\hline
\end{tabular}

Fifty-eight project proposals were submitted for possible inclusion in NSBRI's initial research program. Five were in Bone Loss: Mechanical Load Effects on Bone Formation and Remodeling; Novel Receptor-Based Countermeasures to Microgravity-Induced Bone Loss; Bone 
Blood Flow and Hindlimb Suspension; The Effects of Partial Mechanical Loading and Ibandronate on Skeletal Tissues in the Adult Rat Hindquarter Suspension Model of Microgravity; and Skeletal Structural Consequences of Reduced Gravity Environments. Eleven were in Cardiovascular Alterations: Human Studies Core; Alterations in Cardiovascular Regulation and Function During Simulated Microgravity; Microgravity-Induced Changes in Vascular Reactivity and Cardiac Mass; Renal and Cardio-Endocrine Responses in Humans to Simulated Microgravity; Non-Invasive Assessment of Susceptibility in Ventricular Arrhythmias During Simulated Microgravity; Rodent Studies of Cardiovascular Deconditioning; Cardiovascular Responses to Gravitational Stress Following Prolonged Exposure to Simulated Microgravity; Effect of Microgravity on Cardiovascular Hemodynamic and Neuroendocrine Responses; Role of Nitric Oxide and ACE in Cardiovascular Deconditioning in Microgravity; Computational Models of the Cardiovascular System and Its Responses to Microgravity; and Cardiac Atrophy.

Six projects were in Human Performance: Circadian Entrainment Sleep-Wake Regulation and Neurobehavioral Performance During Extended Duration Space Flight; Countermeasures to Neurobehavioral Deficits from Cumulative Partial Sleep Deprivation During Space Flight; Topographical EEG Monitoring of Vigilance: Effects of Sleep Deprivation and Posture; OnLine Analysis of Physiologic and Neurobehavioral Variables During Long-Duration Space Missions; Human Interaction with Trusted Automation; P.I-in-a-Box. Four were in Immunology, Infection, and Hematology: Cellular and Molecular Mechanisms of Immune Dysfunction in Space Flight; Immune Function and Reactivation of Latent Virus; Molecular Pathogenesis of Infection Caused by Opportunistic Gram-Positive Bacteria; and Neocytolysis: Mechanisms and Limitations.

Nine projects were in Muscle Alterations and Atrophy: GH/IGF-1 Transgene Expression on Muscle Homeostasis; $\beta$-Adrenergic Receptor Agonist Countermeasures; Pharmacological Inhibitors of the Proteosome in Atrophying Muscles; Proprioceptive Regulation Release of Growth Factors; Molecular Signaling in Muscle Plasticity; Activity Dependent Signal Transduction in Skeletal Muscle; Molecular Mechanisms Regulating Muscle Fiber Composition Under Microgravity; Motoneuron Influences on Muscle Atrophy in Simulated Microgravity Induced Muscle Atrophy; Aging as a Model for Microgravity-Induced Functional Deficit: Pulsive Exercise as a Countermeasure. Five projects were in Neurovestibular Adaptation: Context-Specific Adaptation of Gravity-Dependent Vestibular Reflex Responses; Visual Orientation in Unfamiliar Gravito-Inertial Environments; Advanced Techniques for Assessment of Postural and Locomotor Ataxia, Spatial Orientation, and Gaze Stability; Validated PostFlight Neurovestibular Countermeasures for Patients and Astronauts; and Predictive Models and Assessment of Astronaut Movement Control Dynamics.

Eleven projects dealt with Radiation Effects: Radiation Effects: Core Project; Chemoprevention of Radiation Induced Rat Mammary Neoplasms; Radiation-Induced Cytogenetic Damage as a Predictor of Cancer Risk for Protons and Fe Ions; Cytogenetic Studies of Mammary Epithelial Cells Exposed to Gamma Rays and Charged Particles; Validating Rodent Chemopreventive Studies for Humans: Repair of Space Radiation DNA Damage; Effects of Whole-Body Proton and ${ }^{60}$ Cobalt Irradiation on Tumor Promotion in an Intact Animal Model; Modulation of Ionizing Radiation Effects in C. Elegans by Genes Regulating Apoptosis and Oxidative Stress; Quantitation of Radiation Induced Deletion and Recombination Events Associated with Repeated DNA Sequences; Ocular Effects of High Atomic Number High Energy (HZE) Particles; Dose-Response Model for Radiation Induced Cataract; Loss of Cell Cycle Control in Radiation Induced Cataracts: A Role for p57 (KIP2). Finally, seven projects 
focussed on Technology Development: Miniature X-ray Bone Densitometer; Instrumentation for Non-Invasive Assessment of Cardiovascular Regulation; Advanced Ingestible Telemetry Pill Development; Miniature Time-of-Flight Mass Spectrometer; In-Situ Spectrometry of Neutrons; Multi-Beam Echocardiography; Development of Rapid, Noninvasive Chemical Sensing and Transdermal Drug Delivery For Space Flight.

Proposals were scored from 0 to 100 points. Each project was placed in one of the following categories.

- Excellent

- Good

- Weak
Scoring Range: 85 - 100 Points

Proposals in this category represent superior proposals and are definite candidates for funding as part of the research program.

Scoring Range: 65 - 84 Points

Proposals in this category represent sound proposals that are worthy of support, but with a lower priority than those in the Excellent category.

Scoring Range: 0 - 64 Points

Proposals in this category represent proposals that have significant weaknesses in any area. They are not worthy of support in their present form.

Figure 1 shows the distribution of scores for all 58 proposals received. Thirty-six proposals were candidates for selection, having scores of 65 or better. From these candidates, 34 projects were selected for funding, although budgetary constraints frequently required that awards were less than the requested level. Funding for these projects began in October 1997.

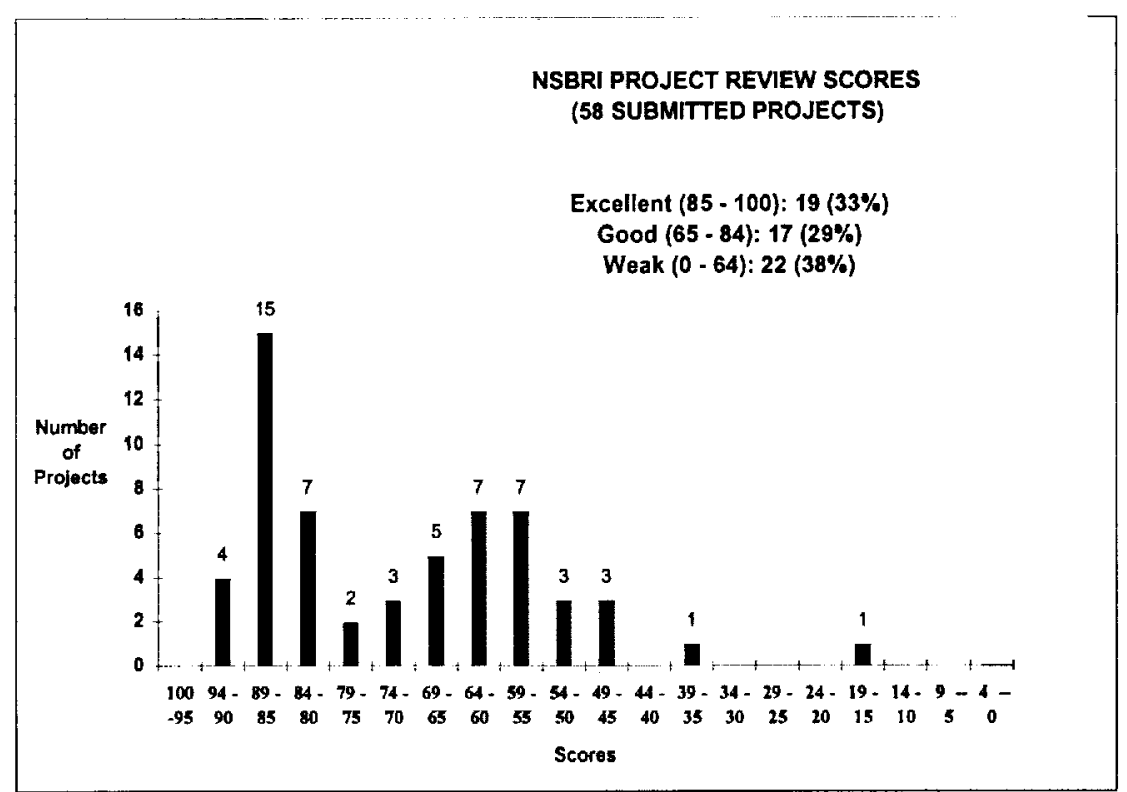

Figure 1. Project review scores for the 58 initial NSBRI project candidates. 
Following the October selection, it became clear that several gaps were present in the NSBRI's research program, particularly in the area of Immunology. Steps were taken to close that particular gap by recruiting a senior scientist from Baylor College of Medicine to develop a key project to study space immunodeficiency. Proposals for this project and several others identified as highly relevant to the research program but requiring revision and further review prior to selection, were prepared and submitted for review in February 1998. They were reviewed to the same standards by the same panels that were used in the Summer 1997 review. Three additional projects were selected for funding (beginning in April 1998) as a result of this review. Finally, the February submission included a special set of "synergy proposals" for research to be carried out and completed in one year at a total cost not to exceed $\$ 50,000$. These synergy proposals were concerned with new research activities that related to currently funded projects in at least two different research areas. Review criteria for this new group of proposals included the scientific and technical merit of the proposal, the ability of the investigator and his team to carry out the proposal to a successful conclusion in the time available, and the contribution that the proposed activity would make to integrating the research activities of two or more teams. Nine synergy proposals were submitted; four were selected for funding.

Appendix B provides abstracts and investigator information for all 41 currently funded research projects. The NSBRI research program involves 133 investigators from 25 institutions.

\subsection{Research Highlights}

All 41 of the NSBRI funded research projects were initiated in FY 1998. Although not all of these studies have had sufficient time to produce results, having completed only 6 months to one year of work, a number of research results and findings are available. These highlights are only some of the initial results from some of the projects and are, by no means, a complete summary of the first year research. They are presented here for NASA internal use only. Results are privileged and should not be published or quoted from directly until the investigators have had the opportunity of publishing them in peer-reviewed journals.

Peripheral quantitative computed tomography (pQCT) was applied to the study of femoral neck bone from male Fischer rats aged 6 months $(n=8)$ and 24 months $(n=8)$. A single slice located at the center of the femoral neck perpendicular to its long axis was assessed for volumetric BMD and area of the entire bone as well as for cortical (CRT) and trabecular (TRB) components. Polar cross-sectional moment of inertia (CSMIp) for total bone were calculated from area and density values. Bones were then subjected to mechanical testing with an Instron 1125 device. Maximal (MAX) load at fracture and stiffness were calculated from the load-displacement curve. When comparing results from the senescent, 24-mo-old rats to those of 6-mo-old adult rats, density of trabecular bone declined $21 \%(\mathrm{p}=0.002)$, whereas density of the cortical shell remained constant. Total bone area and cross-sectional moment of inertia increased $11 \%$ and $23 \%$, respectively. Direct measurement of structural properties shows that MAX load is higher by $23 \%$ and stiffness by $52 \%$ in older rats. Multiple linear regression analysis of pooled data suggests that variations in femoral neck morphometry (i.e., cross-sectional moment of inertia) are largely responsible for the higher MAX load and stiffness of femoral necks in aged male rats, and that alterations in trabecular bone mineral density of the femoral neck minimally affect its strength. These same analyses are being applied to various bone sites, including the femoral neck, in animals subjected to hindlimb unloading as a model of microgravity. (Bloomfield) 
Bioreactors have been used to grow three-dimensional arrays of MG-63 cells and the responses of these cells have been compared with those at unit gravity and with those exposed to microgravity aboard the Foton 10 satellite by Carmeliet et al. (J. Bone Miner Res 1997:786-794). Carmeliet et al. measured alkaline phosphatase activity, as well as the mRNA levels for a number of marker genes. They found that in microgravity, induction of alkaline phosphatase by TGF- $\beta$ and $10^{-7} \mathrm{M}$ calcitriol was only about 1.8 fold. In agreement with this, a similar increase was found in the present bioreactor study. The flight studies showed that microgravity treatment reduced the levels of osteocalcin mRNA to about 15-20\% of control, but the investigators were unable to measure osteocalcin secretion for technical reasons. In the present studies, osteocalcin was measured by immunoassay. While there are essentially identical extremely low levels of osteocalcin in the uninduced conditions, osteocalcin increased 100 fold upon treatment in unit gravity whereas no increase was detected in the bioreactor. Measurements of mRNA levels are ongoing. These studies support the hypothesis that that the bioreactors are mimicking the microgravity conditions. In order to begin to understand the reasons for the lack of response to calcitriol, vitamin D receptor levels have been measured in cells grown in the bioreactor versus control cells. Initial immunoblots suggest that the levels of the vitamin D receptor are substantially reduced in the bioreactor. To determine whether the cells exposed to microgravitylike conditions in the bioreactor alter their basal signaling responses, phosphorylation sitespecific antibodies have been used to measure the levels of mitogen-activated protein kinases (MAPK) and stress-activated protein kinases (SAPK). Although there was little change in activation of MAPK, the SAPK activity was greatly increased indicating that the MG-63 cells respond to microgravity as a stress condition. If these findings are confirmed in the ongoing experiment, then a major defect in microgravity may be downregulation of the vitamin $\mathrm{D}$ receptor. Microgravity-induced bone loss is a consequence of bone resorption in excess of bone formation. Although both decreased bone formation and increased resorption have been documented in different animal models and in bed rest studies, the flight response appears weighted towards increased bone resorption. Increased Calcium Receptor (CaR) activity promotes bone formation and inhibits bone breakdown. CaR activity may modulate increased osteoblastogenesis and reduced osteoclastogenesis. Thus, $\mathrm{CaR}$ activators could be beneficial for the treatment of microgravity-induced osteoporosis. Results to date indicate that $\mathrm{CaR}$ agonists stimulate chemotaxis and DNA synthesis in MC3T3-E1 osteoblastic cells. The treatment of mixed mouse marrow cultures with 1,25-dihydroxyvitamin $\mathrm{D}$ promotes the formation of $\mathrm{CaR}$ positive multinucleated osteoclast-like cells that also express tartrate-resistant alkaline phosphatase characteristic of osteoclasts. This result suggests strongly that the osteoclast will be responsive to the inhibitory action of $\mathrm{CaR}$ agonists. (O'Malley)

The project on Circadian Entrainment, Sleep-Wake Regulation and Neurobehavioral Performance has carried out seven experiments in healthy adults in which circadian rhythms of body temperature and hormones, as well as sleep, performance and mood were measured 24 hours a day for 55 consecutive days in the laboratory, to determine the light exposure (intensity, duration, and timing) necessary for humans to maintain circadian entrainment to the Martian day $(24.61 \mathrm{hr})$ relative to the Earth day $(24.0 \mathrm{hr})$. This research on light as a countermeasure for extended duration flight was complemented by research these investigators completed on (i) the implementation of pre-launch bright light exposure to help shuttle astronauts quickly adjust to circadian inversions caused by dual-shift missions; and on (ii) flight-based studies of circadian physiology, sleep, and performance aboard 1998 space shuttle missions STS-90 and STS-95, to determine the effectiveness of melatonin to improve in-flight sleep of astronauts. These investigators have also recently received an NIH grant to perform ground-based experiments on the effectiveness of melatonin as a hypnotic. (Czeisler) 
The project on Countermeasures to Neurobehavioral Deficits from Cumulative Partial Sleep Deprivation has studied 30 healthy adults in which circadian core body temperature, sleep physiology, and a range of neurobehavioral functions were measured 24 hours a day for 14 consecutive days in the laboratory, to determine the sleep timing (episodes, duration, circadian placement) necessary to prevent cumulative performance deficits. Eventually, 18 different sleep regimes will be evaluated and compared quantitatively using response surface modeling. This NSBRI project is complemented by research these investigators have underway for NIH on the nature of cumulative cognitive performance deficits when sleep restriction occurs chronically at different circadian phases. A second major goal of this project is to develop novel technologies for the objective assessment of human functional capability relative to chronic sleep loss and circadian disturbance in space flight. To this end, three advances have been made in year 1: (i) the deployment of highly sensitive, brief performance tests (e.g., PVT) in other team projects and for testing astronauts in STS-90 and STS-95 shuttle missions; (ii) testing of a new nonthrombogenic catheter and miniature blood pump system for the study of growth hormone secretion during altered sleep and waking; and (iii) through a complementary project with the Department of Transportation, validation of a new, objective non-performance-based biobehavioral technique for detecting drowsiness during work. (Dinges)

The project on Quantitative EEG Monitoring of Vigilance has analyzed EEG and EOG correlates of decrements in neurobehavioral performance associated with circadian melatonin phase and sleep loss in ten healthy adults under the unmasking conditions of a constant routine. The results confirm a close relationship between sleepiness, slow eye movements, and melatonin levels, and indicate that low frequency EEG activity $(1-7 \mathrm{~Hz})$ recorded from frontal areas of the brain changes in response to the duration of wakefulness. (Dijk)

The phi-X174 bacteriophage has been grown in culture to test up to 60 Antarctic study subjects for this project. The bacteriophage and other reagents will be taken to the Antarctic outposts by an ice-breaker supply ship in December 1998. This sophisticated neo-antigen will yield extremely valuable information on the ability of T-lymphocytes to signal B-lymphocytes to switch from transient $\operatorname{IgM}$ antibody to long-lasting $\operatorname{IgG}$ antibody production, a previously untested component of space research. (Shearer)

The project involving Immune Function and Reactivation of Latent Viruses has made substantial progress in completing the creation of viral nucleic acid probes which will enable investigators to determine latent virus (e.g., EBV, HSV, CMV) activation in study subjects in the Antarctic and in earth-bound space capsules. (Butel)

A real-time bacterial contamination system is nearing completion and can already detect many bacteria found in drinking water. Plans are being made to develop an instantaneous readout system that can send space capsule drinking water contamination information back to Mission Control on Earth. (Fox)

Young red blood cells have been identified successfully by the binding of wheat germ lectin to membrane sialic acid molecules with flow cytometry. This is important as a first step in determining why young red blood cells are so susceptible to the effects of leaving and entering Earth's gravity. (Alfrey)

Procedures have been established for this project to perform hindlimb unweighting and resistance training in mice. The development of mice as an experimental model allows the addition of the powerful tool of transgenic animals to NASA's toolbox. Mice with normal cage activity that 
were genetically engineered to over express IGF-I had muscle hypertrophy. However, the excess amount of IGF-I in muscle did not prevent atrophy in the Earth-model of space flight either in mice without a countermeasure or in mice with two daily bouts of treadmill walking. Currently a new group of mice with excess IGF-I in their skeletal muscles are undergoing concentric and eccentric resistance training while in the Earth model of space flight. In very exciting data being collected now, growth hormone releasing factor administration to normal young pigs resulted in doubling their growth rate. Next, this technology will be applied to hindlimb-unweighted mice performing resistance training. (Schwartz)

Muscle is converted to an inefficient motor during space flight because skeletal muscle loses its efficient myosin enzyme and burns extra ATP resulting in premature fatigue. NSBRI research has shown that the loss of the efficient enzyme from the muscle is due to a reduced translational formation of this protein. In addition, space flight induced muscle loss is produced in part by increased breakdown of existing muscle proteins. It has been found that most of this breakdown occurs in the "N-end" ubiquitination pathway in skeletal muscle myosin. (Goldberg)

In examining head/neck reflexes in response to whole body rotation in different orientations, it has been found that yaw head rotation is the largest response component to on-axis yaw trunk rotation, roll is the largest response component to eccentric rotation while facing (or back to) the direction of motion (centripetal force along the inter-aural axis), and pitch is the largest response component to eccentric rotation facing (or back to) the rotation axis. Seventeen subjects have now been tested, with three-dimensional measurements made of head and trunk motion during yaw rotation while centered or at the end of a short-radius centrifuge. This systematic investigation using the combination of three-dimensional measures of both head and body has never been done before. (Shelhamer)

In human experiments conducted in a tumbling room $(n=17)$ or in a similar virtual room created using the NASA Virtual Environment Generator $(n=6)$, it was found that the majority of subjects viewing a room with visual verticals aligned with the head to foot axis report feeling subjectively nearly upright, even though they are actually supine. (When subjects raise their hands, they feel curiously weightless). Tests in the rotatable room indicate visual vertical cues can dominate for prone and inverted subjects as well. We have also found a new simple technique for inducing a levitation illusion which may be useful in some training applications: the subject lies supine, and observes the world through a mirror set at $45^{\circ}$ so that it is sloping up from below the nose to above the forehead. In addition, susceptibility to visual reorientation illusions (VRIs) in 1-G can be assessed by measuring the subjective vertical in a virtual tilted room. Among visually dependent subjects, results appear sensitive to head/body tilt. Subjects can be successfully trained using an exocentric strategy to perform a three-dimensional spatial memory task analogous to that required to traverse a space station node module. Once trained, performance in this task appears insensitive to gravitational orientation of the head. This finding suggests that the orientation of a trainee's head may not be as critical as had previously been thought for effective astronaut preflight orientation training. (Oman)

In recent parabolic flight experiments while recording from several head direction (HD) cells in the anterior thalamic nucleus of Sprague-Dawley rats, it was found that directional tuning was often maintained during both the $0-\mathrm{G}$ and $1.8 \mathrm{G}$ (pullout) phases of parabolic flight. Animals were tested in a rectangular chamber, gridded on the floor, ceiling, and one wall so the animals could walk in $0-G$. The plane of sensitivity generally remained aligned with the $1-G / 1.8 \mathrm{G}$ "floor" of the chamber, even when the animal climbed on a "wall" in 0-G. The latter finding suggests that the plane of sensitivity is determined by the animal's cognitive reference frame, and 
not simply by the plane of its locomotion. Further, when animals crawled on the "ceiling" of the chamber in $0-G$, the direction of sensitivity sometimes reversed direction, across the principal axis of symmetry of the container, as would be expected if the animal, like an astronaut, experienced a VRI. This is the first time an animal model has been successfully used to define the limbic basis of an important $0-\mathrm{G}$ spatial orientation illusion. (Oman)

Discriminant analysis has been successfully applied to distinguish unilateral vestibular lesions from normal responses using sinusoidal harmonic rotation, and to distinguish between patients having Ménière's disease and migraine associated dizziness. To understand how discrete angular and linear motions of the visual surround influence the body segment variables during normal gait initiation and straight and circular treadmill walking, a unique circular treadmill has been constructed and an ISCAN binocular eye movement monitor has been integrated with an Optotrak system so that eye movements as well as head and body part motion can be recorded during natural linear and circular locomotion. It has been found that walking over a large range of velocities has a tight frequency bound around $2 \mathrm{~Hz}$. The implication is that increased walking velocity is achieved primarily by increasing stride length rather than increasing stepping frequency. An optimal walking velocity ranges from $1.4-1.8 \mathrm{~m} / \mathrm{sec}$. In this range, there is the highest coherence between head, trunk and stepping. Head pointing stays approximately constant over the optimal range of walking velocities. Head and trunk rotations in the pitch plane during linear forward locomotion are governed by two overlapping mechanisms: one mechanism works at low velocities where head rotation compensates for trunk rotation, while at higher walking velocities head translation plays a role in controlling the head pitch. These results are consistent with our hypothesis that at low walking velocities the head is predominantly controlled by the angular vestibulo-collic reflex, while at higher walking velocities it is mainly controlled by the linear vestibulo-collic reflex. (Wall)

Experiments were carried out at Brookhaven National Laboratory with Sprague-Dawley rats of approximately 60 to 65 days of age receiving total-body irradiations at three doses, $0.05,0.16$, and $0.5 \mathrm{~Gy}$, of $1-\mathrm{GeV}$ iron ions at two depths. The first group was irradiated with minimum absorber upstream and the second with a Lucite absorber producing a mean energy of $600 \mathrm{MeV}$ (typical Berkeley energy) at the breasts of the animals. Eighteen rats were also irradiated at 2 Gy. Control experiments were performed with cesium before and after the iron irradiations at doses of .50, 1.60, and 5.0 Gy. Sham irradiations were included in all cases. Both human and rat mammary cells were irradiated in vitro. Human cells from individual donors and rat lymphocytes from pooled donors were irradiated at four doses, $0.1,0.25,0.5$, and $1.0 \mathrm{~Gy}$. In addition, human lymphocytes and human colorectal cells were also irradiated at the same doses. Because lymphocytes and colorectal cells are well studied in vitro, the results will provide insights into the differences in mechanisms leading to carcinogenesis for different particle types. Corresponding experiments with both rats and cells have been done at one depth with $250-\mathrm{MeV}$ protons at Loma Linda University. This was the first experiment done at this new NASA-supported facility. Tumors began to appear in the iron study, including the unirradiated shams, at about three months after irradiation. The proton group also began developing tumors at about the same time after irradiation, but the proton studies were started several months later, so the numbers are few at this point. The frequency of tumors appears to increase with increasing dose, although the statistics are still poor; however, the frequencies with iron are about the same as those with photons, indicating that the estimated RBEs used to design the experiments were approximately correct. There is an enhanced response in a small set of animals at $2 \mathrm{~Gy}$ of iron. These animals were irradiated intentionally at a higher dose, in case the RBE was overestimated significantly. This group is developing tumors significantly more rapidly than the photon -irradiated animals, again substantiating the original hypotheses used to design the original experiments. Despite the 
rapid tumor development at $2 \mathrm{~Gy}$, there has been no clinical bone-marrow toxicity, gut complications, or CNS damage to date. Pathological examination of the excised tumors from all irradiated animals shows that the majority are carcinomas. The colony remains healthy, with no animals lost at the highest iron dose. All of the cell data have not been analyzed, but the analyzed data show increased efficacy of iron ions for the induction of complex chromosome aberrations. An interpretation of the data might be that biological processes contribute more to carcinogenesis than the initial induction of irreparable lesions. (Dicello)

\subsection{KEY PERSONNEL}

Senior Institute management personnel (Bobby R. Alford, M.D., Chairman of the Board and Chief Executive Officer, Laurence R. Young,Sc.D., Director, and Ronald J. White, Ph.D., Associate Director) have developed a stable, fully functioning management unit. One Team Leader change was instituted in April 1998, involving the Immunology, Infection and Hematology Team. Dr. Fred Rudolph of Rice University asked to be relieved of his duties since he is not personally involved in the NSBRI research program at the present time. He was replaced by Dr. William T. Shearer, the principal investigator for the key immunology project added at mid-year.

Dr. Shearer is the Director of the Allergy and Immunology Training Program at Baylor College of Medicine and Professor of Pediatrics and Microbiology and Immunology. He graduated from Washington University School of Medicine in St. Louis in 1970 and received his clinical training in pediatrics and allergy and immunology at the Washington University's affiliated hospitals, St. Louis Children's Hospital and Barnes Hospital. Dr. Shearer received a Research Scholar Award of the Cystic Fibrosis Foundation and a Faculty Research Award from the American Cancer Society for his early research work. He joined the faculty of Washington University in 1974 and was promoted to professor in 1978 prior to moving to Baylor College of Medicine. In 1981 he was elected to membership in the American Society for Clinical Investigation and received the Distinguished Teacher Award in 1984 from Baylor College of Medicine. Dr. Shearer has been active in professional clinical immunology organizations at the national level for many years, serving as Director and Chair of the American Board of Allergy and Immunology, Chair of the American Academy of Allergy, Asthma, and Immunology Training Program Directors Committee, Chair of the Academy's National Issues Subcommittee, and Chair of the Academy's Clinical and Laboratory Immunology Committee which published the Core Content Outline for Clinical and Laboratory Immunology and the Practice Parameters for the Diagnosis and Management of Immunodeficiency. Dr. Shearer has been an appointed (1994) and elected (1997) Councilor of the Clinical Immunology Society and has also served as Chair of its American Board of Allergy and Immunology Nominations Committee.

Dr. Shearer's basic research work deals with immunoglobulin gene activation in HIV infection and his clinical research involves directing the Pediatric HIV/AIDS Research Center at Baylor College of Medicine and Texas Children's Hospital, a center currently involving over 100 professionals and funded by 12 National Institutes of Health and private organization grants and contracts. Dr. Shearer is Vice-Chair of the Pediatric AIDS Clinical Trials Group, 22-center national research group devoted to the study of antiretroviral and immune-based therapies in HIV-infected children. A brief biographical sketch for Dr. Shearer is provided as Appendix C.

Three principal investigators (PIs) were changed during the first year of operation of the Institute. On the Bone Loss Team, L. W. Schultheis replaced J. R. Shapiro as PI for the project "The 
effects of Partial Mechanical Loading and Ibandronate on Skeletal Tissues in the Adult Rat Hindquarter Suspension Model of Microgravity." Dr. Shapiro moved from John Hopkins School of Medicine to Uniformed Services University of the Health Sciences (USUHS) and Walter Reed Army Medical Center and will continue to work on the project at Johns Hopkins, but as a coinvestigator. On the Radiation Effects Team, D. L. Huso replaced S. P. Howard as PI for the project "Chemoprevention of Radiation-Induced Rat Mammary Neoplasms." Dr. Howard moved to another institution. On the Technology Development Team, R. S. Potember of the Johns Hopkins Applied Physics Laboratory (APL) replaced H. W. Ko as PI for the project "Miniature Time-of-Flight Mass Spectrometer." Dr. Ko asked to be replaced to allow him to spend more time working on another large project at APL.

\subsection{MANAGEMENT PLAN}

By the end of the Institute's first year of operation, the Management Plan described in the original proposal to NASA had been fully and faithfully implemented. Figure 2 presents a sketch of the relationships among the elements of the originally proposed plan. The optional part of the program concerned with the management of the non-Institute NASA biomedical research program has been removed, as this option was not exercised.

Current membership of the NSBRI Board of Directors is shown in Table 3. The Board of Directors has met three times since the formation of the Institute, on September 22-23, 1997, March 19-20, 1998, and September 24-25, 1998. All meetings were held in Houston. At each meeting, they reviewed and approved the program plan for the Institute.

Current membership of the NSBRI External Advisory Council is shown in Table 4. The External Advisory Council also met three times, on September 15-16, 1997 and March 16-17, 1998 in Houston, and on September 3-4, 1998 in Boston. Two members, Drs. Ann Kennedy and M. Rhea Seddon, were added to the Council and attended the September 1998 meeting. At each of the meetings, the status of the entire research program and the Institute outreach program was presented and discussed. In-depth presentations and corresponding discussions were initiated in March (Muscle Team) and continued in September 1998 (Human Performance Team). This approach will be continued and the meeting location will rotate from Houston to Boston to Baltimore in order to expose the Council to the investigators and vice versa.

Membership in the NSBRI Board of Scientific Counselors is shown in Table 5. This Board will function as a standing peer panel or study section for the NSBRI's intramural core research program, reviewing new proposals as required and providing an annual assessment of the quality of the ongoing program. The initial meeting of the Board of Scientific Counselors was held on June 7-11, 1998 at the NSBRI retreat location near Houston (Del Lago Conference Center). The Board provided NSBRI management with a written critique of progress made during the Institute's first year.

Finally, membership in the NSBRI User Panel is shown in Table 6. The User Panel met on June 9, 1998 at the Del Lago Conference Center during the NSBRI retreat. Short overview briefings were provided by each of the Team Leaders in order to acquaint the panel with the general approach taken by the Institute to develop countermeasures. 


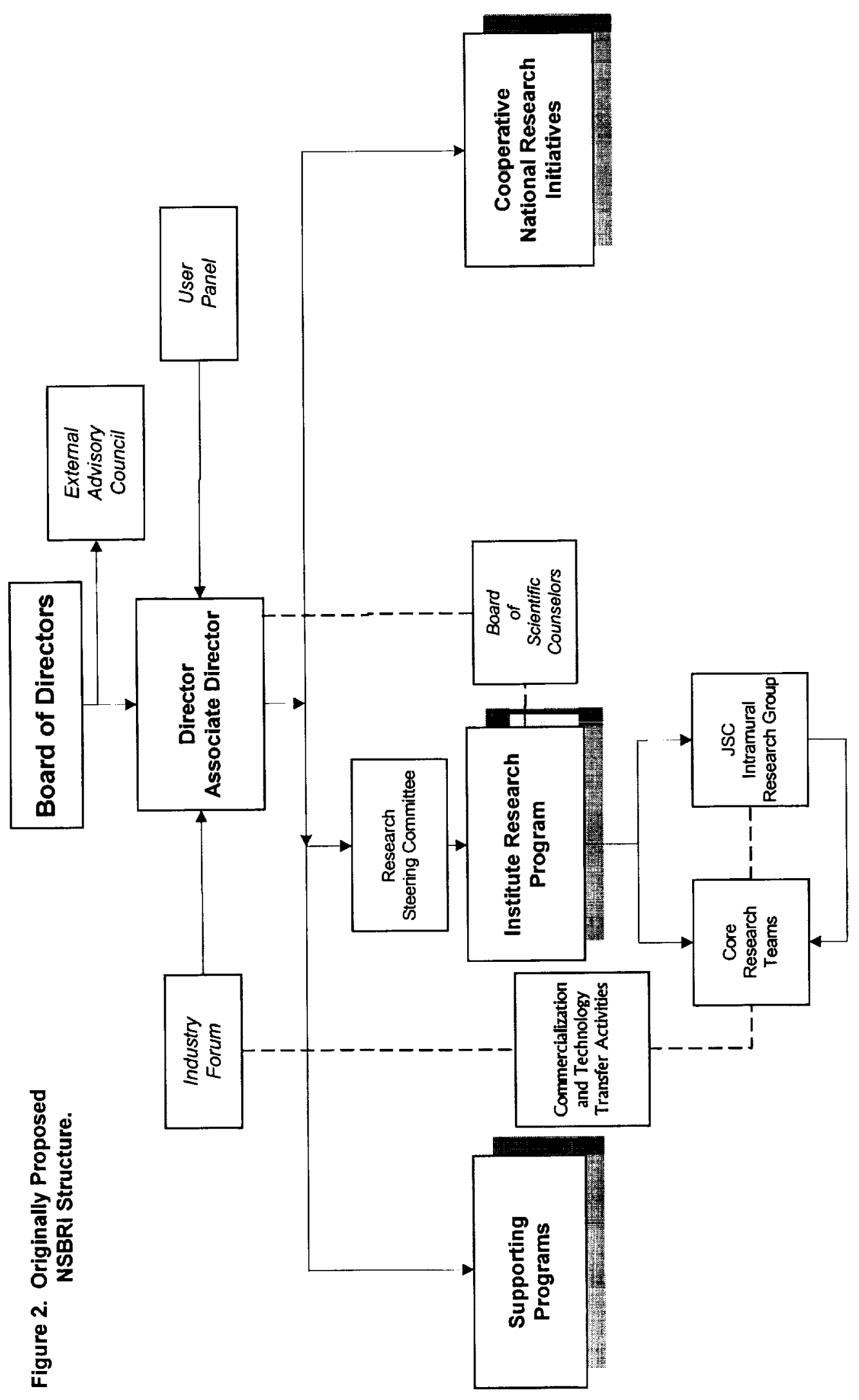

$n$ 
Table 3. National Space Biomedical Research Institute BOARD OF DIRECTORS.

Bobby R. Alford, M.D. (Chairman and CEO)

Executive Vice President and Dean of Medicine

Baylor College of Medicine

Joseph V. Bonventre, M.D., Ph.D.

Co-Director, Harvard University-MIT

Division of Health Sciences \& Technology

Harvard Medical School

Aaron Cohen

Zachry Professor

Department of Mechanical Engineering

Texas A\&M University

\section{E. Nigel Harris, M.D.}

Dean and Senior Vice President

for Academic Affairs

Morehouse School of Medicine

Dennis Kasper, M.D.

Executive Dean of Academic Programs

Harvard Medical School

Joseph P. Kerwin, M.D.

Senior Vice President

Wyle Laboratories

J. David Litster, Ph.D.

Vice President for Research and

Dean of Graduate Education

Massachusetts Institute of Technology

Francis D. Moore, M.D.

Moseley Professor of Surgery, Emeritus

Harvard Medical School

Gary L. Smith, Ph.D.

Director

Johns Hopkins University

Applied Physics Laboratory

W. Dalton Tomlin (Secretary/Treasurer)

Senior Vice President and General Counsel

Baylor College of Medicine

Torsten N. Wiesel, M.D.

Former President

Rockefeller University

Laurence R. Young, Sc.D. (Ex Officio)

Director, NSBRI

Massachusetts Institute of Technology
William L. Allen

Editor

National Geographic Magazine

James F. Buchli

Manager, Mission Support

Boeing Defense \& Systems Group

Michael DeBakey, M.D.

Chancellor Emeritus

Baylor College of Medicine

Richard J. Johns, M.D.

Distinguished Service Professor of Biomedical

Engineering and Professor of Medicine

Johns Hopkins Medical School

Robert A. Kennedy, Ph.D.

Vice President for Research and

Associate Provost for Graduate Studies

Texas A\&M University

Jordan Konisky, Ph.D.

Vice Provost for Research and Graduate Studies Rice University

Larry McIntire, Ph.D.

Chairman, Institute of Biosciences and

Bioengineering \& Department of Bioengineering

Rice University

James W. Patrick, Ph.D.

Vice President and Dean for Research

Professor of Neuroscience and

Chairman of the Division of Neuroscience

Baylor College of Medicine

Walter Sullivan, Ph.D.

Vice President of Operations and Planning

Morehouse School of Medicine

Arnold N. Weinberg, M.D.

Medical Director

Massachusetts Institute of Technology

Bernard Cohen, M.D. (Ex Officio)

Professor, Department of Neurology

Mount Sinai School of Medicine 
Table 4. National Space Biomedical Research Institute EXTERNAL ADVISORY COUNCIL.

Bernard Cohen, M.D. (Chairman)

Professor, Department of Neurology

Mount Sinai School of Medicine

Antonio Gotto, M.D.

Provost for Medical Affairs

The Stephen and Suzanne Weiss Dean

Cornell University Medical College

Michael F. Holick, M.D., Ph.D.

Professor of Medicine, Physiology

and Dermatology

Boston University Medical Center

Martin J. Kushmerick, M.D., Ph.D.

Professor of Radiology, Bioengineering and

Physiology and Biophysics

University of Washington School of Medicine

Robert Y. Moore, M.D., Ph.D.

Professor \& Chairman

Department of Neurology

University of Pittsburgh

Richard M. Satava, M.D., F.A.C.S.

Professor of Surgery

Yale Laparoendoscopic Center

Warren K. Sinclair, Ph.D.

National Council on Radiation Protection \&

Measurement

Thomas J. Wronski, Ph.D.

Department of Physiological Sciences

The University of Florida

Ronald J. White, Ph.D. (Ex Officio)

Associate Director

National Space Biomedical Research Institute
Martin J. Fettman, D.V.M., Ph.D.

Mark L. Morris Chair in Clinical Nutrition

Department of Pathology

College of Veterinary Medicine \& Biomedical

Sciences

Colorado State University

Michael N. Gould, Ph.D.

Professor of Human Oncology

University of Wisconsin

Ann R. Kennedy, D.Sc.

Richard Chamberlain Professor of Research Oncology

Department of Radiation Oncology

University of Pennsylvania School of Medicine

Donald J. Marsh, M.D.

Dean of Medicine and Biological Sciences

Brown University School of Medicine

Danny A. Riley, Ph.D

Department of Cellular Biology \& Anatomy

Medical College of Wisconsin

M. Rhea Seddon, M.D.

Assistant Chief Medical Officer

Vanderbilt University Medical Center

Victor J. Wilson, Ph.D.

Professor of Neurophysiology

Rockefeller University

Bill J. Yates, Ph.D.

Assistant Professor of Otolaryngology

and Neuroscience

Eye and Ear Institute

University of Pittsburgh

Laurence R. Young, Sc.D. (Ex Officio)

Director, NSBRI

Massachusetts Institute of Technology

During the first year of operation of the Institute, we began a special activity in partnership with the biomedical personnel at the Johnson Space Center called the Critical Path Roadmap Project. This activity began for the NSBRI with a special workshop held in Houston from January 6 to January 9, 1998. The purpose of the roadmap is to relate the biomedical risks and questions critical to the human exploration of Mars to the sequence of risk mitigation activities. It is designed to build a pathway that is dynamic and evolving as new knowledge and mission planning develops. The Critical Path Workshop had three objectives. First, to define the risks to crew health and performance resulting from a human expedition to Mars and to categorize those 
risks according to their risk type and level. Risks were defined by DISCIPLINE using the seven scientific research areas of the NSBRI as the starting list of disciplines. Primary Risks involve known risks with severe impacts on either mission completion or crew health during or after the expedition. Potential Risks involve potential risks with severe impacts on either mission completion or crew health during or after the expedition. Secondary Risks include all other risks. The second objective was to define the critical questions that should be addressed for each RISK defined above and to categorize those questions as to their question type. Risk Definition or Clarification Questions are those which involve questions aimed at defining and clarifying a

Table 5. National Space Biomedical Research Institute BOARD OF SCIENTIFIC COUNSELORS.

\begin{tabular}{|ll|}
\hline Hal E. Broxmeyer, Ph.D. (Chairman) & H. Elliott Albers, Ph.D. \\
Indiana University School of Medicine & Laboratory of Neuroendocrinology \& Behavior \\
Cancer Research Institute Building & Departments of Biology \& Psychology \\
& Georgia State University \\
David J. Anderson, Ph.D. & David M. Bader, Ph.D. \\
$\begin{array}{l}\text { Department of Electrical Engineering } \\
\text { and Computer Science }\end{array}$ & Vanderbilt School of Medicine \\
University of Michigan & Division of Cardiology \\
James B. Bassingthwaighte, Ph.D. & \\
Center for Bioengineering & Mary A. Carskadon, Ph.D. \\
University of Washington & Emma P. Bradley Hospital \\
& Sleep Research Laboratory \\
Arthur A. Ciarkowski & \\
Food and Drug Administration & Priscilla M. Clarkson, Ph.D. \\
& Department of Exercise Science \\
& School of Public Health and Health Sciences \\
& Amherst \\
Paul M. DeLuca, Jr., Ph.D. & Paul A. DiZio, Ph.D. \\
Department of Medical Physics & Ashton Graybiel Spatial Orientation Laboratory \\
University of Wisconsin-Madison & Brandeis University \\
& \\
R. J. Michael Fry, M.D. & Benjamin D. Levine, M.D. \\
Oak Ridge National Laboratory & Institute for Exercise \& Environmental Medicine \\
& Presbyterian Hospital of Dallas \\
Peter E. Lipsky, M.D. & Robert Marcus, M.D. \\
Department of Internal Medicine & Geriatrics Research, Education \& Clinical Center \\
University of Texas Southwestern Medical Center & Veterans Affairs Medical Center, Palo Alto \\
& \\
Connie Weaver, Ph.D. & \\
Department of Foods and Nutrition & \\
Purdue University & \\
& \\
\hline
\end{tabular}

certain risk. Risk Mitigation Questions involve questions aimed at reducing or otherwise mitigating a certain risk. The third objective was to initiate the development of a critical path diagram by relating the questions defined above to each other by development of a critical path flow diagram that includes the necessary research progression required to answer the questions and mitigate the risk. This activity continued at the NSBRI retreat in June and is ongoing. 
As a result of extensive discussions during the first few months of the Institute's existence, the NSBRI signed a five-year Affiliation Agreement with the Institute of Aerospace Medicine of the German Aerospace Center in Köln, Germany on January 21, 1998. This agreement will enable German scientists to join NSBRI Teams and will augment the NASA-funded projects with complementary German-funded activities. The research projects to be undertaken by the German scientists will consist entirely of new projects that have been peer reviewed in the standard NSBRI manner, selected jointly by the NSBRI and the German Aerospace Center, and funded by the German Aerospace Center. A copy of this agreement is included in Appendix D.

In the original NSBRI proposal, it was stated that "Every other year, beginning in 1999, the Institute will hold a one-week retreat for all its investigators, Industry Forum and User Forum members, and selected NASA scientists, medical personnel, and administrators. The purposes of these retreats are to enable and encourage dialogue and synergy across the teams, to foster critical examination of research pathways, and to enable technology transfer to and from the private sector. This process should lead to a dynamic, synergistic research program appropriate to the NSBRI."

Table 6. National Space Biomedical Research Institute USER PANEL.

\begin{tabular}{|c|c|}
\hline $\begin{array}{l}\text { David Hilmers, M.D. (Chairman) } \\
\text { Baylor College of Medicine }\end{array}$ & $\begin{array}{l}\text { Joseph P. Allen, Ph.D. } \\
\text { Chairman } \\
\text { Veridian }\end{array}$ \\
\hline $\begin{array}{l}\text { Ellen S. Baker, M.D., M.P.H. } \\
\text { Lyndon B. Johnson Space Center }\end{array}$ & $\begin{array}{l}\text { Roger D. Billica, M.D. } \\
\text { Chief, Medical Operations Branch } \\
\text { Lyndon B. Johnson Space Center }\end{array}$ \\
\hline $\begin{array}{l}\text { William R. Carpentier, M.D. } \\
\text { Division Director of Nuclear Medicine } \\
\text { Scott \& White } \\
\text { Temple, TX }\end{array}$ & $\begin{array}{l}\text { Laurel B. Clark, M.D. } \\
\text { Lyndon B. Johnson Space Center }\end{array}$ \\
\hline $\begin{array}{l}\text { John M. Fabian, Ph.D. } \\
\text { President \& CEO } \\
\text { ANSER }\end{array}$ & $\begin{array}{l}\text { Owen K. Garriott, Ph.D. } \\
\text { Huntsville, AL }\end{array}$ \\
\hline $\begin{array}{l}\text { Robert L. Gibson } \\
\text { Murfreesboro, TN }\end{array}$ & $\begin{array}{l}\text { Joseph P. Kerwin, M.D. } \\
\text { Senior Vice President } \\
\text { Wyle Laboratories }\end{array}$ \\
\hline $\begin{array}{l}\text { Byron K. Lichtenberg, Ph.D. } \\
\text { Gunbarrel, TX }\end{array}$ & $\begin{array}{l}\text { Sam L. Pool, M.D. } \\
\text { Chief, Medical Sciences Division } \\
\text { Lyndon B. Johnson Space Center }\end{array}$ \\
\hline
\end{tabular}

It was decided to initiate the biennial retreats in 1998 instead of 1999 in order to foster a strong sense of NSBRI identity as early as possible in the life of the Institute. The first retreat was held from June 8 through June 11, 1998 at the Del Lago Conference Center just north of Houston. The agenda for this retreat is included as Appendix E. The retreat was highly successful. Attendance was over 200, including significant NASA participation. The first User Panel meeting and the first Board of Scientific Counselors meeting were held in conjunction with the retreat. The 
NSBRI's Industry Forum played an important role in the retreat activities. Further steps in the Critical Path Roadmap Project were taken at the retreat.

\subsection{COMMERCIALIZATION, EDUCATION AND PUBLIC OUTREACH}

Even before NASA selected the present consortium to form NSBRI, the consortium recognized the critical importance to the future of human space exploration of close collaboration between the NSBRI and the industrial community. For industry to build the operational systems to support exploration, the Institute will have to find solutions to the deleterious effects of space flight on humans. Conversely, the Institute will be strengthened by industry's efforts to identify operational problems, contribute to cost-sharing, and assist in leveraging Federal support to the Institute through cooperative activities. Thus, an Industry Forum (see Table 7) composed of

Table 7. Membership in the National Space Biomedical Research Institute INDUSTRY FORUM.

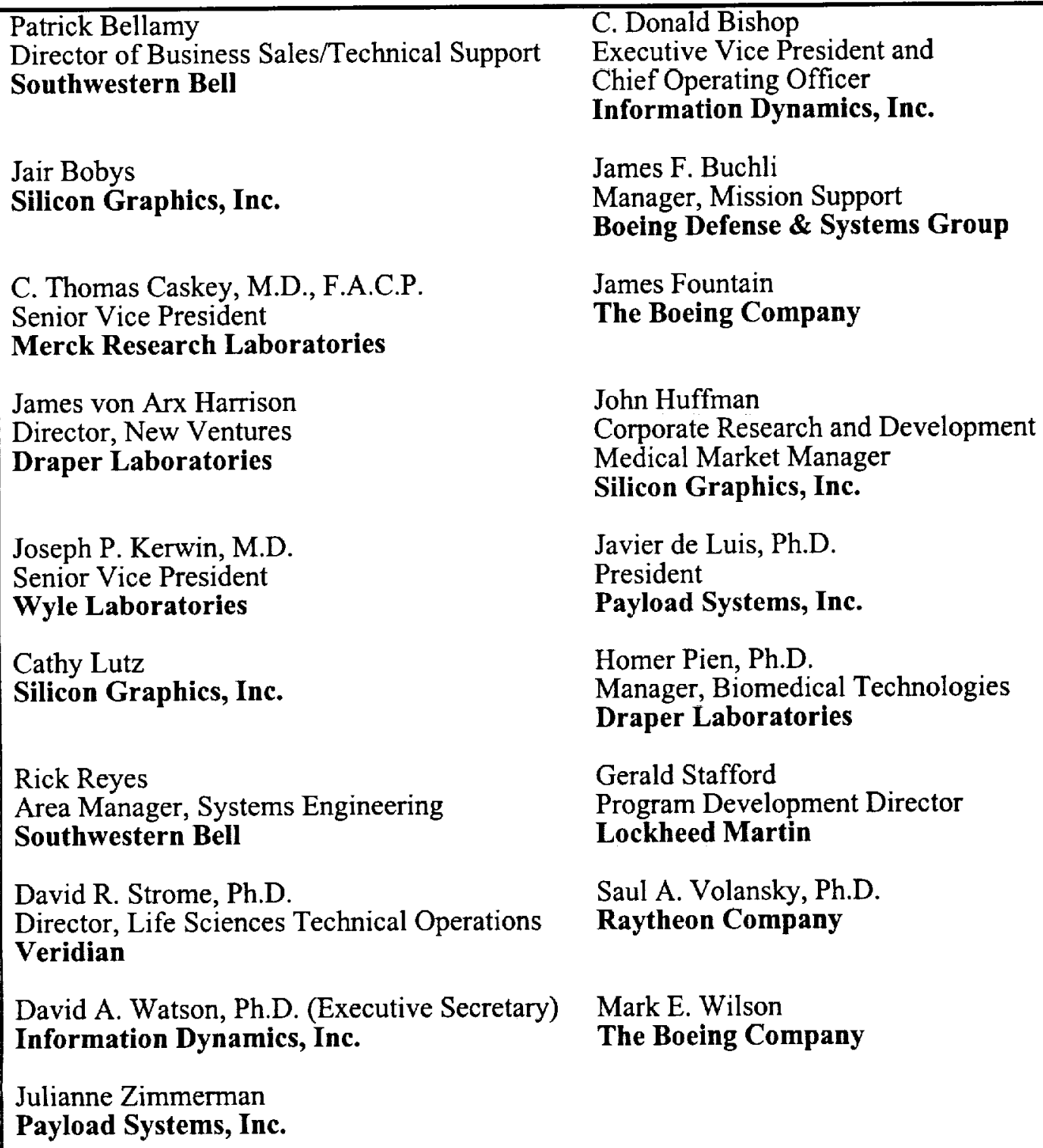


representatives from the aerospace industry, pharmaceutical companies, biotechnology firms, and other relevant organizations was formed to: advise the Director and the Board of Directors, provide technological advice and support to the Institute and its investigators, and assist in technology transfer.

The Industry Forum has held two meetings (including one at the Institute retreat) and numerous telecons to organize and discuss technology issues related to the NSBRI research program. The members have developed a charter, guidelines for membership in the Forum and a proposal for partnering, all of which are included in Appendix F.

The NSBRI education and public outreach activities directly support the mission of the Institute that involves ensuring open involvement in the Institute's activities by the scientific community, industry, and the public at large, and a robust exchange with NASA. By targeting multiple and diverse populations, Institute outreach programs aim to inform a large community about NSBRI activities; attract young people to related fields in science, engineering and medicine; provide opportunities for promoting excellence and innovation in America's science education system; promote scientific literacy among teachers, students and their families, and the general population; and engender public awareness and appreciation of the opportunities and benefits of space life sciences research. This is being accomplished through an integrated array of programs that focuses on students and teachers at all levels, $\mathrm{K}$-undergraduate, as well as the general public.

The educational programs created for the NSBRI respond to the needs of the full educational spectrum and focus on three primary areas: creation of supplementary educational materials for use by teachers and students in elementary and secondary schools; development of educational opportunities and courses for undergraduate students and teachers; and production of educational resources for school audiences and the general public using a variety of electronic media, such as computer-based multimedia (including the World Wide Web), radio and television.

Activities in these three areas are supported by the creation of a compendium of existing educational resources from NASA and NSBRI consortium institutions, and through the identification of relevant content areas described within the National Science Education Standards that can be taught by using space life sciences as unifying themes.

Within the overall vision of the Institute, NSBRI educational outreach activities have the following objectives: promote scientific literacy among teachers, students and their families, and the general population; foster excellence in America's science education systems; and engender public awareness and appreciation of the opportunities and benefits of space life sciences research. The educational programs created for the NSBRI respond to the needs of the full educational spectrum and focus on the following three primary areas:

1. Creation of supplementary educational materials for use by teachers and students in elementary and secondary schools.

2. Development of educational opportunities and courses for undergraduate students and teachers.

3. Production of educational resources for school audiences and the general public using a variety of electronic media, including computer-based multimedia, radio and television.

Activities in these three areas are supported by the creation of a compendium of existing educational resources from NASA and NSBRI consortium institutions and through the 
identification of relevant content areas described within the National Science Education Standards (National Research Council, 1996) that can be taught by using space life sciences as unifying themes.

Current outreach activities are being led by teams at three consortium institutions: Morehouse School of Medicine, Texas A\&M University and Baylor College of Medicine. Project activities being conducted by each partner are described below.

Morehouse School of Medicine (MSM). The goals of the MSM-NSBRI Education and Outreach Program are to establish partnerships to produce multimedia educational materials that bring NSBRI's science activities to America's teachers and students and that extend the benefits of space life sciences technology to the general public. To accomplish these goals, the MSMNSBRI Education and Outreach Program is carrying out activities within the following areas.

1. Elementary and Secondary Education. MSM is developing the following products to support elementary and secondary school education programs: (a) two secondary casebased lessons (focusing on circadian rhythms and neurovestibular research), to be prepared in consultation with the Harvard Medical School Teacher Institute; and (b) a color version of the NASA-approved Neurolab curriculum, The Brain in Space, for inclusion on the NSBRI educational Web site and dissemination to secondary school audiences.

2. Undergraduate Education. MSM aims to attract young people to science careers through the following two training and educational opportunities that introduce students to space biomedical research: (a) design and implementation of a Human Body in Space Course for undergraduate students, taught for the first time in spring, 1998; and (b) sponsorship of internships for undergraduate students in the MSM Neuroscience Institute and the MSM-NASA Space Medicine Life Sciences Research Center each summer. Both of these programs were created to encourage women and minority-group students to pursue careers in science and to provide pathways for students to access other NSBRI opportunities.

3. Public Outreach. In collaboration with the Atlanta Educational Telecommunications Collaborative (AETC), which encompasses Atlanta's Public Broadcasting Services (PBS) television and radio activities, MSM is (a) creating a series of twelve short-format radio programs (Life in Space) on NSBRI science and activities; (b) carrying out archival filming to document the development of the NSBRI; and (c) establishing partnerships to produce at least two PBS documentaries on NSBRI research and human exploration of space.

4. Space Life Sciences Archives. MSM is establishing a multimedia archive containing educational materials on human exploration of space and on NSBRI scientific and technological developments. This archive will serve as a resource for all related education and outreach activities. The film archives contain all footage and multimedia resources associated with the Neurolab Education Program, a five-day teacher training workshop on the brain, summer intern presentations, and selected NASA films and print materials.

Texas A\&M University (TAMU). Education and outreach activities conducted by TAMU provide innovative space life sciences leaming experiences and resources for teachers. To this end, current work is focusing on the following two primary project activities.

1. Teacher Academy Program. This activity is preparing a national group of teachers to lead their peers in implementing learning activities in K-12 science classrooms. Young people will thereby gain an understanding of the medical and policy issues associated with sus- 
tained space flight to Mars. The Teacher Academy Program, initiated in summer 1997, is designed to: (a) enhance the background of fellows of the Academy in medical science concepts, and in the educational and research implications of sustained manned space flight; (b) prepare a small national cadre of science teachers who will lead in the identification, development and implementation of NSBRI-related learning activities in their classrooms; (c) develop peer training protocols and develop leadership skills of the Academy fellows to enable them to lead NSBRI staff development activities with outreach activities for other K-12 science teachers; and (d) collect instructional resources for science teachers to use in teaching future citizens the medical concepts and issues associated with sustained manned space flight.

2. Electronic Textbook-Website Development. Through applications of multimedia technologies, TAMU is preparing electronic curricular materials for $\mathrm{K}-12$ science classrooms to promote students' understanding of the medical and policy issues associated with sustained space flight to Mars. TAMU also is creating and managing the primary educational Web site for NSBRI. These activities are focusing on (a) completing the development of a prototype electronic on-line secondary school human physiology course based on the text Human Physiology in Space (Lujan and White, 1997) and (b) refining the Website homepage of the NSBRI education and outreach component, so that educational resources provided by all partners and supporting resources will be available through a centralized location.

Baylor College of Medicine (BCM). Education and outreach activities conducted by BCM aim to (a) facilitate the acquisition of inquiry skills and science content knowledge-particularly in the areas of physical, earth/space and life science related to the research areas of the NSBRI-by elementary and secondary school teachers and students, and (b) generate public awareness and enthusiasm for space biomedical research. These objectives are being met through the following activities.

1. Resources for Educational Activities. To guide curriculum development and other outreach activities, content areas described within the National Science Education Standards (National Research Council, 1996) that can be taught by using space life topics as unifying themes have been aligned to NSBRI research areas. The resulting matrices, which identify grade level appropriate science concepts for grades K-4 and 5-8, guided selection of the topics for supplementary curriculum materials. TAMU's outreach team compiled a similar grid of concepts for grades 9-12.

2. Collaboration of scientists and educators for curriculum development. Unique topical areas related to NSBRI research are being presented in an inquiry-based format for elementary and secondary school teachers, students and families. Ten age-appropriate, supplemental K-12 curriculum modules based on space biomedical themes (two modules per year) are being produced.

3. Public Education and Awareness. Bimonthly news format radio stories on NSBRI research areas and related topics are being produced and distributed free-of-charge through BCM's Radio HealthLine series to more than 2,800 radio stations nationally in English and/or Spanish.

4. Support for Public Outreach. Public awareness of NSBRI research also is being engendered through the following products designed to reach additional national audiences: (a) an eight-by-eight foot traveling NSBRI exhibit for use at conventions; (b) a series of informational brochures about the NSBRI and individual research team activities; (c) activity-based educational posters for $\mathrm{K}-8$ students, teachers and parents, to be distributed free-of-charge to approximately 8,400 elementary and middle schools (representing 
4,900,000 students) in home states of consortium institutions; and (d) an NSBRI Home Web site for researchers and the general public.

Thus, NSBRI education and outreach activities are designed to reach a wide spectrum of audiences, including undergraduate students and $\mathrm{K}-12$ school teachers, students and families. In addition to targeted educational activities, considerable efforts are being devoted to promoting public understanding of the relevance of NSBRI research to solving diverse ailments on Earth. To accomplish program goals efficiently, each collaborating institution is focusing on a different subset of activities, based on individual areas of expertise and experience. Outreach partner institutions and areas of concentration are presented in Table 8.

Table 8. Outreach and Public Education Partners and Areas of Concentration

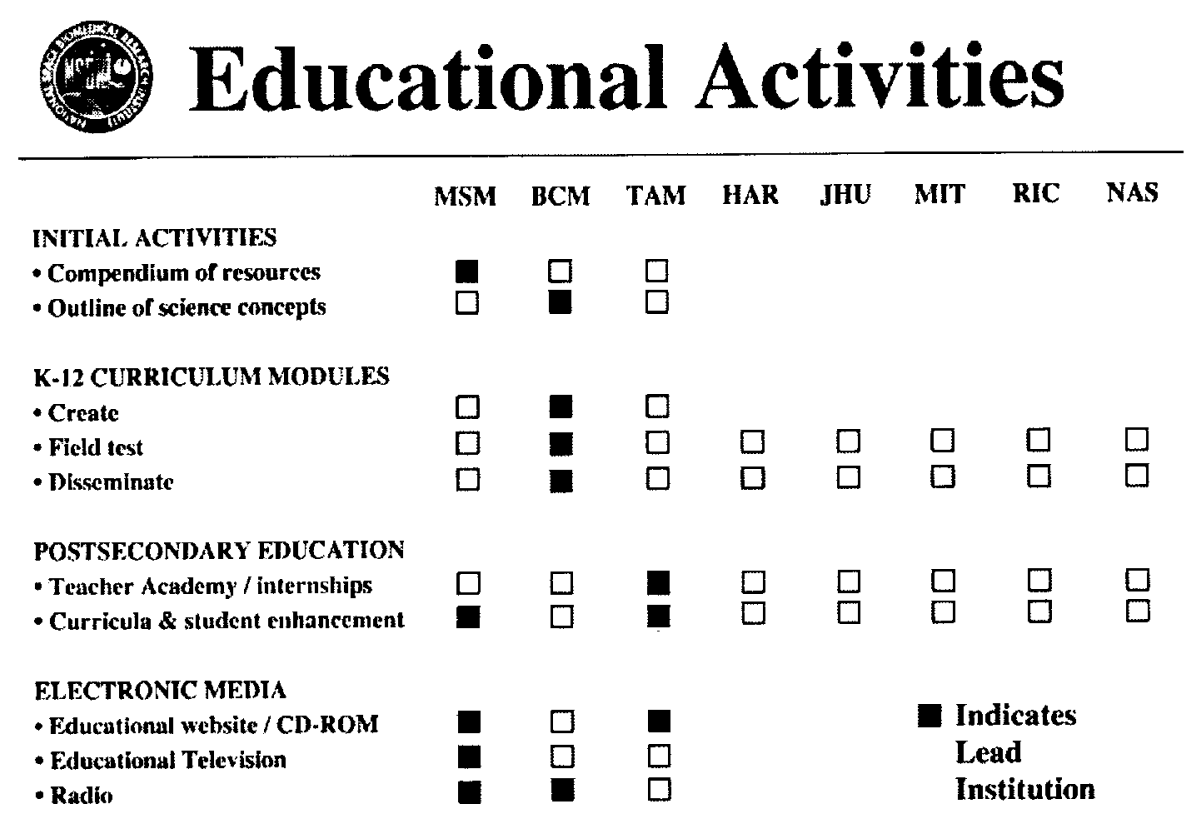

The major accomplishments in the education and public outreach area are summarized in Table 9. 
Table 9. First year accomplishments of the NSBRI education and public outreach team.

INSTITUTION YEAR ONE ACCOMPLISHMENTS

\begin{tabular}{|c|c|}
\hline $\begin{array}{l}\text { Morehouse School of } \\
\text { Medicine (MSM) }\end{array}$ & $\begin{array}{l}\text { Neurolab curriculum completed-ready for Web conversion. } \\
\text { Undergraduate pilot course, The Human Body in Space, taught at } \\
\text { Spelman College in Spring } 1998 \text { (seven participants). } \\
\text { Students selected for } 199812 \text {-week intensive MSM Neuroscience } \\
\text { Institute Summer Program (program also will sponsor two school-wide } \\
\text { lectures by Dr. Shin Yamazki and Dr. Clarence Sams). } \\
\text { Participated in } 1997 \text { NSBRI summer research program by two } \\
\text { Morehouse undergraduate students. } \\
\text { First stage approval, pre-production and staffing arrangements made } \\
\text { for June initiation of video filming production of documentaries by } \\
\text { AETC. } \\
\text { State-of-the-art technology suite, including AVID editing system, } \\
\text { established to create comprehensive space life sciences archives; } \\
\text { multimedia technology director hired. }\end{array}$ \\
\hline $\begin{array}{l}\text { Texas A\&M University } \\
\text { (TAMU) }\end{array}$ & $\begin{array}{l}\text { Pilot Teacher Academy conducted during July } 1997 \text { (six participants). } \\
\text { Follow-up activities held for Teacher Academy Fellows in October and } \\
\text { November 1997, and in January, February and March } 1998 \text {. } \\
\text { Two "Field Trip to Mars" workshops given to students and teachers } \\
\text { attending the Science, Technology and YOUth Symposium at TAMU } \\
\text { in March } 1998 \text {. } \\
\text { Academy Fellows documented and refined classroom implementation } \\
\text { strategies and created web pages to present information and classroom } \\
\text { applications. } \\
\text { Second wave of } 13 \text { middle school Teacher Fellows (representing } 11 \\
\text { states) recruited to participate in Teacher Academy, June } 20-26 . \\
\text { NSBRI educational web site (nsbri.tamu.edu/ nsbri/) created and } \\
\text { under continued development; currently includes complete electronic } \\
\text { version of textbook, Human Physiology in Space and audio and video } \\
\text { media clips from NASA Spacelab Life Sciences Missions. } \\
\text { NSBRI research areas aligned to science standards for grades } 9-12 \text {. }\end{array}$ \\
\hline $\begin{array}{l}\text { Baylor College of Medicine } \\
\text { (BCM) }\end{array}$ & $\begin{array}{l}\text { NSBRI research areas aligned to science standards for grades K-4 and } \\
5-8 \text {. } \\
\text { Topics for development of ten supplementary curriculum modules } \\
\text { identified. } \\
\text { Field test version of K-4 educational module, Sleep and Daily } \\
\text { Rhythms, produced; currently being field tested in } 20 \text { classrooms with } \\
\text { ca. } 400 \text { students. } \\
\text { Background research and activities development underway for } \\
\text { educational module, Bones and Calcium, aimed at grades 5-8. } \\
\text { Three bimonthly Radio HealthLine stories produced and distributed for } \\
\text { broadcast; will be made available on NSBRI Web site. } \\
\text { Traveling NSBRI exhibit and nine informational brochures designed } \\
\text { and produced. } \\
\text { NSBRI home Web site (www.nsbri.org) deployed and under continued } \\
\text { development; recent features include video greetings by Directors and } \\
\text { Team Leaders, descriptions of research areas and projects, internal } \\
\text { information for NSBRI collaborators, and new user interface with pull- } \\
\text { down menus. }\end{array}$ \\
\hline
\end{tabular}




\subsection{INSTITUTE DIVERSITY AND SCIENTIFIC COMMUNITY OUTREACH}

The initial NSBRI research program consists of 41 research projects focussed on eight research areas and on synergistic activities relating two or more areas. The total number of different principal and co-investigators involved in NSBRI research is 133 (see Appendix G for a list of investigators). These investigators are from 25 different institutions: Andersen Consulting, Australian Antarctic Division, Baylor College of Medicine, Brookhaven National Laboratory, Brooklyn College, Dartmouth College, Harvard Medical School, Loma Linda University Medical Center, Massachusetts Institute of Technology, Mayo Clinic, Morehouse School of Medicine, NASA Johnson Space Center, SmithKline Beecham Pharmaceuticals, Texas A\&M University, The Johns Hopkins University, Uniformed Services University of the Health Sciences, University of California, Irvine, University of Florida, University of Houston, University of Pennsylvania, University of Texas Health Science Center at Houston, University of Texas M. D. Anderson Cancer Center, University of Washington, University of Wisconsin, and York University. Rice University, a member of the NSBRI consortium, does not participate presently in the research program, but it does participate in the data archiving project of the Institute.

Thus, the Institute activities include a diverse research base from the seven consortium member schools and nineteen research institutions outside of the consortium. In order to broaden that extramural base even more, the Institute developed an agreement with the National Institute on Deafness and Other Communication Disorders to jointly fund research projects of mutual interest. The NSBRI pledged to raise private money $(\$ 400,000 /$ year) for its share of the monies to support this joint program. This led to the publication of a Program Announcement in the NIH Guide in June 1998. A copy of that announcement is included in Attachment H. Fourteen investigators responded to that Program announcement. Selection is expected in the summer of 1999.

\subsection{SPECIAL PROJECTS}

In the Cooperative Agreement Management Plan (CAMP) signed by NASA and Institute representatives on May 29, 1997, provision was made to undertake special projects outside of the core funding envelope of the NSBRI. Section 5.6, dealing with Addition of Work Elements, states that: "It is expected that additional specific work elements may be jointly agreed to be within the original intent and within the overall scope of the NASA CAN and the resulting CA/CAMP scope of this effort. An initial work element (project) identified in the CAN was the Life Science Data Archive (LSDA) effort, which is not within the core funding envelope. NASA and NSBRI agree that either entity can propose specific work element/projects that are within the overall scope of the NASA CAN, but by their nature would not normally be research activities included within the NSBRI core research plan. When both NASA and NSBRI agree to the implementation of a new work element/project, a project plan will be prepared and included as a supplement to the CA."

During the first year of Institute operation, four special projects were initiated. Three of them were related to transitioning senior scientific personnel from a support contractor or visiting scientist base to an academic research base more appropriate to their future role in the life sciences program at both the Institute and JSC. The fourth had to do with the data archive activity mentioned above. 
Project 97-1, a Transition Plan for Senior Scientific Personnel Currently Employed by KRUG Life Sciences Inc. (currently Wyle Laboratories), described a strategy to continue the uninterrupted involvement of six identified employees of Wyle Laboratories ( $\mathrm{T}$. Brown, $\mathrm{C}$. Layne, V. McDonald, W. Waters, J. Wood, and S. Wood) as they transition from research (coinvestigator) involvement simultaneous with their Wyle employment. The strategy consisted of three phases of activity, of six months duration each:

- Phase I (July 1, 1997 through December 31, 1997). During this period, an individual transition plan was developed for each of the affected scientists. This was done by interviewing each person and discussing their personal career plans, reviewing their resumes, and arranging for visits with appropriate senior NSBRI scientists. The transition plan took into account their own and NASA's research program and the research strengths of the NSBRI.

- Phase II (January 1, 1998 through June 30, 1998). During this period, the individual transition plans were implemented. Most persons transitioned from KRUG during this period, so long as there was sufficient research funding to support them beyond the start of FY 1999 (October 1998).

- Phase III (July 1, 1998 through December 31, 1998). During this period, all transitions are to be completed. In fact, the goal of the plan was to complete transitions by the beginning of FY 1999. The last three months (October - December 1998) were available as a contingency period in case NASA funding decisions for new grant awards were not made on schedule.

Project 97-2, Transition Plan: Universities Space Research Association (USRA) Visiting Scientist Personnel, described a similar plan for five identified USRA employees (M. Clarke, J. Conkin, P. Foster, R. Nammagudda, and J. Penkala), but with a time frame of only 15 months.

Finally, Project 97-3, National Space Biomedical Research Institute Visiting Scientist/Research Associate Program, established an appropriate host program for senior scientific personnel within the Institute using Baylor College of Medicine infrastructure. Table 10 presents the final results of implementing these three projects. Note that all transitions were completed no later than October 1998, one of the goals set early in the development of these projects. Note also that, at the request of NASA, two additional researchers were included in Project 97-3, one from the Aerospace Medicine Residency Program and one from the National Research Council Resident Research Associates Program. Projects 97-1 and 97-2 are complete and will end officially by December 31, 1998. Project $97-3$ is ongoing.

Project 98-1, the NSBRI Data Archive System, was initiated in April 1998, mid-way through the first year of the research program. This project was identified in NASA's Cooperative Agreement Notice (CAN) defining the basic structure of the NSBRI: "One of the initial projects that may be supported by this Cooperative Agreement (outside of the core and grant funding) will be the Life Sciences Data Archive Project (LSDA). This project, as it applies to the NSBRI, is to ensure that all data collected as part of the NASA biomedical research program are properly acquired, catalogued, archived, and disseminated to the general scientific community. Initially, $\$ 400 \mathrm{~K} /$ year will be provided to the Institute for collaborative work on this project. These funds will be in addition to Institute core funding." 
Table 10. Life Sciences Scientific Personnel Transitions.

\begin{tabular}{|c|c|c|c|}
\hline Name & Initial Status & Final Status & $\begin{array}{l}\text { Transition } \\
\text { Date }\end{array}$ \\
\hline Troy Brown, Ph.D. & Wyle Employee & $\begin{array}{l}\text { Wyle Employee } \\
\text { (Support Staff Only) and } \\
\text { Adjunct Assistant } \\
\text { Professor, Baylor } \\
\text { College of Medicine }\end{array}$ & $9 / 30 / 98$ \\
\hline Mark Clarke, Ph.D. & USRA Employee & $\begin{array}{l}\text { USRA Employee (Non- } \\
\text { Research Duties) }\end{array}$ & $6 / 30 / 98$ \\
\hline Johnny Conkin, Ph.D. & USRA Employee & $\begin{array}{l}\text { Assistant Professor, } \\
\text { Baylor College of } \\
\text { Medicine }\end{array}$ & $6 / 1 / 98$ \\
\hline Dominick D'Aunno, M.D. & $\begin{array}{l}\text { Aerospace } \\
\text { Medicine } \\
\text { Residency, UTMB } \\
\text { Galveston }\end{array}$ & $\begin{array}{l}\text { Assistant Professor, } \\
\text { Baylor College of } \\
\text { Medicine }\end{array}$ & $11 / 1 / 97$ \\
\hline Philip Foster, M.D. & USRA Employee & $\begin{array}{l}\text { Assistant Professor, } \\
\text { Baylor College of } \\
\text { Medicine }\end{array}$ & $10 / 19 / 98$ \\
\hline Brian Hashemi, Ph.D. & $\begin{array}{l}\text { NRC Resident } \\
\text { Research Associate }\end{array}$ & $\begin{array}{l}\text { Research Associate, } \\
\text { Baylor College of } \\
\text { Medicine }\end{array}$ & $10 / 6 / 97$ \\
\hline Charles S. Layne, Ph.D. & Wyle Employee & Resigned & $8 / 5 / 97$ \\
\hline Vernon McDonald, Ph.D. & Wyle Employee & $\begin{array}{l}\text { Wyle Employee } \\
\text { (Support Staff Only) and } \\
\text { Adjunct Assistant } \\
\text { Professor, Baylor } \\
\text { College of Medicine }\end{array}$ & 9/30/98 \\
\hline Ram Nimmagudda, Ph.D. & USRA Employee & Resigned & $3 / 31 / 98$ \\
\hline Joseph Penkala, Ph.D. & USRA Employee & Resigned & $1 / 11 / 98$ \\
\hline Wendy Waters, Ph.D. & Wyle Employee & $\begin{array}{l}\text { Assistant Professor, } \\
\text { Baylor College of } \\
\text { Medicine }\end{array}$ & $11 / 24 / 97$ \\
\hline JoAnna Wood, Ph.D. & Wyle Employee & $\begin{array}{l}\text { Assistant Professor, } \\
\text { Baylor College of } \\
\text { Medicine }\end{array}$ & $10 / 1 / 98$ \\
\hline Scott Wood & Wyle Employee & $\begin{array}{l}\text { Research Associate, } \\
\text { Baylor College of } \\
\text { Medicine }\end{array}$ & 9/14/98 \\
\hline
\end{tabular}


Thus, Project 98-1 defines the plan to collect, catalogue, archive, and provide retrieval access to the scientific community for data collected under the auspices of the NSBRI. A team has been formed from NSBRI Consortium members to establish an Institute Data Archiving System (IDAS). The Team Leader is Lora L. Suther of the Johns Hopkins University Applied Physics Laboratory (APL). Team members include Anthony Elam and Ross Reedstrom of Rice University, and Joan Fetter and Bruce Hamill of APL. This team is responsible for identifying the Institute data archiving needs and requirements, carrying out a functional analysis of those requirements, and, finally, determining an architecture and design compatible with the Life Sciences Data Archive (LSDA) at the Johnson Space Center. In addition, they are responsible for establishing and maintaining the Institute data archive, identifying the operating procedures, identifying data rights and release procedures, and specifying the management and development process for Institute data archives.

The Institute Data Archive team has had several meetings with the NASA data archive group based at JSC, presented the issues in data archiving to NSBRI researchers at the June retreat, and selected a small number of model projects as examples to initiate archiving activities. The team will receive its guidance and priorities from an Institute Special Interest Group focusing on data archiving with representatives from each integrated research team and from the NASA data archive group. This Special Interest Group will be chaired by Vincent Pisacane (Johns Hopkins University Applied Physics Laboratory) and will have Ronald White, the Associate Director of NSBRI as an ex-officio member. The planned architecture for the Institute archive is shown in Figure 3.

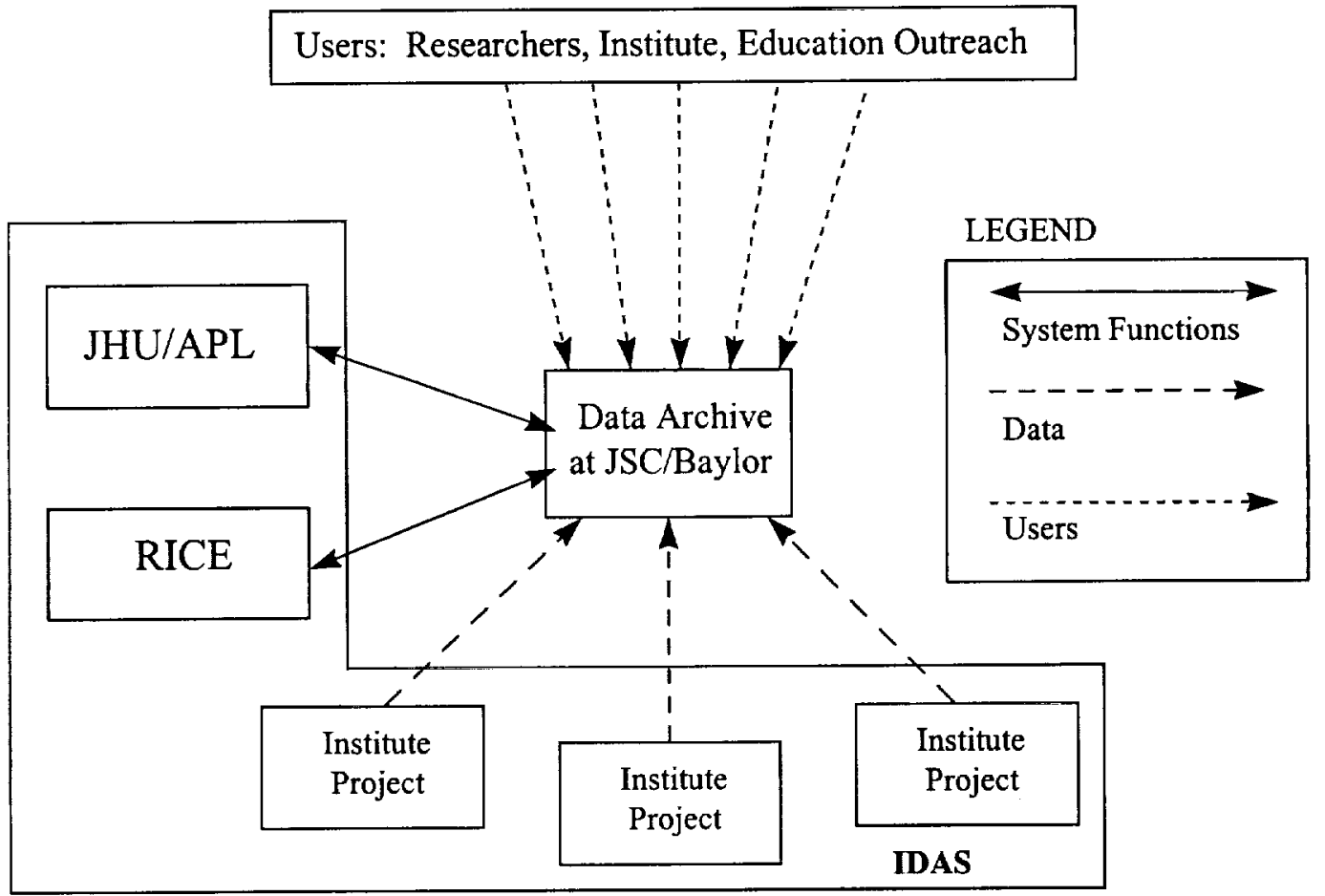

Figure 3. Architecture planned for the Institute Data Archiving System (IDAS). 


\section{PEER REVIEW PANELS}

PARTICIPATING

IN THE

\section{REVIEW OF NSBRI'S INITIAL PROPOSALS}

SUMMER 1997

A-1 


\section{National Space Biomedical Research Institute \\ Bone Loss Panel \\ July 30-August 1, 1997 \\ Baltimore, MD}

\section{Chair:}

Dr. John Alan Yee

Department of Biomedical Sciences

Creighton University

School of Medicine

Omaha, NE 68178

\section{Panel Members:}

Dr. Stephen B. Doty

Analytical Microscopy Laboratory

Hospital for Special Surgery

New York, NY 10021

Dr. Michael McClung

Endocrine \& Osteoporosis Association

Portland, OR 97213

Dr. Scott C. Miller

Division of Radiobiology

University of Utah

Salt Lake City, UT 84112-5860

Dr. Roy Ogle

University of Virginia

Department of Neurological Surgery

Charlottesville, VA 22908
Peer Review Administrator:

Ms. Victoria Friedensen

Information Dynamics, Inc.

Washington, DC 20024

NSBRI Logistics Coordinator:

Ms. Candace Solomon

Information Dynamics, Inc.

Washington, DC 20024 


\section{National Space Biomedical Research Institute \\ Cardiovascular Alterations Panel \\ July 20-22, 1997 \\ Boston, MA}

\section{Chair:}

Dr. William B. Hood, Jr.

Cardiology Unit

University of Rochester Medical Center

Rochester, NY 14642

\section{Panel Members:}

Dr. Peter Buttrick

Section of Cardiology MC787

University of Illinios at Chicago

Chicago, IL 60612

Dr. Mark W. Chapleau

Associate Professor

Department of Internal Medicine

University of Iowa

Iowa City, IA 52242

Dr. Louis G. D'Alecy

Professor of Physiology

Departments of Physiology and Surgery

University of Michigan School of Medicine

Ann Arbor, MI 48109-0622

Dr. Jeff Rottman

Cardiology Division

Vanderbilt University School of Medicine

Nashville, TN 37232

\section{NSBRI Peer Review Administrator:}

Dr. Francis Haddy

Information Dynamics, Inc.

Washington, DC 20024

\section{NSBRI Logistics Coordinator:}

Ms. Candace Solomon

Information Dynamics, Inc.

Washington, DC 20024 


\section{National Space Biomedical Research Institute Human Performance Factors, Sleep and Chronobiology Panel \\ August 5-7, 1997 \\ Boston, MA}

Chair:

Dr. H. Elliott Albers

Laboratory of Neuroendocrinology and Behavior

Departments of Biology and Psychology

Georgia State University

Atlanta, GA 30303

\section{Panel Members:}

Dr. Eric L. Bittman

Department of Biology

University of Massachusetts

Amherst, MA 01003

Dr. Joseph D. Miller

Department of Pharmacology

Texas Tech University

Health Sciences Center

Lubbock, TX 79430

Dr. Christine M. Mitchell

Center for Human-Machine Systems Research

School of Industrial \& Systems Engineering

Georgia Institute of Technology

Atlanta, GA 30332-0205

Dr. Robert L. Sack

Sleep and Mood Disorder Laboratory, L-469

Oregon Health Sciences University

Portland, OR 97201
NSBRI Peer Review Administrator:

Dr. Catherine Golden

Information Dynamics, Inc.

Washington, DC 20024

NSBRI Logistics Coordinator:

Ms. Candace Solomon

Information Dynamics, Inc.

Washington, DC 20024 


\section{National Space Biomedical Research Institute Immunology, Infection, and Hematology Panel \\ July 24-26, 1997 \\ Houston, TX}

Chair:

Dr. Gerald Sonnenfeld

Division of Research and Immunology

Department of General Surgery Research

Carolinas Medical Center

Charlotte, NC 28232-2861

\section{Panel Members:}

Dr. Wallace D. Berry, Jr.

Research Associate

Department of Physiology and

Pharmacology

College of Veterinary Medicine

Auburn University

Auburn, AL 36849-5520

Dr. Stephen K. Chapes

Division of Biology

Kansas State University

Manhattan, KS 66506-4901

Dr. Albert T. Ichiki

University of Tennessee Medical Center

Department of Medical Biology

Knoxville, TN 37920-6999

Dr. Edwin Stiles Miller, Jr.

Texas Tech University Health Sciences

Center

School of Pharmacy

Department of Pharmaceutical Sciences

Amarillo, TX 79106
NSBRI Peer Review Administrator:

Dr. David Watson

Information Dynamics, Inc.

Nassau Bay, TX 77058

NSBRI Logistics Coordinator:

Candace Solomon

Information Dynamics, Inc.

Washington, DC 20024 


\section{National Space Biomedical Research Institute \\ Muscle Alterations and Atrophy Panel \\ August 3-5, 1997 \\ Houston, TX}

Chair:

Dr. David Bader

Vanderbilt Medical School

Division of Cardiology

Nashville, TN 37232-6300

Panel Members:

Dr. Mohamed A. Attawia

Allegheny University Hospital

East Falls

Department of Orthopedic Surgery

Philadelphia, PA 19129

Dr. Priscilla M. Clarkson

University of Massachusetts

Department of Exercise Science

Amherst, MA 01003

Dr. Robert S. Hikida

Biological Sciences

Ohio University

Athens, OH 45701

Dr. Jiri Turinsky

Albany Medical College

Department of Physiology and Cell

Biology

Albany, NY 12208
NSBRI Peer Review Administrator:

Dr. Edith R. Schwartz

Information Dynamics, Inc.

Washington, DC 20024

\section{NSBRI Logistics Coordinator:}

Ms. Candace Solomon

Information Dynamics, Inc.

Washington, DC 20024 


\section{National Space Biomedical Research Institute Neurovestibular Adaptation Panel \\ July 22-24, 1997 \\ Boston, MA}

\section{Chair:}

Dr. David J. Andersen

EECS Building

University of Michigan

Ann Arbor, MI 48109-2122

Panel Members:

Dr. Carey D. Balaban

University of Pittsburgh, School of Medicine

Pittsburgh, PA 15213

Dr. Paul Dizio

Graybiel Laboratory

Brandeis University

Waltham, MA 02254-9110

Dr. Michael Hassul

Manhattan Beach, CA 90266

Dr. Glenn Knox

University of Pennsylvania Medical Center

Department of Otorhinolaryngology - Head

and Neck Surgery

Philadelphia, PA 19104

Dr. Arthur D. Kuo

University of Michigan

Department of Mechanical Engineering \&

Applied Mechanics

Ann Arbor, MI 48109-2125
NSBRI Peer Review Administrator:

Dr. Francis Haddy

Information Dynamics, Inc.

Washington, DC 2024

\section{NSBRI Logistics Coordinator:}

Ms. Candace Solomon

Washington, DC 20024 


\section{National Space Biomedical Research Institute Radiation Effects: DNA Damage and Repair Panel \\ August 10-12, 1997 \\ Baltimore, MD}

\section{Chair:}

Dr. William F. Morgan

Laboratory of Radiobiology

University of California

San Francisco, CA 94143-0750

\section{Panel Members:}

Dr. Antone L. Brooks

Washington State University

Richland, WA 99335-1643

Dr. Ray Meyn

Department of Experimental Radiation

Oncology

M.D. Anderson Cancer Center

University of Texas

Houston, TX 77030

Dr. Julian Preston

Chemical Industry Institute of Toxicology

Research Triangle Park, NC 17709

Dr. Raymond L. Warters

Division of Experimental Oncology

Department of Radiation Oncology

University of Utah School of Medicine

Salt Lake City, UT 84132

\section{NSBRI Peer Review Administrator:}

Dr. David Watson

Information Dynamics, Inc.

Nassau Bay, TX 77058

\section{NSBRI Logistics Coordinator:}

Ms. Candace Solomon

Information Dynamics, Inc.

Washington, DC 20024 


\section{National Space Biomedical Research Institute \\ Technology Development Panel \\ July 29-31, 1997 \\ Laurel, MD}

\section{Chair:}

Dr. Arthur A. Ciarkowski

Food and Drug Administration

Dr. Gregg E. Trahey

Duke University

Office of Device Evaluation

Department of Biomedical Engineering

Division of Cardiovascular, Respiratory,

Durham, NC 27708-0281

and Neurological Development

Rockville, MD 20850

\section{Panel Members:}

NSBRI Peer Review Administrator:

Dr. Louis Lippiello

Harrington Arthritis Research Center

Phoenix, AZ 85006

Dr. Francois Padovani

Dr. Edith R. Schwartz

Information Dynamics, Inc.

Washington, DC 20024

\section{NSBRI Logistics Coordinator:}

Ms. Candace Solomon

Westwood, MA 02090

Information Dynamics, Inc.

Washington, DC 20024

Dr. Jerome Schultz

University of Pittsburgh

Center for Biotechnology and

Bioengineering

Pittsburgh, PA 15219 


\section{NATIONAL SPACE BIOMEDICAL RESEARCH INSTITUTE}

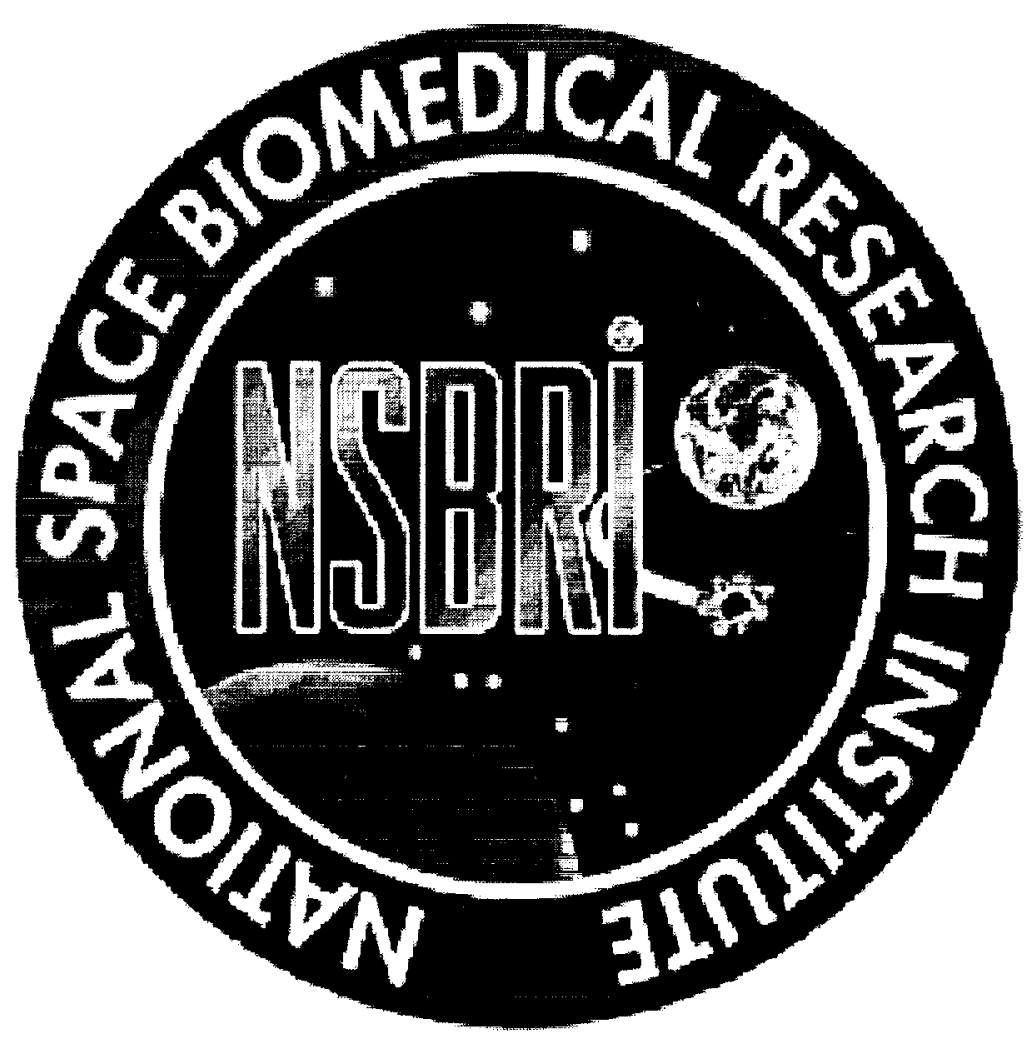

Updated July 31, 1998

Research Program - Year 1

October 1, 1997 - September 30, 1998 


\section{National Space Biomedical Research Institute Research Program - Year 1 \\ Funding Period: October 1, 1997 - September 30, 1998 \\ (Updated July 31, 19989) \\ TABLE OF CONTENTS}

BONE LOSS

..B-1

CARDIOVASCULAR ALTERATIONS B-6

HUMAN PERFORMANCE B-15

IMMUNOLOGY, INFECTION \& HEMATOLOGY

MUSCLE ALTERATIONS \& ATROPHY B-31

NEUROVESTIBULAR ADAPTATION B-38

RADIATION EFFECTS B-43

TECHNOLOGY DEVELOPMENT B-49

SYNERGY PROJECTS B-54 


\section{NSBRI RESEARCH PROGRAM \\ BONE LOSS}

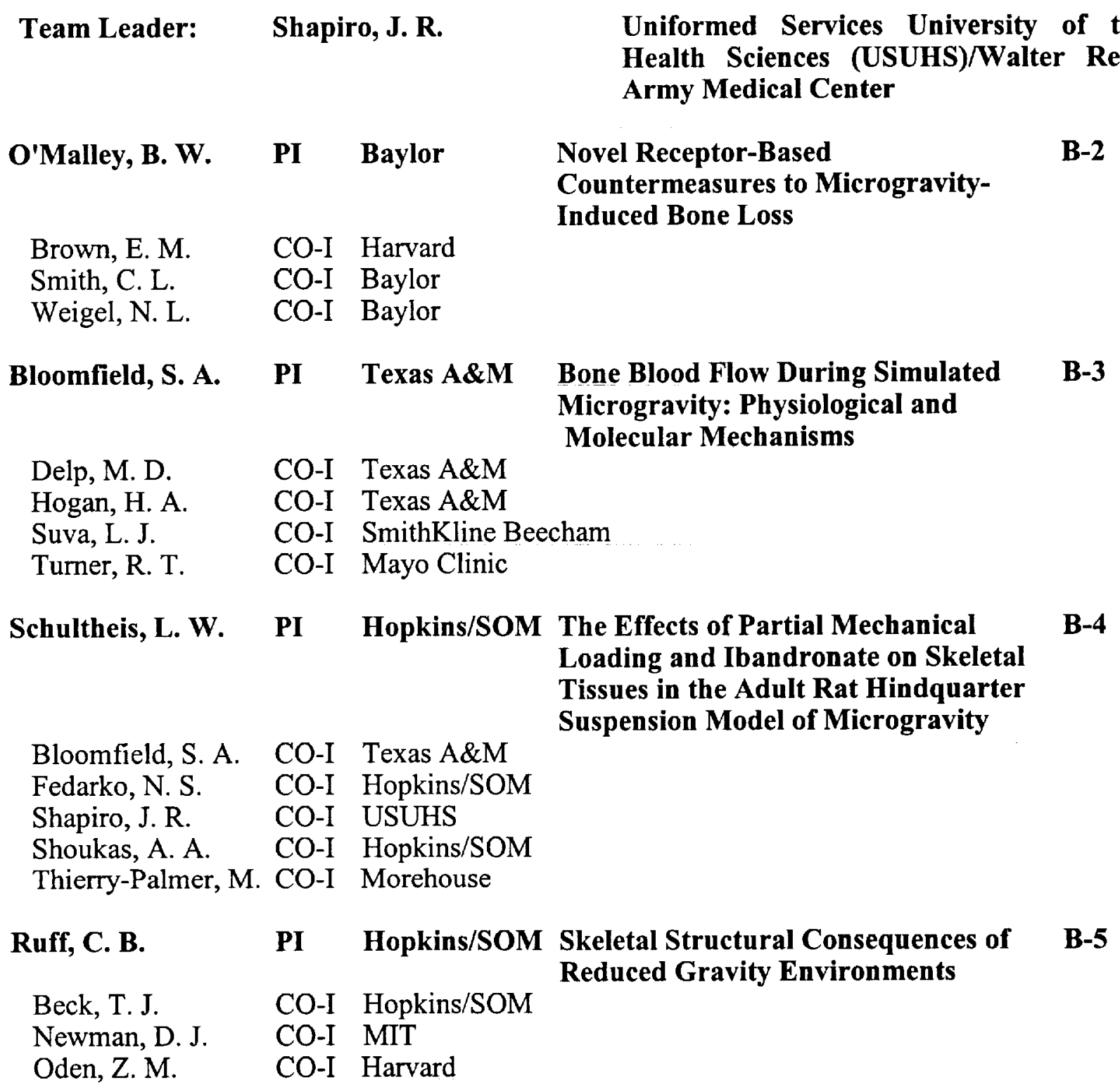




\begin{tabular}{|ll|}
\hline RESEARCH AREA: & Bone Loss \\
PRINCIPAL INVESTIGATOR: Bert W. O'Malley, M.D. \\
\begin{tabular}{ll} 
ORGANIZATION: & Baylor College of Medicine \\
PROJECT TITLE: & Novel Receptor-Based Countermeasures to Microgravity-Induced \\
& $\begin{array}{l}\text { Bone Loss } \\
\text { FUNDING: }\end{array}$ \\
\hline 281,000 (FY1998)
\end{tabular} \\
\hline
\end{tabular}

\section{PROJECT SUMMARY}

The biological actions mediated by the estrogen receptor (ER), vitamin D receptor (VDR) and $\mathrm{Ca}^{2+}$ sensing receptor $(\mathrm{CaR})$ play key roles in the normal control of bone growth and skeletal turnover that is necessary for skeletal health. These receptors act by controlling the differentiation and/or function of osteoblasts and osteoclasts, and other cell types within the bone and bone marrow microenvironment. The appropriate use of selective ER modulators (SERMs) which target bone, vitamin $\mathrm{D}$ analogs that favor bone formation relative to resorption, and $\mathrm{CaR}$ agonists that modulate osteoclastogenesis, should make it possible to prevent the reduction in bone formation and increase in bone resorption that normally contribute to the bone loss induced by weightlessness. Indeed, there may be synergistic interactions among these receptors that enhance the actions of any one used alone. Therefore, we propose to: 1) assess the in vitro ability of novel ER, VDR and $\mathrm{CaR}$ agonists, alone or in combination, to modulate osteoblastogenesis and mature osteoblast function under conditions of $1 \mathrm{~g}$ and simulated microgravity; 2) assess the in vitro ability of novel ER, VDR and CaR agonists, alone or in combination, to modulate osteoclastogenesis and bone resorption under conditions of $1 \mathrm{~g}$ and in normal rat bone as well as the in vivo actions of our novel ER-and VDR-based therapeutics in the rat in preparation for their use, alone or in combination, in well-established ground-based models of microgravity and eventually in space flight. 


\begin{tabular}{|ll|}
\hline RESEARCH AREA: & Bone Loss \\
PRINCIPAL INVESTIGATOR: Susan A. Bloomfield, Ph.D. \\
ORGANIZATION: & Texas A\&M University \\
PROJECT TITLE: & $\begin{array}{l}\text { Bone Blood Flow During Simulated Microgravity: Physiological } \\
\text { and Molecular Mechanisms } \\
\$ 212,000 \text { (FY1998) }\end{array}$ \\
FUNDING: & \begin{tabular}{l}
$\$ 212$ \\
\hline
\end{tabular}
\end{tabular}

\section{PROJECT SUMMARY}

There is a demonstrable relationship between bone blood flow and indices of bone mass in human and animal models. Large increases or decreases in bone blood flow appear to stimulate resorption and/or suppress bone formation, resulting in decreases in bone mass. Preliminary data indicate that blood flow to the rat femur decreases after 14 days of hindlimb suspension. Administration of dobutamine, a $B_{2}$-agonist, prevents the loss of cortical bone area observed after 28 days hindlimb suspension in adult rats. An increase in peripheral blood flow to the unloaded hindlimb as stimulated by the $B_{2}$-agonist may provide the mechanism for this protective effect. Further, potential molecular mechanisms exist to link changes in bone blood flow to changes in bone cell activity, particularly for vasoactive agents like endothelium-derived nitric oxide (EDNO). The decreases in fluid shear stress associated with the shifts of plasma volume during microgravity may result in alterations in expression of vasoactive agents such as EDNO having important functional effects on bone cells. The primary aim of this project is to characterize changes in 1) bone blood flow, 2) indices of bone mass, geometry, and strength, and 3) changes in gene expression for modulators of nitric oxide activity (e.g., nitric oxide synthase) and other candidate genes involved in mechanotransduction after $7,14,21$, and 28 days of hindlimb suspension in the adult rat. Utilizing the results of these studies, we will then define the mechanistic contribution of altered blood flow to changes in bone with simulated microgravity by administering a vasodilatory agent during hindlimb suspension. In all studies, responses in the unloaded hindlimb bones (tibial shaft, femoral neck) will be compared with those in the weightbearing humeral shaft and the non-weightbearing calvarium from the same animal. Bone mineral density, mineral content, and geometry will be quantified by high-resolution radiography; structural and material properties of the long bones will be determined by 3-point bending (tibia humerus) or compression (femoral neck) testing to failure. A unique aspect of these studies will be defining the time course of changes in gene expression in bone cell populations with unloading, accomplished with Northern blots, in situ hybridization and immunohistochemistry. These studies have high relevance for concurrent protocols being proposed by investigators on NSBRI Cardiovascular and Muscle teams with blood flow data available on a number of tissues other than a bone. Further, dobutamine and other $\beta_{2}$-agonists have been tested as countermeasures for altered muscle and cardiovascular function. Results of the intervention tested in our studies have potential relevance for a number of systemic changes seen with prolonged exposure to microgravity. 


\section{RESEARCH AREA: Bone Loss PRINCIPAL INVESTIGATOR: Lester W. Schultheis, M.D. ORGANIZATION: Johns Hopkins School of Medicine PROJECT TITLE: The Effects of Partial Mechanical Loading and Ibandronate on Skeletal Tissues in the Adult Rat Hindquarter Suspension Model for Microgravity \\ FUNDING:}

\section{PROJECT SUMMARY}

Exposure to microgravity as occurs in extended space flight is associated with bone loss that ranges from $0.5 \%-2.0 \%$ per month. Nutritional and physical countermeasures employed to diminish bone loss have not thus far proven effective. We hypothesize that the maximal protection against microgravity induced bone loss will be provided by a combination of partial weight bearing and episodic full weight bearing, combined with ibandronate. Ibandronate, a powerful, third generation bisphosphonate, can be administered parentally at infrequent intervals with minimal toxicity. Specific aims: 1) The hindquarter suspended adult rat model of weightlessness will be studied using a novel force plate system for the application of graded amounts of mechanical loading on the fore limbs. Animals will be suspended for 35 days after appropriate acclimation, 2) the additional effect of episodic full weightbearing will be determined in the suspended rat model, 3) The skeletal actions of ibandronate will be studied as a countermeasure to bone loss, 4) Combination therapy of partial weightbearing on the forelimbs, episodic full weightbearing and ibandronate will be evaluated. Ibandronate will be administered in a dose of $10 \mathrm{ug} / \mathrm{kg}$, and $30 \mathrm{ug} / \mathrm{kg}$ on day 0 . Specific cellular, histomorphometric, biochemical and biomechanical properties of bone will be assayed and compared in control, suspended and ibandronate treated animals.

Study Groups Year 1 (15 animals per group) : 1) control-free roaming, 2) hindlimb suspensionforce monitored, 3) hindlimb suspension-ibandronate $10 \mathrm{ug} / \mathrm{kg}, 4)$ hindlimb suspensionibandronate $30 \mathrm{ug} / \mathrm{kg}, 5$ ) suspension-50\% chronic weight bearing, 6) suspension-50\% chronic weightbearing and episodic full weightbearing. Study Groups Year 2: 1) control-free roaming, 2) hindlimb suspension-front full weightbearing, force plate monitored, 7) hindlimb suspension$50 \%$ front weightbearing, ibandronate $10 \mathrm{ug} / \mathrm{kg}, 8)$ hindlimb suspension- $50 \%$ front weightbearing, ibandronate $30 \mathrm{ug} / \mathrm{kg}$, 9) suspension-50\% front weightbearing + episodic full weightbearing + ibandronate, $10 \mathrm{ug} / \mathrm{kg} ; 10$ ) suspension- $50 \%$ front weightbearing + episodic full weightbearing + ibandronate $30 \mathrm{ug} / \mathrm{kg}$. Expected outcomes are that compared to the same bones under non- weightbearing suspension: 1) $50 \%$ chronic weightbearing will reduce bone loss, 2) $50 \%$ chronic weightbearing + episodic full weightbearing will further reduce bone loss, 3 ) ibandronate will independently reduce bone loss, 4) ibandronate $+50 \%$ weight bearing + episodic full weightbearing will further reduce bone loss. Thus, we will compare: 1) full weight bearing on fore- and hindlimbs to unloaded hindlimbs and $50 \%$ weightbearing forelimbs, 2) episodic full weightbearing to chronic full weightbearing and $50 \%$ only weightbearing models and, 3 ) the effects of ibandronate in each model. This project will provide a comprehensive evaluation of tissue and cellular effects of graded mechanical loads and antiresorptive therapy on bone. The $50 \%$ weightbearing model is relevant to the $0.4 \mathrm{~g}$ environment on Mars and permits an evaluation of potential limited artificial gravity on spacecraft. 


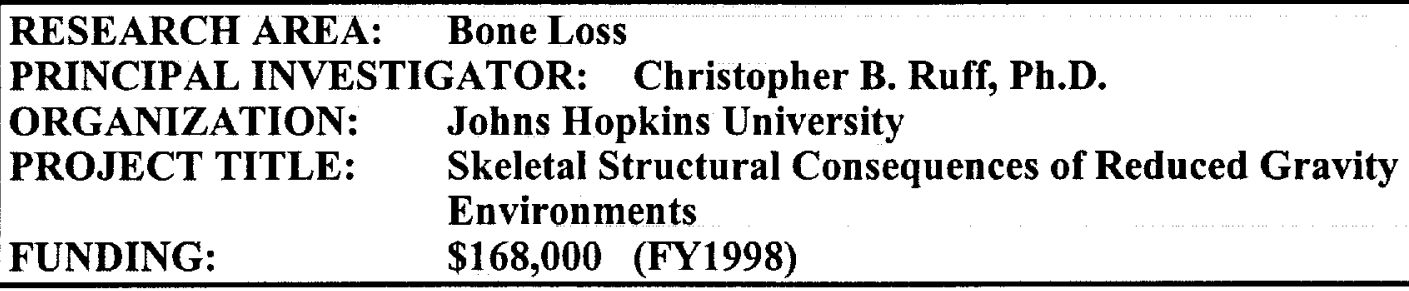

\section{PROJECT SUMMARY}

The main goal of this project is to provide a better assessment of bone strength and fracture risk following extended exposure to a microgravitational environment. Another goal is to evaluate the effectiveness of countermeasures (intermittent or partial weight-bearing, resistive exercise, treatment with bisphosphonates) in maintaining bone structure under conditions of microgravity. Using semiautomated programs developed by us, bone structural parameters will be determined from DEXA scans of the hip and thigh of astronauts/cosmonauts who flew aboard the Mir Space (data provided by $A$. Leblanc and L. Schackelford). In addition, bone structural parameters of the femur and humerus will be derived from pQCT scanning of rats subjected to partial weight-bearing, again with and without treatment with periodic exercise and ibandronate. Bone stresses before and after experimental periods will be calculated under simulated applied loadings. 3-D finite element analyses will be used to verify and extend loading configurations, including loadings encountered during space flight. Results will also be compared to those obtained from direct mechanical testing of rat femurs and humeri. 


\section{NSBRI RESEARCH PROGRAM \\ CARDIOVASCULAR ALTERATIONS}

\begin{tabular}{|c|c|c|c|c|}
\hline Team Leader: & Cohe & , R. J. & MIT & \\
\hline $\begin{array}{l}\text { Williams, G. H. } \\
\text { Cohen, R. J. } \\
\text { Mullen, T. J. } \\
\text { Ofili, Elizabeth } \\
\text { Ramsdell, C. R. }\end{array}$ & $\begin{array}{l}\text { PI } \\
\text { CO-I } \\
\text { CO-I } \\
\text { CO-I } \\
\text { CO-I }\end{array}$ & $\begin{array}{l}\text { Harvard } \\
\text { MIT } \\
\text { Harvard } \\
\text { Morehouse } \\
\text { Harvard }\end{array}$ & Human Studies Core & B-7 \\
\hline Cohen, R. J. & PI & MIT & $\begin{array}{l}\text { Alterations in Cardiovascular } \\
\text { Regulation and Function During } \\
\text { Simulated Microgravity }\end{array}$ & B-8 \\
\hline $\begin{array}{l}\text { Mullen, T. J. } \\
\text { Ramsdell, C. R. }\end{array}$ & $\begin{array}{l}\text { CO-I } \\
\text { CO-I }\end{array}$ & $\begin{array}{l}\text { Harvard } \\
\text { Harvard }\end{array}$ & & \\
\hline Williams, G. H. & PI & Harvard & $\begin{array}{l}\text { Renal and Cardio-Endocrine } \\
\text { Responses in Humans to Simulated } \\
\text { Microgravity }\end{array}$ & B-9 \\
\hline Bonventre, J. V. & CO-I & Harvard & & \\
\hline Mullen, T. J. & CO-I & Harvard & & \\
\hline Ramsdell, C. R. & CO-I & Harvard & & \\
\hline Shoukas, A. A. & PI & Hopkins/SOM & $\begin{array}{l}\text { Rodent Studies of Cardiovascular } \\
\text { Deconditioning }\end{array}$ & B-10 \\
\hline Berkowitz, D. & CO-I & Hopkins/SOM & & \\
\hline Kamm, R. D. & PI & MIT & $\begin{array}{l}\text { Computational Models of the } \\
\text { Cardiovascular System and Its } \\
\text { Responses to Microgravity }\end{array}$ & B-11 \\
\hline Mark, R. G. & CO-I & MIT & & \\
\hline $\begin{array}{l}\text { Schneider, M. D. } \\
\text { Abdellatif, M. M. } \\
\text { Lorell, B. H. }\end{array}$ & $\begin{array}{l}\text { PI } \\
\text { CO-I } \\
\text { CO-I }\end{array}$ & $\begin{array}{l}\text { Baylor } \\
\text { Baylor } \\
\text { Harvard }\end{array}$ & Cardiac Atrophy & B-12 \\
\hline Cohen, R. J. & PI & MIT & $\begin{array}{l}\text { Non-Invasive Assessment of } \\
\text { Susceptibility to Ventricular } \\
\text { Arrhythmias During Simulated } \\
\text { Microgravity }\end{array}$ & B-13 \\
\hline $\begin{array}{l}\text { Mullen, T. J. } \\
\text { Ramsdell, C. R. }\end{array}$ & $\begin{array}{l}\text { CO-I } \\
\text { CO-I }\end{array}$ & $\begin{array}{l}\text { Harvard } \\
\text { Harvard }\end{array}$ & & \\
\hline
\end{tabular}




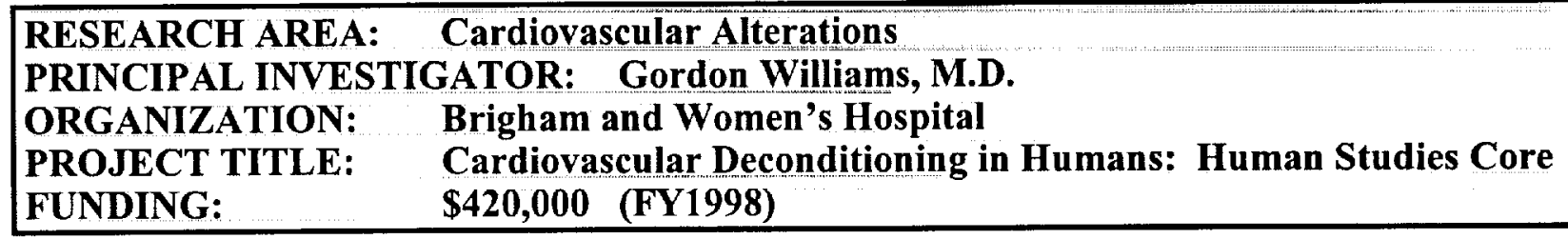

\section{PROJECT SUMMARY}

Major cardiovascular problems, secondary to cardiovascular deconditioning, may occur on extended space missions. While it is generally assumed that the microgravity state is the primary cause of cardiovascular deconditioning, sleep deprivation and disruption of diurnal rhythms may also play an important role. Factors that could be modified by either or both of these perturbations include: autonomic function and short-term cardiovascular reflexes, nitric oxide mediated vasoreactivity, circadian rhythm of cardiovascular hormones (specifically the reninangiotensin system) and renal sodium handling and hormonal influences on that process, venous compliance, cardiac mass, and cardiac conduction processes. The purpose of the Human Studies Core is to provide the infrastructure to conduct human experiments that will allow for the assessment of the likely role of such factors in the space travel associated cardiovascular deconditioning process and to develop appropriate countermeasures. The Core will take advantage of a newly created Intensive Physiologic Monitoring (IPM) Unit at the Brigham and Women's Hospital, Boston, MA, to perform these studies.

The Core includes two general experimental protocols. The first protocol involves a supine bedrest study to simulate microgravity. The second protocol includes the addition of a disruption of circadian rhythms to the simulated microgravity environment. Before and after each of these environmental manipulations, the subjects will undergo acute intensive stressors simulating changes in volume and/or stress, which could occur in space and on return to Earth. The subjects will be maintained in a rigidly controlled environment with fixed light/dark cycles, activity pattern, and dietary intake of nutrients, fluids, ions and calories. 


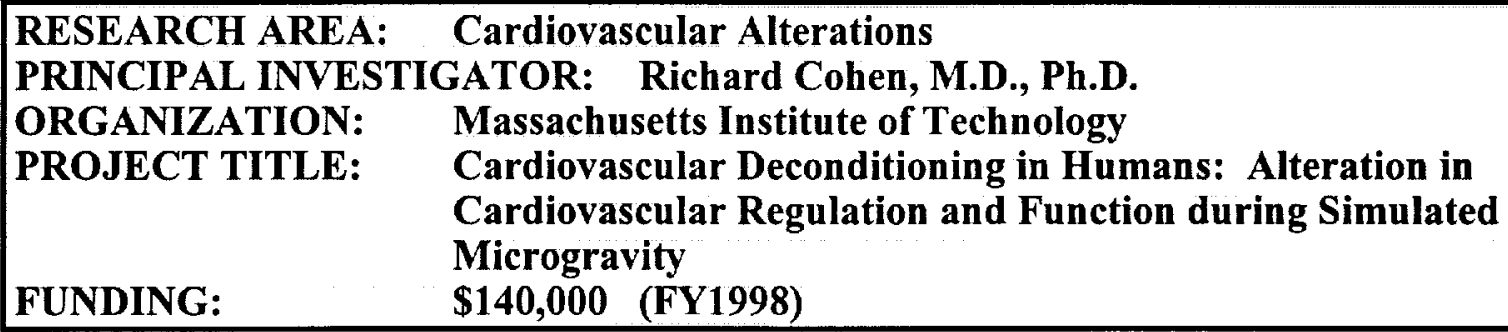

\section{PROJECT SUMMARY}

Alterations in cardiovascular regulation and function that occur during and after space flight have been reported. These alterations are manifested, for example, by reduced orthostatic tolerance upon reentry to the Earth's gravity from space. However, the precise physiologic mechanisms responsible for these alterations remain to be fully elucidated. Perhaps, as a result, effective countermeasures have yet to be developed. We propose to apply a powerful, new method cardiovascular system identification (CSI) - for the study of the effects of space flight on the cardiovascular system so that effective countermeasures can be developed.

CSI involves the mathematical analysis of second-to-second fluctuations in non-invasively measured heart rate, arterial blood pressure (ABP), and instantaneous lung volume (ILV - respiratory activity) in order to characterize quantitatively the physiologic mechanisms responsible for the couplings between these signals. Through the characterization of all the physiologic mechanisms coupling these signals, CSI provides a model of the closed-loop cardiovascular regulatory state in an individual subject. The model includes quantitative descriptions of the heart rate baroreflex as well as other important physiologic mechanisms. With an additional non-invasive measurement of stroke volume (SV - ultrasound Doppler method), the model may be extended to also include the characterization of the peripheral resistance baroreflex - which may play a central role in the development of orthostatic intolerance - and measures of systolic and diastolic function.

We will apply CSI in conjunction with the two general protocols of the human studies core. The first protocol involves ground-based, human bed-rest to simulate microgravity and acute stressors - standing and lower body negative pressure (LBNP) - to provide orthostatic challenges. The second protocol is the same as the first but with the addition of circadian rhythm disruption to determine whether such disruption contributes to cardiovascular alterations. In these studies, we will focus on the basic physiologic mechanisms responsible for the alterations in cardiovascular regulation and function during the simulated microgravity in order to formulate hypotheses regarding what countermeasures are likely to be most effective.

In future studies, we plan to apply CSI to test the potential countermeasures in conjunction with the same bed-rest and acute stressor models. We also anticipate applying CSI for studying astronauts before and after space flight and ultimately, during space flight. The application of CSI, along with the other specialized measurement techniques proposed for the human core studies, promise to provide information relevant to the development and evaluation of effective countermeasures allowing humans to adapt appropriately upon reentry to the Earth's gravity and to live and work for longer periods of time in microgravity. 


\begin{tabular}{|ll|}
\hline RESEARCH AREA: & Cardiovascular Alterations \\
PRINCIPAL INVESTIGATOR: Gordon H. Williams, M.D. \\
ORGANIZATION: & Brigham and Women's Hospital \\
PROJECT TITLE: & $\begin{array}{l}\text { Renal and Cardio-Endocrine Responses in Humans to Simulated } \\
\text { Microgravity }\end{array}$ \\
FUNDING: & \begin{tabular}{l} 
Included in Human Studies Core Funding \\
\hline
\end{tabular}
\end{tabular}

\section{PROJECT SUMMARY}

The volume regulating systems are integrated to produce an appropriate response to both acute and chronic volume changes. Their responses include changing the levels of the hormones and neural inputs of the involved systems and/or changing the responsiveness of their target tissues. Weightlessness during space travel produces a volume challenge which is unfamiliar to the organism. Thus, it is likely that these volume regulatory mechanisms may respond inappropriately, e.g., a decrease in total body volume in space and abnormal responses to upright posture and stress on return to Earth. A similar "inappropriateness" also can occur in disease states, e.g., congestive heart failure. While it is clear that weightlessness produces profound changes in sodium and volume homeostasis, the mechanisms responsible for these changes are incompletely understood. Confounding this analysis is sleep deprivation, common in space travel, which can also modify volume homeostatic mechanisms.

The purpose of this project is to provide the required understanding and then to design appropriate countermeasures to reduce or eliminate the adverse effects of microgravity. To accomplish this we will address five Specific Aims: 1) To test the hypothesis that microgravity modifies the acute responsiveness of the renin-angiotensin-aldosterone system (RAAS) and renal blood flow; 2) Does simulated microgravity change the circadian rhythm of the volume-regulating hormones?, 3) Does a simulated microgravity change the target tissue responsiveness to angiotensin II (AngII)?; 4) Does chronic sleep deprivation modify the circadian rhythm of the RAAS and change the acute responsiveness of this system to posture beyond what a microgravity environment alone does? and 5) What effect does salt restriction have on the volume homeostatic and neurohumoral responses to a microgravity environment? Because the renin-angiotensin system (RAS) plays a pivotal role in blood pressure control and volume homeostasis, it likely is a major mediator of the adaptive cardio-renal responses observed during space missions and will be a special focus of this project. Thus, the overall goal of this proposal is to assess the impact of microgravity and sleep deprivation in humans on volume-regulating systems. To achieve this overall objective, we will evaluate renal blood flow and the status and responsiveness of the volume-regulating systems (RAAS, atrial natriuretic peptide and vasopressin), and the adrenergic system (plasma and urine catecholamines) in both simulated microgravity and normal gravity with and without sleep deprivation. Furthermore, the responses of the volume homeostatic mechanisms to acute stimulation by upright posture and exercise will be evaluated before and after achieving equilibrium with these interventions.

This work has implications for the treatment and prevention of maladaptive hemodynamic responses experienced by astronauts in flight and on return to Earth. It will increase our understanding of the mechanisms by which weightlessness and sleep deprivation change plasma volume and sodium homeostasis, thereby providing entrée to develop appropriate counter-measures. 


\begin{tabular}{|ll|}
\hline RESEARCH AREA: & Cardiovascular Alterations \\
PRINCIPAL INVESTIGATOR: Artin A. Shoukas, Ph. D. \\
ORGANIZATION: & Johns Hopkins University School of Medicine \\
PROJECT TITLE: & Rodent Studies of Cardiovascular Deconditioning \\
FUNDING: & $\$ 175,000$ (FY1998) \\
\hline
\end{tabular}

\section{PROJECT SUMMARY}

Changes in cardiac output can occur for two reasons: the altered contractility of the heart or through changes in venous filling pressure of the heart via the Frank Starling mechanism. The observed changes in cardiac output after long term long term space flight cannot be entirely explained through changes in contractility or heart rate alone. Therefore, changes in filling pressure mediated through changes in systemic venous capacitance function may be an important determinant of cardiac after long-term space flight. Our laboratory has previously shown the importance of veno-constriction by the carotid sinus baroreceptor reflex system on overall circulatory homeostasis and in particular the regulation of cardiac output.

Our proposed experiments will test our overall hypothesis, that alterations in venous capacitance function by the carotid sinus baroreceptor reflex system is an important determinant of the cardiac output response seen in astronauts after returning to Earth from long term exposure to micro gravity. This hypothesis is important to our overall understanding of circulatory adjustments made during long-term space flight as well as to provide for counter measures to reduce the incidence of orthostatic hypotension caused by an attenuation of cardiac output. We will use the tail suspended rat model to simulate the pathophysiological effects as they related to cardiovascular deconditioning in microgravity. We will study the baroreceptor reflex control from the organism level to the level of venous micro vessels and the adrenergic receptors responsible for veno constriction. This proposal advances a novel hypothesis: orthostatic intolerance following microgravity exposure is due in part to changes in function of intestinal (splanchnic) capacitance vessel alpha-1 adrenoreceptors (ARs). This hypothesis is based on: 1) our preliminary animal and human data which demonstrate that inhibition of a single alpha-1 AR subtype results in both blockade of sympathetically mediated splanchnic capacitance vessel constriction and orthostatic intolerance, and 2) published studies which document intact efferent sympathetic responses to postural stress (norepinephrine (NE) release) in returning astronauts, possibly pointing to a vascular smooth muscle insensitivity as contributing to orthostatic intolerance. This proposal will test the hypothesis that simulated microgravity produces alterations in alpha 1 AR-mediated control of splanchnic capacitance vessel tone. A chronic rat model and in vitro microvessel bioassay will be sued to investigate effects of simulated microgravity on splanchnic vessel responses to adrenergic stimulation. These studies will provide important new data concerning normal capacitance vessel function in compensating for postural blood volume redistribution, test our novel hypothesis regarding the pathogenesis of orthostatic intolerance following microgravity exposure and provide insights into potential countermeasures and therapies to prevent problematic postural hypotension on reentry. 


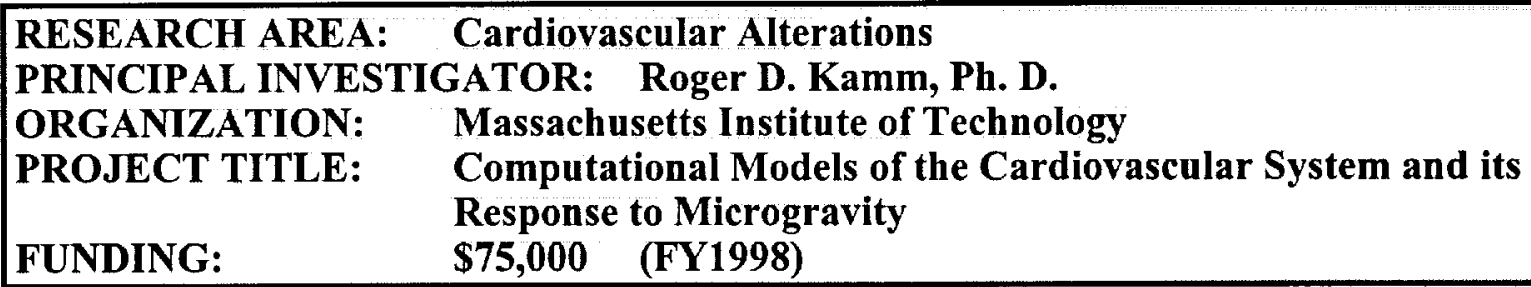

\section{PROJECT SUMMARY}

Experimental studies of the cardiovascular system in humans, and even in laboratory animals, are necessarily limited in scope because of restrictions on the types of measurements that can be made. Often, the true parameter of interest cannot be measured directly so it must be inferred from other measures. Even when appropriate measurements can be made, the cause of the observed variations may not be evident because of the complexity of the interactions between the numerous components of the system. These and other issues can often be addressed more effectively with the aid of a computational model that simulates the critical components and behaviors of the cardiovascular system. Models depend upon experiments for refinement and specification of their parameters, but also illuminate and enhance the interpretation of experimental results. We view the experiments and computational models as highly synergistic in that the value of one is greatly enhanced by the existence of the other. It could be argued that these are not merely advantages, but essential aspects of a study of orthostatic intolerance.

The primary objectives of this project are to develop a general, modular model of cardiovascular function that contains the essential features associated with the effects of gravity, and to use this model to examine the short term effects of (1) transitions between normal gravity and microgravity, (2) interventions to minimize or eliminate the adverse effects of re-entry, (3) countermeasures that might be used by astronauts while in the micro-gravity environment and in preparation for re-entry, and (4) screening measures that might be used to identify high risk individuals who may require special interventions or countermeasures to avoid orthostatic hypotension. The model will also be used in conjunction with land-based experiments on human subjects to enhance the interpretation of the experimental data. We also propose to develop a finite element model of the electrical activity of the heart to support research study of cardiac electrical instability and arrhythmogenesis. 


\section{RESEARCH AREA: Cardiovascular Alterations \\ PRINCIPAL INVESTIGATOR: Michael D. Schneider, M.D. \\ ORGANIZATION: Baylor College of Medicine \\ PROJECT TITLE: Cardiac Atrophy \\ FUNDING: \\ $\$ 140,000$ (FY1998)}

\section{PROJECT SUMMARY}

The objective of this project is to determine the cellular and molecular mechanisms of cardiac atrophy caused by microgravity (already demonstrated in space-flown rats), determine the functional consequences on basal cardiac function and contractile reserve, and identify specific countermeasures. We will study a well-established rodent model of cardiac unloading that results in atrophy, heterotopic transplantation of the heart to the abdomen, as a test-bed for genes and gene products to protect against atrophy. The project will utilize measurements of cardiac genes which modulate growth, contractility, and calcium homeostasis. Cardiac muscle cell contractility and intracellular calcium will be assessed using fluorescence microscopy, and activity of key endogenous growth regulators will be monitored. We propose to address three Specific Aims: (1) Are ventricular myocyte intrinsic contractile function and intracellular calcium regulation impaired in cardiac atrophy, and are endogenous growth-regulators affected, such as the angiotensin converting enzyme (ACE)-angiotensin pathway, which augments growth and contractility, and nitric oxide formation, which inhibits growth and contractility? (2) Do hormonal countermeasures with direct trophic effects on cardiac cell growth (growth hormone) effectively blunt atrophy of the unloaded heart in vivo, or block the functional impairments? (3) Do genetic countermeasures that augment cardiac protein synthesis protect myocardium from cardiac atrophy? 


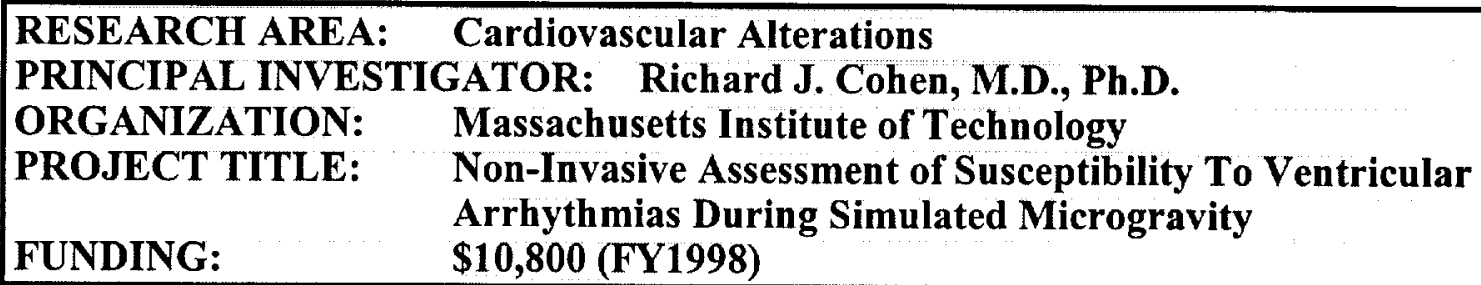

\section{PROJECT SUMMARY}

The Cardiovascular Alterations Team is currently conducting studies to determine what alterations in hemodynamic regulation result from ten days of simulated microgravity exposure in normal human subjects. We propose here to make additional measurements on these same study subjects in order to determine whether there is an increase in susceptibility to ventricular arrhythmias resulting from simulated microgravity exposure. We wish to emphasize the fact that all measurements described in this proposal can be made with instruments already being used in our ongoing studies at no additional expense and very little additional effort by the investigators and study subjects. The only budget item is for fifty percent support for a graduate research assistant who will analyze the data that will be generated by this effort.

Numerous anecdotal and documented reports from the past 30 years suggest that the incidence of ventricular arrhythmias among astronauts is increased during space flight. For example, documented runs of ventricular tachycardia have been recorded from crew members of Skylab and Mir [Charles JB, Bungo MW, and Fortner GW, 1994, Yelle, in press], there was much attention given by the lay press to Mir Commander Vasily Tsibliyev's complaints of heart rhythm irregularities in July of 1997, and cardiovascular mechanisms are suspected to be causal in the recent deaths of two experimental primates shortly after return from space [Richard Grindeland, Bion 11 Project Scientist, personal communication]. In 1986, a Mir cosmonaut, Alexander Laveikin, was brought home and replaced with an alternate cosmonaut as a result of cardiac dysrhythmias that began during extravehicular activity [Charles, 1998]. Furthermore, at a joint NASA/NSBRI workshop held in January 1998, cardiac arrhythmias were identified as the highest priority cardiovascular risk to a human Mars mission [Workshop to Develop Critical Path Roadmap, 1998]. Despite the evidence for the risk of a potentially lethal arrhythmia resulting from microgravity exposure, the effects of space flight and the associated physiologic stresses on cardiac conduction processes are not known, and an increase in cardiac susceptibility to arrhythmias has never been quantified.

In this project, we will determine whether simulated space flight increases the risk of developing life-threatening heart rhythm disturbances such as sustained ventricular tachycardia (defined as ventricular tachycardia lasting at least 30 seconds or resulting in hemodynamic collapse) and ventricular fibrillation. We will obtain measures of cardiac susceptibility to ventricular arrhythmias in subjects exposed to simulated space flight in the Human Studies Core protocol being conducted by the Cardiovascular Alterations Team, which involves ten days of bed rest. In particular, we will apply a powerful new non-invasive technology, developed in Professor Cohen's laboratory at MIT, for the quantitative assessment of the risk of life-threatening ventricular arrhythmias. This technology involves the measurement of microvolt levels of $T$ wave alternans during exercise stress. In addition, we will obtain other non-invasive markers of susceptibility to ventricular arrhythmias based on signal-averaged electrocardiography (SAECG), QT dispersion, and 24 hour Holter monitoring (to detect non-sustained ventricular tachycardia and to assess heart rate variability). We have also developed protocols to obtain these same measures on a monthly basis for up to four months in subjects in the Bone Demineralization/Calcium Metabo- 
lism Team's long term bed-rest study. These protocols were submitted as an NSBRI Synergy Proposal in February 1998.

The information obtained in this study will enable us to determine for the first time whether simulated space flight has a systematic and measurable effect on susceptibility to life threatening ventricular arrhythmias. The methodologies employed, such as $\mathrm{T}$ wave alternans analysis, are very sensitive, and do not require the presence of visually apparent arrhythmias to quantify an increased susceptibility to ventricular arrhythmias. Merely the presence of subtle alterations in $T$ wave morphology on the electrocardiogram indicates an increased susceptibility to such arrhythmias. Therefore, we believe it will be possible to quantify an increase in susceptibility to arrhythmias if it is present, even in a small population of healthy volunteers. In the event that simulated space flight increases such susceptibility, we will be better able to hypothesize potential countermeasures, such as specific anti-arrhythmic agents and electrolyte therapy. In the future, we may employ the same non-invasive measurement techniques to evaluate the effectiveness of these countermeasures. 


\section{NSBRI RESEARCH PROGRAM \\ HUMAN PERFORMANCE}

\begin{tabular}{|c|c|c|}
\hline Team Leader: & \multicolumn{2}{|c|}{ Czeisler, C. A. } \\
\hline Czeisler, C. A. & $\mathbf{P I}$ & Harvard \\
\hline Jewett, M. E. & CO-I & Harvard \\
\hline Khalsa, S. B. & CO-I & Harvard \\
\hline Kronauer, R. E. & $\mathrm{CO}-\mathrm{I}$ & Harvard \\
\hline Ronda, J. M. & $\mathrm{CO}-\mathrm{I}$ & Harvard \\
\hline Wright, K. P. & $\mathrm{CO}-\mathrm{I}$ & Harvard \\
\hline
\end{tabular}

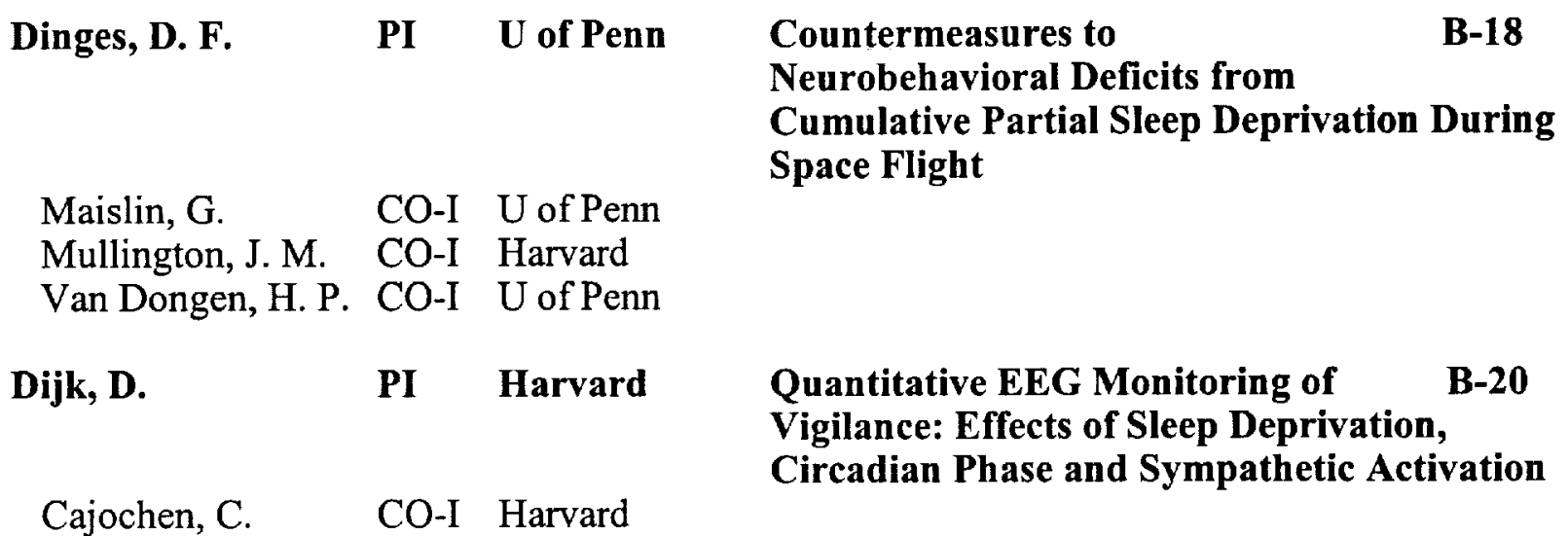

Circadian Entrainment, Sleep-

Brown, E. $\quad$ PI Harvard

On-Line Analysis of Physiologic and

B-21 Neurobehavioral Variables During Long-Duration Space Missions

Jewett, M. E. CO-I Harvard

Kronauer, R. E. CO-I Harvard

Luithardt, H. H. CO-I Harvard

Young, L. R. PI MIT

Natapoff, A. CO-I MIT

Szolovits, P. CO-I MIT

PI-in-a-Box

B-23 


\section{RESEARCH AREA: Human Performance Factors, Sleep and Chronobiology \\ PRINCIPAL INVESTIGATOR: Charles A. Czeisler, Ph.D., M.D. ORGANIZATION: Harvard Medical School and Brigham and Women's Hospital \\ PROJECT TITLE: Circadian Entrainment, Sleep-Wake Regulation and Neurobehavioral Performance during Extended Duration Space Flight \\ FUNDING: $\quad \$ 390,600$ (FY1998)}

\section{PROJECT SUMMARY}

Sustaining high levels of performance throughout extended duration space missions requires: 1) circadian entrainment of the intrinsic longer-than-24-hour period of the human circadian pacemaker to the 24-hour day; 2) maintenance of an appropriate phase relation of the human circadian pacemaker to the 24-h sleep-wake schedule. In space, astronauts are often exposed to light-dark cycles that are characterized by either an abnormal period, i.e., 1.5 hours during Earth orbit, or by a reduced intensity, i.e., between $20-50$ lux in the angle of gaze, when the space craft is illuminated artificially and under power constraints. Preliminary data suggest that such lightdark cycles are inadequate to maintain the appropriate phase-relation between the 24-h sleepwake cycle and the circadian system and will typically result in misalignment of circadian phase.

Such circadian phase misalignment can result in sleep disturbances, reduced attention, gastrointestinal disorders and impaired daytime alertness. Our preliminary data suggest that exposures to bright light episodes of very short duration are effective in resetting the human circadian pacemaker.

Based on these preliminary results, we propose four testable hypotheses, the evaluation of which will be critical for the development of effective countermeasures to prevent circadian misalignment: 1) that synchronization of the human circadian pacemaker will be disturbed in men and women by the reduction in LD cycle strength during space flight; 2) that this disturbed circadian synchronization will result in the secretion of the sleep-promoting hormone melatonin during the waking day, disturbed sleep, reduced growth hormone secretion, and impaired performance and daytime alertness; 3 ) that four brief (12 minute) daily exposures to mid-day bright light (10,000 lux) will reestablish normal entrained circadian phase, resulting in improved sleep consolidation, normalized sleep structure and endogenous growth hormone secretion and enhanced daytime performance; and 4) that the same intermittent bright light exposures in the late evening will on average worsen circadian phase misalignment, causing an exacerbation of the sleep disruption, further reduction in growth hormone secretion and greater impairment of daytime performance.

To test hypotheses 1 and 2, a long-term (48-day) clinical trial is proposed for Year 1 utilizing methodologies that allow direct measurement of endogenous circadian phase and amplitude before, during and after extended duration exposure to an environment with a reduction in the strength of external synchronizing cues [i.e., low (50 lux) daytime light intensities]. Hypotheses 3 and 4 will then be tested during Years 2 and 3 by evaluating the efficacy of properly timed exposure to intermittent bright light as a countermeasure in a randomized, long-term clinical trial. Subjects will be randomly assigned to receive four brief (12-minute) daily exposures to bright light at either mid-day (treatment condition) or in the late evening (active "placebo" condition) to evaluate intermittent mid-day bright light exposure as a countermeasure to maintain appropriate circadian phase during entrainment.

This work has important implications for the treatment of circadian rhythm sleep disorders, such 
as delayed sleep phase syndrome and shift-work dyssomnia, which are anticipated to have a high incidence and prevalence during extended duration space flight. Careful analysis of the efficacy of brief, intermittent bright light episodes in the treatment of these conditions has important ramifications for the practical application of bright light treatment during space flight, since repetitive uninterrupted exposure to bright light for many hours each day would not be feasible due to the operational demands of space missions. The results of the proposed research could have a profound effect on the health, productivity and safety of astronauts during extended missions, such as those planned for the International Space Station. 


\author{
RESEARCH AREA: Human Performance Factors, Sleep and Chronobiology \\ PRINCIPAL INVESTIGATOR: David F. Dinges, Ph.D. \\ ORGANIZATION: University of Pennsylvania \\ PROJECT TITLE: Countermeasures to Neurobehavioral Deficits from Cumulative \\ Partial Sleep Deprivation During Space Flight \\ FUNDING: \\ $\$ 297,700$ (FY1998)
}

\title{
PROJECT SUMMARY
}

The performance capability of astronauts during extended duration space missions depends heavily on achieving recovery through adequate sleep. Even with appropriate circadian alignment, sleep loss will erode fundamental elements of human neurobehavioral performance capability including vigilance, cognitive speed and accuracy, working memory, reaction time, and physiological alertness, leading to diminished executive functions and loss of situational awareness. Chronic sleep restriction has been a common experience during manned space flight, occurring in response to endogenous disturbances of sleep by microgravity and related factors (motion sickness, stress, circadian rhythms), environmental disruptions of sleep (noise, temperature, light), and curtailment of sleep due to the extended work demands that accompany space flight sustained operations. However, reductions in total sleep per $24 \mathrm{hr}$ can lead to elevated homeostatic pressure for sleep and compromise astronaut performance. Preliminary data indicate that a "sleep debt" can lead to cumulative waking neurobehavioral deficits in the form of vigilance errors, slowed thought processes, and fatigue. These experiments also reveal that such deficits occur reliably when sleep is limited to $4-6 \mathrm{hr}$ per day, which is a range commonly experienced by astronauts. To counter cumulative waking deficits from sleep restriction, research suggests that either the sleep drive must be met through increased duration of the major (anchor) sleep period, and/or through the strategic use of a single pre-planned (preemptive) nap, which also segments one long waking period into two shorter durations. However, there is a critical deficiency in knowledge of the effects of varying combinations of anchor sleep and nap durations that will yield the most efficient return of performance per unit time invested in sleep. The primary aim of this project is to meet this critical deficiency through utilization of a response surface experimental paradigm, testing in a dose-response manner varying combinations of anchor sleep and nap sleep durations for the purpose of establishing how to most effectively limit the cumulative effects of chronic sleep restriction in space flight. An algorithm involving a twostage regression analysis will be used to test the hypothesis that the addition of a relatively brief preemptive nap to restricted sleep each day will markedly attenuate the slope (growth) of the cumulative performance deficits developing across days. This approach will also be used to test the hypothesis that the addition of a nap to anchor sleeps will yield the optimal sleep-related secretion of growth hormone, which may be a natural countermeasure for limiting the effects of microgravity on muscle, bone, and cardiovascular systems. To apply this approach, healthy men and women will undergo a 14-day ground-based laboratory protocol involving random assignment to one of 17 cells, each involving the same sleep ration for 10 consecutive days. The sleep-ration assignments will involve 4 anchor sleep durations (4.2, 5.2, 6.2, $8.2 \mathrm{hr}$ ) and 6 nap sleep durations $(0.4,0.8,1.2,1.6,2.0,2.4 \mathrm{hr})$ crossed to yield a total of 4 anchor-sleep-only conditions, and 14 anchor + nap sleep conditions, and spanning a dynamic range of cumulative sleep debts (i.e., up to $40 \mathrm{hr}$ in a 10-day period). The results of this experiment will be used in development of a mathematical model of the effects of cumulative sleep loss (across days) relative to circadian dynamics (within days), in collaboration with investigators in Project 1 . In addition, the data will be used to prospectively test the hypothesis that a probed performance algorithm, to be derived retrospectively from a database of previously sleep-deprived subjects, can be used to prospectively predict individual vulnerability to sleep loss, thereby permitting 
more precise utilization of countermeasures for prevention of performance-impairing sleep loss during extended manned space flight. The project affords a high return of information regarding the duration and timing of sleep that most effectively promotes optimal waking performance and healthy functioning during space flight. 


\section{RESEARCH AREA: Human Performance Factors, Sleep and Chronobiology PRINCIPAL INVESTIGATOR: Derk-Jan Dijk, Ph.D. ORGANIZATION: Harvard Medical School and Brigham and Women's Hospital PROJECT TITLE: Quantitative EEG Monitoring of Vigilance: Effects of Sleep Deprivation, Circadian Phase and Sympathetic Activation FUNDING: $\$ 137,700$ (FY1998)}

\section{PROJECT SUMMARY}

Shuttle astronauts typically lose 2 hours of sleep per day while in orbit. This sleep loss is related to recurrent sleep cycle shifting due to mission-dependent orbital mechanics and mission duration requirements, the operational demands of space flight, noise and space motion sickness. Such cumulative sleep loss is known to produce predictable changes in sleep structure and the spectral composition of the EEG during sleep, daytime sleepiness, reduced attention, negative mood, slower reaction times, gastrointestinal disorders and impaired daytime alertness. The need to develop effective but safe countermeasures to allow crew members to obtain an adequate amount of sleep has been recognized and such countermeasures are being investigated. However, it is necessary to develop methods which allow effective and attainable in-flight monitoring of vigilance to evaluate the effectiveness of these countermeasures and to detect and predict online critical decrements in alertness/performance. During the past decade we and others have demonstrated that the spectral composition of the EEG during nonREM sleep accurately reflects the status of the sleep homeostat, i.e. there is a quantitative relationship between EEG power density and sleep loss even within the physiologic range of 1 to 2 hours of sleep loss. There is growing evidence to indicate that the status of the sleep homeostat and the effects of sleep loss and decrements in neurobehavioral function are also reflected in the spectral composition of the EEG. Furthermore, our preliminary data indicate that these changes in the EEG during wakefulness are more pronounced when subjects are in a supine posture. Since a supine posture mimics some of the physiologic effects of microgravity, such as changes in sympathetic activation, these preliminary data suggest that in microgravity EEG changes similar to those observed during sleep deprivation while in a supine posture may occur. Therefore, we propose to evaluate the following hypotheses: (1) that during a $40 \mathrm{~h}$ period of wakefulness (i.e., one night of total sleep deprivation) neurobehavioral function deteriorates and EEG power density in the theta frequencies increases especially in frontal areas of the brain; (2) that the sleep deprivation induced deterioration of neurobehavioral function and changes in the spectral composition of the EEG are more pronounced when subjects are in a supine position; and (3) that based on quantitative on-line topographical analyses of EEG during wakefulness an EEG parameter can be derived/constructed which accurately predicts changes in neurobehavioral function.

If shown to be accurate this EEG based online monitoring of alertness/performance would serve as a practical and attainable tool to predict and prevent critical decrements in performance and alertness. It would complement investigations of the effectiveness of countermeasures based on neurobehavioral function. Understanding the relationship between EEG and neurobehavioral function could thus have a profound effect on the health, productivity and safety of astronauts during space missions. The proposed research is relevant for the round-the-clock work schedules (day, evening and night work) on the International Space Station, the altered sleep/wake schedule on a Mars surface station, or any other situation where the work-rest schedule is shifted and sleep loss is incurred. It also has relevance for ground personnel monitoring orbiting crewmembers who must do so working round-the-clock schedules. 


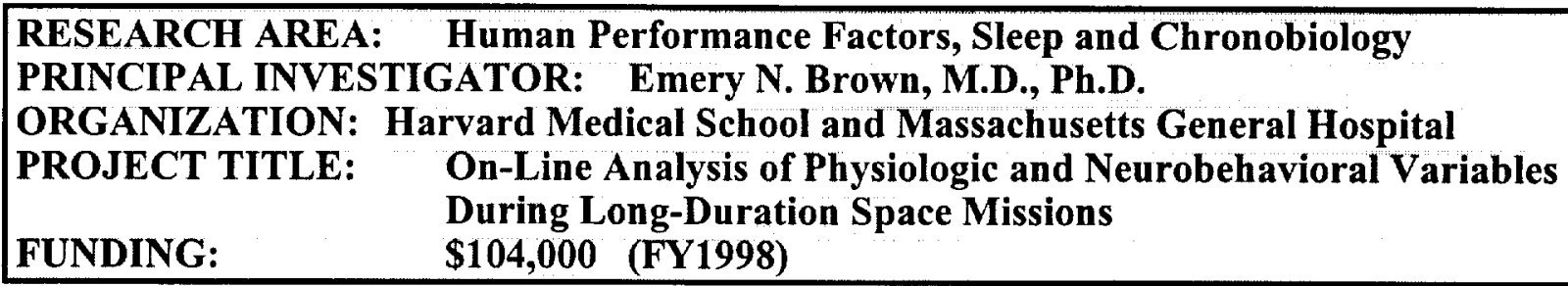

\section{PROJECT SUMMARY}

The goal of this project is to develop reliable statistical algorithms for on-line analysis of physiologic and neurobehavioral variables monitored during long-duration space missions. Maintenance of physiologic and neurobehavioral homeostasis during long-duration space missions is crucial for ensuring optimal crew performance. If countermeasures are not applied, alterations in homeostasis will occur in nearly all physiologic systems. During such missions data from most of the systems will be either continually and/or continuously monitored. Therefore, if these data can be analyzed as they are acquired and the status of these systems can be continually assessed, then once alterations are detected, appropriate countermeasures can be applied to correct them.

One of the most important physiologic systems in which to maintain homeostasis during longduration missions is the circadian system. Alterations in the circadian system will occur due to loss of contact with the normal geophysical light-dark cycles. Assessing the status of the circadian system is an especially challenging task because this normally requires special protocols such as the constant routine, free-run and forced desynchrony. Under these protocols the status of the circadian oscillator is assessed by statistical analyses of phase, amplitude and period of circadian marker rhythms such as core-temperature, cortisol, melatonin, mental alertness and actographic data. The use of these protocols on long-duration space missions is not possible since they would disrupt crew work schedules.

To detect and treat alterations in circadian physiology during long-duration space missions requires development of: 1) a ground-based protocol to assess the status of the circadian system under the light-dark environment in which crews in space will typically work; and 2) appropriate statistical methods to make this assessment. The protocol in Project 1, Circadian Entrainment, Sleep-Wake Regulation and Neurobehavioral will study human volunteers under the simulated light-dark environment of long-duration space missions. Therefore, we propose to develop statistical models to characterize in near real time circadian and neurobehavioral physiology under these conditions.

The specific aims of this project are to test the hypotheses that: 1) Dynamic statistical methods based on the Kronauer model of the human circadian system can be developed to estimate circadian phase, period, amplitude from core-temperature data collected under simulated lightdark conditions of long-duration space missions. 2) Analytic formulae and numerical algorithms can be developed to compute the error in the estimates of circadian phase, period and amplitude determined from the data in Specific Aim 1. 3) Statistical models can detect reliably in near realtime (daily) significant alternations in the circadian physiology of individual subjects by analyzing the circadian and neurobehavioral data collected in Project 1.4) Criteria can be developed using the Kronauer model and the recently developed Jewett model of cognitive performance and subjective alertness to define altered circadian and neurobehavioral physiology and to set conditions for immediate administration of countermeasures. 
Our framework will help ensure circadian and neurobehavioral homeostasis during long-duration missions and will define paradigm for monitoring and maintaining homeostasis of other physiologic systems under the same conditions. 


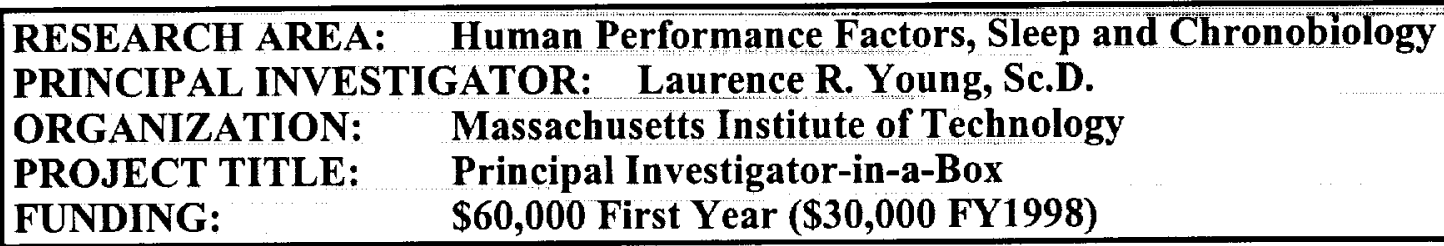

\section{PROJECT SUMMARY}

This project will investigate the ability of a real-time expert system to improve performance and reduce the time needed to diagnose errors and troubleshoot a realistic space life science experiment that monitors sleep. The experiment will test the efficacy of "Principal Investigator in a Box", or [PI], as a human factors tool for assisting relatively untrained "astronaut surrogates" to detect and correct realistic experiment artifacts. It will be the first evaluation of such a decision aid under controlled conditions, and should help to determine the applicability of expert systems in future space flight research. Matched groups of subjects, receiving identical training on sleep monitoring will be tested. Their time to detect and identify randomly introduced artifacts and to complete a normal sleep monitoring calibration will be measured with and without [PI]. Half of the subjects will receive [PI] assistance in their first, and half in their second exposure to the tests. The expert system rules build on the existing [PI] strategies for troubleshooting and error detection developed for the Neurolab Sleep experiment. 


\section{NSBRI RESEARCH PROGRAM \\ IMMUNOLOGY, INFECTION AND HEMATOLOGY}

\begin{tabular}{|c|c|c|c|c|}
\hline Team Leader: & Shear & $\mathrm{er}, \mathbf{W}$ & Baylor & \\
\hline $\begin{array}{l}\text { Shearer, W. T. } \\
\text { Dinges, D. F. } \\
\text { Lugg, D. J. } \\
\text { Mullington, J. M. } \\
\text { Ochs, H. D. } \\
\text { Pierson, D. L. } \\
\text { Reuben, J. M. } \\
\text { Rosenblatt, H. M. } \\
\text { Sams, C. } \\
\text { Smith, C. W. } \\
\text { Smith, E. O. } \\
\text { Smolen, J. E. }\end{array}$ & $\begin{array}{l}\text { PI } \\
\text { CO-I } \\
\text { CO-I } \\
\text { CO-I } \\
\text { CO-I } \\
\text { CO-I } \\
\text { CO-I } \\
\text { CO-I } \\
\text { CO-I } \\
\text { CO-I } \\
\text { CO-I } \\
\text { CO-I }\end{array}$ & $\begin{array}{l}\text { Baylor } \\
\text { U of Penn } \\
\text { Australia } \\
\text { Harvard } \\
\text { U of Washington } \\
\text { NASA JSC } \\
\text { M. D. Anderson } \\
\text { Baylor } \\
\text { NASA JSC } \\
\text { Baylor } \\
\text { Baylor } \\
\text { Baylor }\end{array}$ & $\begin{array}{l}\text { Space Flight Immunodeficiency } \\
\text { n }\end{array}$ & B-25 \\
\hline $\begin{array}{l}\text { Butel, J. S. } \\
\text { Conner, M. E. } \\
\text { Dinges, D. F. } \\
\text { Lednickey, J. A. } \\
\text { Ling, P. D. } \\
\text { Mullington, J. M. } \\
\text { Pierson, D. L. }\end{array}$ & $\begin{array}{l}\text { PI } \\
\text { CO-I } \\
\text { CO-I } \\
\text { CO-I } \\
\text { CO-I } \\
\text { CO-I } \\
\text { CO-I }\end{array}$ & $\begin{array}{l}\begin{array}{l}\text { Baylor } \\
\text { of Latent Viruse } \\
\text { Baylor }\end{array} \\
\text { U of Penn } \\
\text { Baylor } \\
\text { Baylor } \\
\text { Harvard } \\
\text { NASA JSC }\end{array}$ & $\begin{array}{l}\text { Immune Function and Reactivation } \\
\text { ses }\end{array}$ & B-27 \\
\hline $\begin{array}{l}\text { Fox, G. E. } \\
\text { Willson, R. C. }\end{array}$ & $\begin{array}{l}\text { PI } \\
\text { CO-I }\end{array}$ & $\begin{array}{l}\text { U of Houston } \\
\text { U of Houston }\end{array}$ & $\begin{array}{l}\text { DNA Probe Design for Preflight and } \\
\text { Inflight Microbial Monitoring }\end{array}$ & B-28 \\
\hline $\begin{array}{l}\text { Alfrey, C. P. } \\
\text { Byme, B. J. } \\
\text { Kessler, P. } \\
\text { Rice, L. } \\
\text { Trial, J. }\end{array}$ & $\begin{array}{l}\text { CO-I } \\
\text { CO-I } \\
\text { CO-I } \\
\text { CO-I }\end{array}$ & $\begin{array}{l}\text { Baylor } \\
\text { U of Florida } \\
\text { Hopkins/SOM } \\
\text { Baylor } \\
\text { Baylor }\end{array}$ & $\begin{array}{l}\text { Neocytolysis: Mechanisms and } \\
\text { Limitations }\end{array}$ & B-29 \\
\hline
\end{tabular}




\section{RESEARCH AREA: Immunology, Infection and Hematology \\ PRINCIPAL INVESTIGATOR: William T. Shearer, M.D., Ph.D. \\ ORGANIZATION: Baylor College of Medicine \\ PROJECT TITLE: $\quad$ Space Flight Immunodeficiency \\ FUNDING: \\ $\$ 330,000$ First Year (\$165,000 FY1998)}

\section{PROJECT SUMMARY}

The potential threat of immunosuppression and abnormal inflammatory responses in long-term space travel, leading to unusual predilection for opportunistic infections, malignancy, and death, is of major concern to the National Aeronautics and Space Administration (NASA) Program. This application has been devised to seek answers to questions of altered immunity in space travel raised by previous investigations spanning 30-plus years. We propose to do this with the help of knowledge gained by the discovery of the molecular basis of many primary and secondary immunodeficiency diseases and by application of molecular and genetic technology not previously available. Two areas of immunity that previously received little attention in space travel research will be emphasized: specific antibody responses and non-specific inflammation and adhesion. Both of these areas of research will not only add to the growing body of information on the potential effects of space travel on the immune system, but be able to delineate any functional alterations in systems important for antigen presentation, specific immune memory, and cell:cell and cell:endothelium interactions. By more precisely defining molecular dysfunction of components of the immune system, it is hoped that targeted methods of prevention of immune damage in space could be devised.

We plan to use ground-based human and animal models of space travel existence in making measurements of immune function. Human studies will include neo-antigen ( $\Phi$ X 174 bacteriophage) challenge of research subjects before and after subjection to eight-month Antartic isolation with the Australian National Antarctic Research Expedition (ANARE) with Dr. Desmond Lugg, Head of Polar Medicine, and six-month closed chamber isolation at the NASA/Johnson Space Center in Houston, in collaboration with Dr. Duane L. Pierson, Director of Microbiology and Dr. Clarence F. Sams, Director of Immunology. Assessments of specific antibody production (IgM or primary and IgG or secondary), IgM to IgG class switching, and antigen clearance will be useful in assessing antibody responses, antigen clearance, and T-cell helper effects. In addition, using 3-color flow cytometry with new monoclonal reagents, we will be able to detect differences in memory and naive T-cells and in activated and cytotoxic T-cells. These new measurements will more carefully define the subpopulations of T-cells that carry out specific effector function. Also, by studying lymphocyte responsiveness to recall antigens, we will be able to detect harmful effects upon cellular-initiated immunity. By assessment of Tlymphocyte helper type 1 (TH1) and TH2 cytokine secretion, we will be able to discem a loss of cytotoxic T-lymphocyte control and a shift to inflammatory cytokine control. By determination of the chemokine secretion patterns of human peripheral blood mononuclear cells, we will be able to discern the likelihood of viral infection in subjects, since several viruses compete with chemokines for chemokine receptor occupancy and cell entry. We will determine nonspecific natural killer (NK) cell activity in subjects under space flight conditions to assess potential damage to this primal protective cellular immune system. Lymphocyte apoptosis studies will enable us to recognize whether space flight conditions accelerate the natural process of planned cell death. Finally, with determination of proto-oncogene, oncogene, and transcription factors in subjects under space flight conditions, we will be able to assess the possibility of abnormal gene

regulation. Since Dr. Janet Butel will be studying reactivation of latent viruses in these same 
subjects in a research project of the Immunology, Infection, and Hematology Research Team, currently funded by the National Space Biomedical Research Institute (NSBRI), we will be able to correlate immune suppression with reactivation of latent virus infections.

Animal model studies by Dr. Wayne Smith will concern the stress and shear forces experienced by cellular membrane adhesion molecules. Specifically, the model (anti-orthostatic suspension) system is already being utilized by Dr. Janet Butel and Dr. Margaret Connor in the funded study on latent viruses and immune function. This is an established model that induces many physiological changes consistent with those observed in humans and animals returning from actual space flight. In an effort to establish whether basic inflammatory mechanisms are influenced by simulated space flight, we will elicit both non-specific, acute inflammation (ischemia/reperfusion), and relatively delayed, antigen-induced specific inflammation (late phase allergic and delayed type hypersensitivity responses) in anti-orthostatically suspended and control mice. Specifically, we will directly determine if anti-orthostatic suspension affects various stages of leukocyte recruitment, which is a key feature of inflammation. We anticipate that any changes in leukocyte recruitment induced by the experimental conditions will significantly contribute to the development and/or resolution of inflammation. In addition, since leukocyte recruitment is almost entirely dependent upon the expression of and interactions between adhesion molecules, we will systematically measure adhesion molecule expression on the surface of both endothelial cells and leukocytes. These assays will be conducted in anti-orthostatically suspended and control mice, under non-inflamed and inflamed conditions. It is likely that any observed changes in adhesion molecule expression will contribute significantly to leukocyte recruitment and the overall inflammatory process. Finally, we will systematically examine whether anti-orthostatic suspension affects the ability of inflammatory leukocytes (neutrophils and macrophages) to perform basic functions, including oxidative burst, phagocytic, bactericidal and candidacidal activity. Insight into these mechanisms in animals models of anti-orthostatic suspension will enhance our understanding of the potentially increased infectious susceptibility associated with long term space travel. The knowledge gained on the importance of phagocytic and endothelial cellular adhesion recognition pathways will be shared with the other NSBRI-funded research project on "Neocytolysis", headed by Dr. Clarence Alfrey, which concerns cellular adhesion pathways on erythrocytes as part of its goals.

By exploring perturbations of specific and non-specific immunity in space models in humans and animals, we expect to be able to make definitive statements concerning the types of cellular and molecular dysfunction likely to be experienced by space travelers on long journeys. With better definition of space-induced defects in immunity, it might be possible to avoid these changes with specific immune intervention. Since immune reconstitution has now become the primary goal of several human diseases, e.g. HIV-infected patients given highly active antiretroviral therapy, it may be possible to prescribe specific immune prophylaxis or early treatment of space flight immunodeficiency. Examples of such prophylaxis and treatment regimens would include potential drugs, such as pentoxiphylline, which inhibits the inflammatory cytokine profile and boosts the cytotoxic cytokine profile, and intravenous immunoglobulin, which contains a panoply of specific antibodies to infectious agents. 


\section{RESEARCH AREA: Immunology, Infection and Hematology PRINCIPAL INVESTIGATOR: Janet S. Butel, Ph.D. ORGANIZATION: Baylor College of Medicine PROJECT TITLE: Immune Function and Reactivation of Latent Viruses FUNDING:}

\section{PROJECT SUMMARY}

A major issue associated with long-duration space flight is whether infectious diseases will pose an unacceptable medical risk for crewmembers. This project is designed to address several questions raised in the Immunology/Infectious Disease Critical Path. We propose to assess the possibility that long-duration space flight conditions may have adverse effects on the immune system, that latent or persistent viruses may be reactivated and shed, and that reactivated viruses may be transmitted among crew members within a confined environment. We will address these questions by focusing on important viruses that establish latent or persistent infections in many people (herpesviruses, polyomaviruses) and are capable of causing disease, either in the initial host after reactivation or following transmission after reactivation to a susceptible person; on functions of the mucosal immune system, the first line of defense against infection by many viruses; and on gastroenteritis viruses (rotaviruses), both as mucosal immunogens and as agents able to cause significant disease.

Specifically, we will determine the frequency and magnitude of reactivation and shedding of latent herpesviruses and polyomaviruses under ground-based models of space flight conditions. First, we will develop and standardize sensitive, quantitative PCR-based assays and establish baseline patterns of reactivation and shedding using those assays in normal volunteers over time. We will then proceed to testing ground-based analogs in collaboration with Dr. D. Pierson, Lyndon B. Johnson Space Center. We believe this approach is necessary to be able to critically evaluate the significance of any virus reactivations detected under space-flight conditions. We will develop molecular genetic virus marker assays to track the transmission of reactivated viruses in ground-based analog tests. We will determine whether immune clearance and protection from mucosal virus infection (rotavirus) are altered in a ground-based mouse model (the anti-orthostatic suspension of mice). Finally, we will determine whether subunit mucosal vaccine countermeasures will induce immune response and protective efficacy in the groundbased mouse model.

We expect that reactivation of latent viruses will be observed and that measurable changes in the mucosal immune system will occur, but the extent of those virus reactivations and immune changes cannot be predicted with confidence. This project is designed to evaluate whether adverse events that occur are of such a nature and magnitude as to pose serious risks to the success of long-term flight missions. Results from these studies will reveal if countermeasures are indicated; we plan to test the use of a subunit mucosal vaccine as one potential countermeasure. 


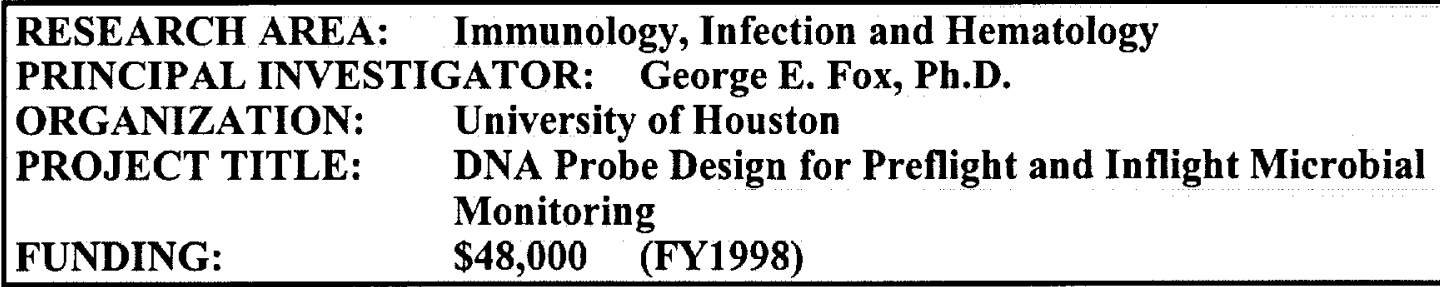

\section{PROJECT SUMMARY}

Crew health is a dominant issue in manned space flight. Microbiological concerns, in particular, have repeatedly emerged as determinants of flight readiness. For example, in at least one case, suspected contamination of the potable water supply nearly forced a launch delay. In another instance, a crewmember's urinary tract infection nearly led to early termination of the mission, in part due to the difficulty of accurately diagnosing the nature of the infection inflight. Microbial problems are an increasing concern with the trend towards longer-duration missions. It is essential to the success of such missions that systems that deliver acceptable quality of air and water during the anticipated lifetime of the spacecraft be available. As mission duration and resupply intervals increase, it will be necessary to rely on advanced life support systems which incorporate both biological and physical-chemical recycling methods for air and water as well as provide food for the crew. It therefore is necessary to develop real-time, robust, inflight monitoring procedures that are sensitive enough to detect less than $100 \mathrm{CFU}$ (colony forming units) of bacteria per 100 milliliters of water. It would be desirable if the monitoring system could be readily "reprogrammed" to identify specific pathogens if an inflight incident were to occur.

The long-term objective of the proposed work is to develop an automated hybridization system that can be used to monitor microbial populations and, when necessary, to identify pathogens in air and water samples during long-duration space missions. We will initially focus on the water system with the intention of developing a prototype general purpose water analysis system as soon as possible. Our specific aims in the current year are (1) to design a set of probes that can in principle be used to simultaneously monitor the levels of total bacteria, fecal coliforms, Escherichia coli, Pseudomonas aeruginosa, Enterococcus and Burkholderia; (2) to synthesize and test the probes needed to implement the prototype system using a microtiter-format fluorescence assay. The utility of each probe will be established individually and then verified when all the probes are used together and to test a ground-based implementation of the probe design using a prototype hybridization array, "DNA chip" system. 


\section{RESEARCH AREA: Immunology, Infection and Hematology PRINCIPAL INVESTIGATOR: Clarence P. Alfrey, M.D., Ph.D. ORGANIZATION: Baylor College of Medicine PROJECT TITLE: Neocytolysis: Mechanisms and Limitations FUNDING: $\$ 230,000$ (FY1998)}

\section{PROJECT SUMMARY}

For decades, it has been reproducibly demonstrated that astronauts journeying in space for even a few days return to Earth with a significant, symptomatic anemia. A previously unsuspected physiologic process that selectively hemolyzes the youngest circulating red blood cells under conditions of red cell excess, termed "neocytolysis" is responsible for this change. This process is operative not only in space flight, but it is generalizable to other physiologic adaptive and pathophysiologic maladaptive situations. For example, neocytolysis occurs when polycythemic individuals acclimated to high altitude are transported to sea level and can be prevented by erythropoietin (Epo) injections. Renal failure represents a pathophysiologic situation in which Epo is depressed, and neocytolysis may be related to the anemia of renal failure. The recognition of neocytolysis is leading to a fresh look at the basis underlying a number of hematologic disorders.

Changes in surface adhesion molecules may lead to an altered red cell-RE cell interaction that culminates in neocytolysis. The proposed study herein begins to address whether the changes in adhesion molecule expression are mainly in non-nucleated red cells or in the RE cell (both cells are not known to have Epo receptors) or somehow through endothelial cell changes. Analysis will include which adhesion molecules are affected and how, what levels of Epo deficiency are required for initiation, and how can these factors be manipulated. A more basic understanding of the process could be directly referable to a space travel countermeasure program. It would also be directly applicable to hematologic disorders, including the anemia of renal disease. This could be a sterling example of how insights gained from the space program can find unforeseen applications in bettering the management of human disease. Finally, more fundamental understanding of neocytolysis seems likely to have broad physiologic and pathophysiologic implications. In addition, a viral gene transfer system will be developed that may have broad application in many of the Institute studies.

Specific studies on the basic mechanisms underlying neocytolysis and the limitations of the process will include:

1. Establish (for the first time) a panel of assays to define normal red cell adhesion molecule expression

2. Quantitate differences between adhesion molecule expression in young red cells (neocytes) and older cells

3. Establish an in vivo model of neocytolysis in normal volunteers given Epo injections. Begin to define the minimum levels of polycythemia and of endogenous Epo suppression necessary to initiate the process. Establish whether there are degrees of neocytolysis, or whether it is an "all or none" phenomenon.

4. Analyze pre- and post- neocytolysis blood specimens in these Epo-treated volunteers employing the previously established adhesion molecule assays. (How does adhesion molecule expression differ after neocytolysis? Are these differences entirely explained by a loss of young cells?) 
5. Investigate these same issues (adhesion molecules, limits of initiation and prevention) through development of an animal model of neocytolysis, the exhypoxic polycythemic mouse.

6. Investigate the borders of neocytolysis in this mouse model by inducing different levels of constitutive Epo secretion through the use of viral vectors. 


\section{NSBRI RESEARCH PROGRAM \\ MUSCLE ALTERATIONS AND ATROPHY}

\begin{tabular}{|c|c|c|c|c|}
\hline $\begin{array}{l}\text { Team Leader: } \\
\text { CO-Leader }\end{array}$ & \multicolumn{2}{|c|}{$\begin{array}{l}\text { Schwartz, R. J. } \\
\text { Booth, F. W. }\end{array}$} & \multicolumn{2}{|l|}{$\begin{array}{l}\text { Baylor } \\
\text { UT HSC at Houston }\end{array}$} \\
\hline Schwartz, R. J. & PI & Baylor & $\begin{array}{l}\text { GH/IGF-I Transgene Expression on } \\
\text { Muscle Homeostasis }\end{array}$ & B-32 \\
\hline Booth, F. W. & $\mathrm{CO}-\mathrm{I}$ & \multicolumn{3}{|c|}{ UT HSC at Houston } \\
\hline Demayo, F. J. & $\mathrm{CO}-\mathrm{I}$ & \multicolumn{3}{|c|}{ Baylor } \\
\hline O'Malley, B. W. Jr. & $\mathrm{CO}-\mathrm{I}$ & \multicolumn{3}{|l|}{ Hopkins/SOM } \\
\hline Goldberg, A. L. & PI & Harvard & $\begin{array}{l}\text { Effect of Unloading on Protein Content } \\
\text { in Skeletal Muscle: Regulation of the } \\
\text { Ubiquitin-Proteasome System }\end{array}$ & B-33 \\
\hline Baldwin, K. M. & $\mathrm{CO}-\mathrm{I}$ & \multicolumn{3}{|l|}{ UC, Irvine } \\
\hline Epstein, H. F. & PI & Baylor & $\begin{array}{l}\text { Molecular Signaling in Muscle } \\
\text { Plasticity }\end{array}$ & B-34 \\
\hline Booth, F. W. & $\mathrm{CO}-\mathrm{I}$ & \multicolumn{3}{|c|}{ UT HSC at Houston } \\
\hline Schwartz, R. J. & $\mathrm{CO}-\mathrm{I}$ & \multicolumn{3}{|c|}{ Baylor } \\
\hline Hamilton, S. L. & PI & Baylor & $\begin{array}{l}\text { Activity Dependent Signal } \\
\text { Transduction in Skeletal Muscle }\end{array}$ & B-35 \\
\hline Armstrong, R. B. & $\mathrm{CO}-\mathrm{I}$ & \multirow{2}{*}{\multicolumn{3}{|c|}{$\begin{array}{l}\text { Texas A\&M } \\
\text { Baylor }\end{array}$}} \\
\hline Reid, M. B. & $\mathrm{CO}-\mathrm{I}$ & & & \\
\hline Rosenthal, N. A. & PI & Harvard & $\begin{array}{l}\text { Molecular Mechanisms Regulating } \\
\text { Muscle Fiber Composition Under } \\
\text { Microgravity }\end{array}$ & B-36 \\
\hline Baldwin, K. M. & $\mathrm{CO}-\mathrm{I}$ & \multicolumn{3}{|l|}{ UC, Irvine } \\
\hline Mosier, D. R. & PI & Baylor & $\begin{array}{l}\text { Motoneuron Influences on Muscle } \\
\text { Atrophy in Simulated Microgravity } \\
\text { Induced Muscle Atrophy }\end{array}$ & B-37 \\
\hline Appel, S. H. & $\mathrm{CO}-\mathrm{I}$ & \multirow{3}{*}{\multicolumn{3}{|c|}{$\begin{array}{l}\text { Baylor } \\
\text { UT HSC at Houston } \\
\text { Baylor }\end{array}$}} \\
\hline Booth, F. W. & $\mathrm{CO}-\mathrm{I}$ & & & \\
\hline Schwartz, R. J. & CO-I & & & \\
\hline
\end{tabular}




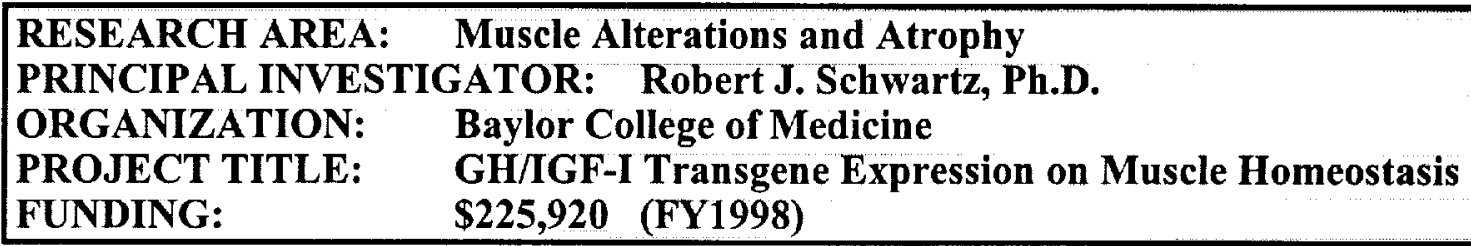

\section{PROJECT SUMMARY}

We propose to test the hypothesis that the GH/IGF-I axis through autocrine/paracrine mechanisms may provide long term muscle homeostasis under conditions of prolonged weightlessness. As a key alternative to hormone replacement therapy, ectopic production of hGH, growth hormone releasing hormone (GHRH), and IGF-I will be studied for its potential on muscle mass impact in transgenic mice under simulated microgravity. Expression of either hGH or IGF-I would provide a chronic source of a growth-promoting protein whose biosynthesis or secretion is shut down in space. Muscle expression of the IGF-I transgene has demonstrated a $20-30 \%$ increase in hindlimb muscle mass over control nontransgenic litter mates. These recent experiments, also establish the utility of hind-limb suspension in mice as a workable model to study atrophy in weight bearing muscles. Thus, transgenic mice will be used in hind-limb suspension models to determine the role of GH/IGF-I on maintenance of muscle mass and whether concentric exercises might act in synergy with hormone treatment. As a means to engineer and ensure long-term protein production that would be workable in humans, gene therapy technology will be used by to monitor muscle mass preservation during hind-limb suspension, after direct intramuscular injection of a genetically engineered muscle-specific vector expressing GHRH. Effects of this gene-based therapy will be assessed in both fast twitch (medial gastrocnemius) and slow twitch muscle (soleus). End-points include muscle size, ultrastructure, fiber type, and contractile function, in normal animals, hindlimb suspension, and reambulation. 


\begin{tabular}{|c|c|}
\hline \multicolumn{2}{|c|}{$\begin{array}{l}\text { RESEARCH AREA: Muscle Alterations and Atrophy } \\
\text { PRINCIPAL INVESTIGATOR: Alfred Goldberg. M.D. }\end{array}$} \\
\hline ORGANIZATION: & Harvard Medical School \\
\hline PROJECT TITLE: & $\begin{array}{l}\text { Effect of Unloading on Protein Content in Skeletal Muscle: } \\
\text { Regulation of the Ubiquitin-Proteasome System }\end{array}$ \\
\hline FUNDING: & $\$ 291,980$ (FY1998) \\
\hline
\end{tabular}

\section{PROJECT SUMMARY}

Previous studies clearly show that the slow (Type I) myosin heavy chain (MHC) and other contractile protein isoforms are down regulated in the antigravity muscles of mammals (rodents) in response to space flight and/or hindlimb unloading. However, relatively little is known concerning the regulation of this process at the subcellular/molecular level. The primary objective of this proposal is to use the rodent hindlimb suspension model, in both the presence and absence of a) resistance loading paradigms; and b)interventions altering the actions of hormones known to regulate muscle protein turnover such as glucocorticoids in order to examine the regulation of type I MHC expression at three distinct, but interrelated levels of investigation. These include: 1) determining protein synthesis rates for fast and slow $\mathrm{MHC}$ isoforms relative to that of total protein as well as determining if there are altered levels of known regulatory factors involved in protein translation; 2) ascertaining the intrinsic level of activity of the ubiquitinproteasome system (changes in conjugating enzyme activity including E1, E2, and E3; ubiquitin and ubiquitin-protein conjugate levels, and proteolytic activity of the proteasome complex), which has been demonstrated recently to be a primary pathway for degradation of proteins such as myosin and other myofibrillar proteins in cell free extracts of skeletal muscle; and 3) determining the transcriptional control of the type I MHC gene by measuring nuclear run-on capacity (as well as activity of a transfected type I promoter construct) coupled with assessing the relative expression of a battery of transcriptional factors (e.g., transcriptional enhancing factor-1, myogenin, myo-D, thyroid receptors, and other putative factors) that interact with cis-regulatory elements in the type I MHC promoter.

To achieve these objectives and to test the six working hypotheses proposed in the text of the proposal, a series of experiments will be performed using adult female rats with initially stable body and muscle mass, i.e., non growing muscles. In the first series of experiments (phase \#1), groups of animals will be studied after one, two, and four weeks of suspension in order to determine the rates of protein synthesis for MHC isoforms as well as the altered functional activity of the ubiquitin-proteasome system including its specificity for degrading the slow type I and fast type Iib native myosins in the context of the atrophy response. The experiments at the four-week time point will be performed in order to identify markers for altered transcriptional activity of the type I MHC gene. In the second series (phase \#2), experiments will be performed to block the interactive effects of glucocorticoids with its receptor complex in the cascade of events causing muscle atrophy. Whereas, subsequent experiments (phase \#3) will utilize a rodent heavy resistance training paradigm as a countermeasure for the atrophic response. Collectively, these experiments will more clearly define the role of several interactive processes in the control of muscle protein turnover along with associated transcriptional factors specifically involved in the control of slow MHC expression, which will be used as a marker system for regulation of muscle atrophy. Also, these experiments will further delineate the role of specific hormonal activity factors in either the induction of atrophy/and or the prevention of atrophy during states of unloading. 


\begin{tabular}{|ll}
\hline RESEARCH AREA: & Muscle Alterations and Atrophy \\
PRINCIPAL INVESTIGATOR: Henry F. Epstein, M.D. \\
ORGANIZATION: & Baylor College of Medicine \\
PROJECT TITLE: & Molecular Signaling in Muscle Plasticity \\
FUNDING: & $\$ 109,500$ (FY1998) \\
\hline
\end{tabular}

\section{PROJECT SUMMARY}

Extended space flight under microgravity conditions leads to significant atrophy of weightbearing muscles. Atrophy and hypertrophy are the extreme outcomes of the high degree of plasticity exhibited by skeletal muscle. Stimuli which control muscle plasticity include neuronal, hormonal, nutritional, and mechanical inputs. The mechanical stimulus for muscle is directly related to the work or exercise against a load performed. Little or no work is performed by weight-bearing muscles under microgravity conditions. A major hypothesis is that focal adhesion kinase (FAK) which is associated with integrin at the adherens junctions and costameres of all skeletal muscles is an integral part of the major mechanism for molecular signaling upon mechanical stimulation in all muscle fibers. Additionally, we propose that myotonic protein kinase (DMPK) and dystrophin (DYSTR) also participate in distinct mechanically-stimulated molecular signaling pathways that are most critical in type I and type II muscle fibers, respectively. To test these hypotheses, we will use the paradigms of hindlimb unloading and overloading in mice as models for microgravity conditions and a potential exercise countermeasure, respectively, in mice. We expect that FAK loss-of-function will impair hypertrophy and enhance atrophy in all skeletal muscle fibers whereas DYSTR and DMPK lossof-function will have similar but more selective effects on Type II and Type I fibers, respectively. Gene expression will be monitored by muscle-specific creatine kinase M promoterreporter construct activity and specific mRNA and protein accumulation in the soleus (type I primarily) and plantaris (type II primarily) muscles. With these paradigms and assays, the following Specific Project Aims will be tested in genetically altered mice: 1) identify the roles of DYSTR and its pathway; 2) evaluate the roles of the DMPK and its pathway; 3) characterize the roles of FAK and its pathway and 4) genetically analyze the mechanisms and interactions between the FAK, DYSTR, and DMPK-associated pathways in single and specific combinations of mutants. The identification of potential signaling mechanisms may permit future development of pharmacological countermeasures for amelioration and prevention of the microgravityinduced atrophy in extended space flight, and the analysis of both overloading and unloading paradigms may provide further support for development of exercise-based countermeasures. Understanding the basic mechanisms of molecular signaling in muscle plasticity may aid our understanding and treatment of skeletal muscle atrophy not only in space flight but in similar problems of the aging population, in prolonged bedrest, and in cachexia associated with chronic disease. 


\section{RESEARCH AREA: Muscle Alterations and Atrophy PRINCIPAL INVESTIGATOR: Susan L. Hamilton, Ph.D. ORGANIZATION: : Baylor College of Medicine PROJECT TITLE: FUNDING: Activity Dependent Signal Transduction in Skeletal Muscle $\$ 94,900$ (FY1998)}

\section{PROJECT SUMMARY}

Significant loss of skeletal muscle mass, especially in slow twitch muscle, occurs in astronauts exposed to microgravity for even relatively short periods of time. Additional damage to muscle occurs upon return to Earth's gravitational field. To develop effective countermeasures the molecular mechanisms that produce these changes need to be identified. We propose to identify the early signal transduction events by which removal of load from the weightbearing muscles alters signal transduction in the muscle ultimately leading to deconditioning and atrophy.

Our working hypothesis is that the transcription factor nuclear factor- $\mathrm{B}(\mathrm{NF}-\kappa \mathrm{B})$ acts as an index of muscle activity and regulates the complex adaptive response of skeletal muscle to chronic loading. We propose to evaluate the early signal transduction mechanisms involved in maintaining muscle phenotype. Preliminary data have shown that hind limb suspension, used as a model of microgravity, alters both $\mathrm{Ca}^{2+}$ levels and $\mathrm{NF}-\kappa \mathrm{B}$ signaling.. We postulate that exposure to microgravity decreases the $\mathrm{NF}-\mathrm{kB}$ signaling via a pathway that involves: 1) changes in intracellular $\mathrm{Ca}^{2+}, 2$ ) a multi-step process involving enzymes such as calpain, protein kinase $\mathrm{C}$ (PKC), and calcineurin, and 3) changes in phosphorylation, ubiquitin conjugation, degradation by $26 \mathrm{~S}$ proteasomes of $\mathrm{I}-\mathrm{kB}$ and movement of NF- $\mathrm{KB}$ to the nucleus. NF- $\mathrm{kB}$ in the nucleus controls several different transcriptional events. We postulate that exposure to microgravity decreases signaling via this pathway, leading to muscle atrophy. We will evaluate the effects of hindlimb suspension on excitation-contraction coupling, the activity of several $\mathrm{Ca}^{2+}$ enzymes and $\mathrm{NF}-\mathrm{kB}$ signaling pathways. 


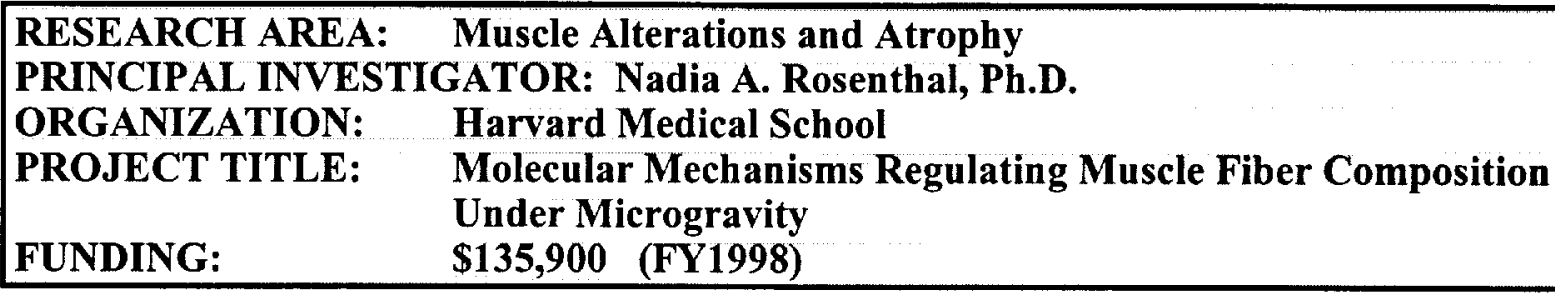

\section{PROJECT SUMMARY}

Molecular mechanisms regulating muscle fiber composition under microgravity. Drs. Rosenthal (Harvard), and Baldwin(UC, Irvine) specifically proposed the hypothesis that impairment of load bearing effect the distribution of $\mathrm{E}$ protein belonging to the basic helix-loop-helix (bHLH) family of transcription factors and that these transfactors control muscle fiber type transitions. Molecular mechanisms underlying the dramatic changes in muscle fiber composition produced by weightlessness will be determined (Rosenthal). Several of the E proteins, belonging to the bHLH family of transcription factors are differentially distributed among mammalian fiber types. Moreover, mice carrying homozygous null mutations in several of the $\mathrm{E}$ proteins exhibit severe postnatal muscle atrophy in each case due to a decrement in a different subset of fiber types. These preliminary data underscore the potential importance of $E$ proteins in regulating fiberspecific patterns of muscle gene expression, and suggest that they may comprise upstream targets for the effects of weightlessness. E protein composition and distribution will be characterized in normal versus unweighted mouse muscles. Fiber specific expression of a potential E protein target, and the Skeletal a-actin promoter driven transgene, will be evaluated during hind-limb unweighting. The SkA b-galactosidase gene in transgenic mice is severely reduced under conditions of weightlessness. The effects of overexpression in vivo of E2-2 and HEB, E proteins in transgenic mice will be used to evaluate their biological role in controlling fast type IIb and IIx fibers respectively, on the fast fiber atrophy observed in unweighted and space flown mice. 


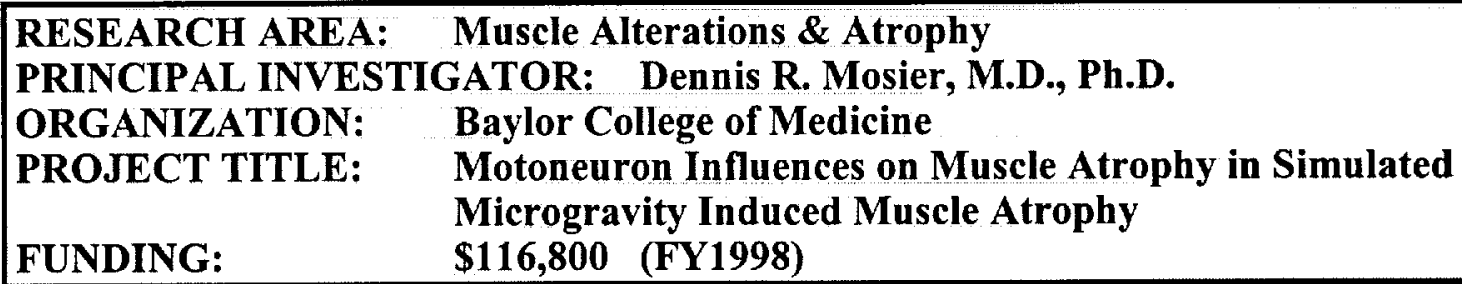

\section{PROJECT SUMMARY}

Numerous alterations in motor unit structure and function occur with exposure to microgravity during space flight, many of which could result in impairment of motor performance. While much work is ongoing to ascertain the nature of biochemical, structural, and physiological changes originating in muscle fibers, comparatively little attention has been paid to the striking changes occurring in motoneuron terminals at the skeletal neuromuscular junction during exposure to microgravity. It is highly unlikely that these changes, whether primary or secondary to changes in the muscle fibers innervated, are without consequences for the regulation of motor unit function. Accordingly, the central hypothesis of this study is that alterations in motoneuron structure and function occur during the process of microgravity-induced muscle atrophy, and that these alterations may significantly influence muscle dysfunction, adaptation, and recovery from atrophy induced by microgravity. These changes may be manifested as early structural and functional alterations in the distal motoneuron terminal, in addition to alterations in motoneuron activity produced by changes in supraspinal drive and in stretch reflexes during microgravity. Initiation of these alterations in motoneuron terminals may be influenced by retrograde signals from muscle which induce, as an early event, alterations in intracellular calcium and transmitter release. A combination of electrophysiologic assays of presynaptic transmitter release, coupled with light and electron microscopic assays of nerve terminal sprouting and junctional remodeling and with electron microscopic assays of synaptic vesicles and intraterminal calcium, is proposed to define quantitatively the nature, extent, and possible significance of changes in motoneuron terminals occurring in a mouse model of unloading-induced muscle atrophy recently developed to simulate aspects of muscle dysfunction in microgravity. This laboratory, in collaboration with the laboratory of Dr. Stanley Appel and other members of the Department of Neurology at Baylor College of Medicine, offers the ability to comprehensively test electrophysiological, anatomical, and biochemical parameters of motoneuron function, particularly with respect to the neuromuscular junction, which will be critical to further our understanding of motoneuron influences on muscle atrophy. This approach will be further extended to determine motoneuronal responses to treatments designed to ameliorate muscle atrophy induced by unloading, and to test the hypothesis that an activity-dependent growth factor released locally by skeletal muscle may produce alterations in presynaptic terminals of innervating motoneurons. The data produced by this study, in addition to increasing our knowledge of mechanisms influencing motor unit dysfunction occurring during space travel, will result in a model with which to test neural influences on other aspects of muscle dysfunction, and are expected to be of interest to a number of different scientific and clinical areas of investigation. 


\section{NSBRI RESEARCH PROGRAM \\ NEUROVESTIBULAR ADAPTATION}

\begin{tabular}{|c|c|c|c|c|}
\hline Team Leader: & \multicolumn{2}{|c|}{ Oman, C. M. } & MIT & \multirow[b]{2}{*}{ B-39 } \\
\hline Shelhamer, M. J. & PI & Hopkins/SOM & $\begin{array}{l}\text { Context-Specific Adaptation Of } \\
\text { Gravity-Dependent Vestibular Reflex } \\
\text { Responses }\end{array}$ & \\
\hline Goldberg, J. & CO-I & Baylor & & \\
\hline Minor, L. B. & CO-I & Hopkins/SOM & & \\
\hline Paloski, W. H. & CO-I & NASA JSC & & \\
\hline Young, L. R. & CO-I & MIT & & \\
\hline Zee, D. S. & CO-I & Hopkins/SOM & & \\
\hline Oman, C. M. & PI & MIT & $\begin{array}{l}\text { Visual Orientation in Unfamiliar } \\
\text { Gravito-Inertial Environments }\end{array}$ & B-40 \\
\hline Beall, A. C. & $\mathrm{CO}-\mathrm{I}$ & MIT & & \\
\hline Carpenter-Smith, $\mathrm{T}$. & $\mathrm{CO}-\mathrm{I}$ & Andersen Const & Ilting & \\
\hline Howard, I. P. & $\mathrm{CO}-\mathrm{I}$ & York University & & \\
\hline Shebilske, W. L. & CO-I & Texas A\&M & & \\
\hline Taube, J. S. & $\mathrm{CO}-\mathrm{I}$ & Dartmouth Coll & ege & \\
\hline Wall, C. C. & PI & Harvard & $\begin{array}{l}\text { Advanced Techniques for Assessment } \\
\text { of Postural and Locomotor Ataxia, } \\
\text { Spatial Orientation and Gaze Stability }\end{array}$ & B-42 \\
\hline Bloomberg, J. J. & $\mathrm{CO}-\mathrm{I}$ & NASA JSC & & \\
\hline Cohen, H. S. & CO-I & Baylor & & \\
\hline Krebs, D. E. & $\mathrm{CO}-\mathrm{I}$ & Harvard & & \\
\hline Oman, C. M. & $\mathrm{CO}-\mathrm{I}$ & MIT & & \\
\hline Raphan, $\mathrm{T}$. & $\mathrm{CO}-\mathrm{I}$ & Brooklyn Colle & & \\
\hline Young, L. R. & $\mathrm{CO}-\mathrm{I}$ & MIT & & \\
\hline
\end{tabular}




\section{RESEARCH AREA: Neurovestibular Adaptation PRINCIPAL INVESTIGATOR: Mark J. Shelhamer, Sc.D. ORGANIZATION: Johns Hopkins School of Medicine PROJECT TITLE: Context-Specific Adaptation of Gravity-Dependent Vestibular Reflex Responses \\ FUNDING:}

\section{PROJECT SUMMARY}

Eye movements are important for keeping the images of objects stationary on our retinas, since visual acuity can be significantly degraded with retinal slip of only a few degrees per second. Impairment of this ability can lead to disorientation and reduced performance in sensorimotor tasks such as piloting of spacecraft. Transitions between different gravitoinertial force environments as during different phases of space flight - provide an extreme test of the adaptive mechanisms. It is vitally important to determine the adaptive capabilities of crewmembers in such a circumstance, so that we can know to what extent the sensorimotor skills acquired in one gravity environment will transfer to others. Our work will begin to lay the foundation for understanding these capabilities, and for determining how we can aid the processes of adaptation and readaptation.

An integrated set of experiments is planned to address this issue. We use the general approach of adapting the vestibulo-ocular reflex (VOR) or the vestibulo-colic reflex (VCR) to a particular change in gain or phase in one condition of gravitoinertial force, and adapting to a different gain or phase (or asking for no change) in a second gravitoinertial force condition, and then seeing if the gravitoinertial force itself - the context cue - can recall the previously learned adapted responses. Previous evidence indicates that unless there is specific training to induce contextspecificity, reflex adaptation is sequential rather than simultaneous.

We will begin to investigate the behavioral properties, neurophysiological basis, and anatomical substrate of context-specific learning mechanisms using otolith (gravity) signals as the contextual cue for elaborating both the angular and the linear vestibulo-ocular reflex (AVOR and LVOR) and the VCR. (By linear VOR we mean the oculomotor response - horizontal, vertical, and torsional - to linear translation of the head and body; it is sometimes referred to as the translationalLVOR.) We will study the effect of context on adaptation of the phase and gain of both the AVOR and LVOR, on ocular counterrolling (OCR) in response to static head tilt, and on head/neck reflexes (VCR) in response to centered and off-axis (eccentric) rotation. Such research is particularly germane to potential problems of postural and oculomotor control upon exposure to different gravitational environments.

The knowledge gained from these studies will help us to design potential pre-adaptation strategies to assist flight crews in making transitions between different gravitoinertial force situations, and can provide design data for spacecraft facilities (artificial gravity, exercise centrifuge) by delineating the limits of human adaptive capabilities. 


\begin{tabular}{|ll|}
\hline RESEARCH AREA: & Neurovestibular Adaptation \\
PRINCIPAL INVESTIGATOR: Charles M. Oman Ph.D. \\
ORGANIZATION: & Massachusetts Institute of Technology \\
PROJECT TITLE: & Visual Orientation in Unfamiliar Gravito-Inertial Environments \\
FUNDING: & $\$ 324,700$ (FY1998) \\
\hline
\end{tabular}

\section{PROJECT SUMMARY}

The goal of this project is to better understand the process of spatial orientation and navigation in unfamiliar gravito-inertial environments. How do we estimate the location, direction, and tilt of our body fixed ("egocentric") reference frame with respect to the external ("exocentric") frame established by the environment? What cues do we use to keep track of this exocentric frame? Our intrinsic sense of location ("place") and direction is ultimately visually determined. On Earth, the gravitational stimulus to our otolith organs, and proprioceptors in skin, muscles and joints strongly influence our sense of "down". In space, the gravitational "down" reference is absent, so our sense of self-orientation becomes much more labile. Crewmembers "visually upright" in a familiar area of the spacecraft are rarely disoriented. However, when working in an unfamiliar "agravic" orientation, they sometimes misinterpret visual cues from surrounding objects, and experience striking "visual reorientation illusions" (VRIs), and misperceive their own orientation with respect to the environment, often because the walls, ceiling, and floors of the spacecraft have exchanged subjective identities. VRIs trigger attacks of space motion sickness. VRIs occur because of scene symmetries, and the subconscious assumption that the floor is beneath their feet. Fluid shift and gravireceptor bias probably also contribute, and make certain astronauts feel continuously inverted. Reports from MIR astronauts indicate that several weeks of weightlessness are required before orientation and navigation become natural, particularly when going between modules. Navigation in $0-G$ has not yet been studied. It appears crewmembers learn routes, but that even after several months, they do not develop 3D "survey" knowledge of the station. It is thought that there are large individual differences in the ability to remain oriented using visual cues, and that experience in mockups, parabolic flight, neutral buoyancy and virtual reality (VR) simulators helps. However, no techniques have been developed to quantify individual differences in orientation and navigation abilities, or the effectiveness of spacecraft-specific or generic preflight visual orientation training. Our understanding of the underlying physiology - for example how orientation and navigation information is neurally coded - is incomplete. We propose a set of collaborative experiments grouped under five specific aims, each the responsibility of a lead investigator:

1. To define how the strength of visually induced tilt and reorientation illusions in humans depends on head orientation with respect to gravity, and the axis of scene polarity. How do these illusions depend on the type of polarity of objects in the visual scene, and their foreground vs. background location? Do they remain while the subject moves over an air bearing surface, or change with foot pressure cues? (Dr. Howard).

2. To see whether the strength of tilt illusions and VRIs correlates with measures of visual field dependence and gravireceptor bias when subjects using a head mounted display view a compelling virtual visual environment. Do results correlate with the same subjects' postural reactions to visual scene motion in Project 3? (Dr. Oman)

3. To understand how human orientation and navigation depend on visual experience. Can virtual reality techniques be used to improve orientation and navigation in simulated agravic environments? Can and should subjects be trained to alternate between "exocentric" and 


\section{Appendix B}

"egocentric" visual orientation strategies? Does training influence response to measures of visual field dependence? Postural responses to scene movement in Project 3? (Dr. Oman)

4. To understand how cognitive and motor abilities as well as visual polarity information influence visually guided search and spatial memory in agravic environments. What cognitive or motor abilities are critical in virtual reality training of visual search and memory for spatial locations? Can added visual polarity cues and/or training within a space station node improve visual search and spatial memory? Do search and memory improvements within a node improve navigation between nodes? (Dr. Shebilske)

5. To develop an animal model for human visual orientation, to better understand some of the neural correlates of visual reorientation illusions, and to define how the plane of head direction cell response in the rat limbic system depends on visual, vestibular, gravireceptive, proprioceptive and motoric cues both in $1-\mathrm{G}$ and in parabolic flight. (Dr. Taube) 


\begin{tabular}{|ll|}
\hline RESEARCH AREA: & Neurovestibular Adaptation \\
PRINCIPAL INVESTIGATOR: Conrad Wall, III, Ph.D. \\
ORGANIZATION: & Harvard Medical School \\
PROJECT TITLE: & Advanced Techniques for Assessment of Postural and Locomotor \\
& $\begin{array}{l}\text { Ataxia, Spatial Orientation, and Gaze Stability } \\
\text { FUNDING: }\end{array}$ \\
\hline 350,800 (FY1998)
\end{tabular}

PROJECT SUMMARY

Major problems of space flight, in addition to adapting to microgravity, include postflight difficulties with standing, walking, turning corners, and other activities that require stable upright posture and gaze stability. These difficulties inhibit astronauts' ability to stand up, bail out or escape from their vehicle during emergencies. The overall goal of this project is to develop quantitative, parametric approaches for assessing gaze stability, and spatial orientation during normal gait and when gait is perturbed. Compared to assessments of the vestibuo-ocular reflex, analysis of vestibular effects on locomotor function is relatively less well developed and quantified. We plan to improve this situation by applying the methodology of nonlinear orbital stability to quantify responses in a single variable and by using multivariate statistical approaches to link together the responses across separate tests. In this way we will exploit the information available and increase the "resolving power" to discriminate between normal and pathological responses. Responses will be studied with, and without, interactive visual environments. Measures of stability and orientation will be compared and assessed with measures of dynamic visual acuity and with other vestibular function tests. The responses of normal human subjects and of subjects having well documented pathophysiologies will be characterized. When these studies are completed, we should have a clearer idea about normal and abnormal patterns of eye, head, and body movements during locomotion and their stability in a wide range of environments. We will then use this information to characterize and validate neurovestibular rehabitative approaches being developed in other projects. 


\section{NSBRI RESEARCH PROGRAM \\ RADIATION EFFECTS}

Team Leader: $\quad$ Dicello, J. F.

Hopkins/SOM

\begin{tabular}{|c|c|c|c|c|}
\hline Dicello, J. F. & PI & Hopkins/SOM & Radiation Effects: Core Project & B-44 \\
\hline Cucinotta, F. A. & CO-I & NASA JSC & & \\
\hline Gridley, D. S. & $\mathrm{CO}-\mathrm{I}$ & Loma Linda & & \\
\hline Howard, S. P. & CO-I & U of Wisconsin & & \\
\hline Huso, D. L. & $\mathrm{CO}-\mathrm{I}$ & Hopkins/SOM & & \\
\hline Novak, G. R. & CO-I & Hopkins/SOM & & \\
\hline Overbeek, P. A. & CO-I & Baylor & & \\
\hline Piantadosi, S. & CO-I & Hopkins/SOM & & \\
\hline Strandberg, J. D. & CO-I & Hopkins/SOM & & \\
\hline Sutherland, B. M. & $\mathrm{CO}-\mathrm{I}$ & Brookhaven & & \\
\hline Huso, D. L. & PI & Hopkins/SOM & $\begin{array}{l}\text { Chemoprevention of Radiation- } \\
\text { Induced Rat Mammary Neoplasms }\end{array}$ & B-45 \\
\hline Dicello, J. F. & CO-I & Hopkins/SOM & & \\
\hline Howard, S. P. & CO-I & U of Wisconsin & & \\
\hline Medina, D. & CO-I & Baylor & & \\
\hline Williams, J. R. & PI & $\begin{array}{l}\text { Hopkins/SOM } \\
\text { Damage as a Pr } \\
\text { Risk for Proton }\end{array}$ & $\begin{array}{l}\text { Radiation-Induced Cytogenetic } \\
\text { dictor of Cancer } \\
\text { and Fe Ions }\end{array}$ & B-46 \\
\hline Griffin, C. A. & $\mathrm{CO}-\mathrm{I}$ & Hopkins/SOM & & \\
\hline Helzlsouer, K. J. & CO-I & Hopkins/SOM & & \\
\hline Jones, R. J. & CO-I & Hopkins/SOM & & \\
\hline Zhang, Y. & CO-I & Hopkins/SOM & & \\
\hline Sinden, R. R. & PI & Texas A\&M & $\begin{array}{l}\text { Quantitation of Radiation-Induced } \\
\text { Deletion and Recombination Events } \\
\text { Associated with Repeated DNA } \\
\text { Sequences }\end{array}$ & B-48 \\
\hline Braby, L. A. & CO-I & Texas A\&M & & \\
\hline
\end{tabular}




\section{RESEARCH AREA: Radiation Effects: DNA Damage and Repair PRINCIPAL INVESTIGATOR: John F. Dicello, Ph.D. ORGANIZATION: Johns Hopkins Oncology Center PROJECT TITLE: $\quad$ Radiation Effects: Core Project FUNDING: $\$ 560,100$ (FY1998)}

\section{PROJECT SUMMARY}

The primary objective of this project is to determine the relative effectiveness of photons, protons, and HZEs for tumorigenesis in female Sprague-Dawley rats at low doses. In addition, as the lead project, this project will establish the protocols and supply appropriately irradiated animals and controls for the other projects in Radiation Effects requiring them. The experimental results from all projects within Radiation Effects will be combined and modeled in this project to establish the relative efficiency of the different types of radiations to induce tumors and other late effects. In a companion project, the novel use of a potentially mild pharmaceutical, tamoxifen (TAM) will be studied in vivo as a countermeasure. Our group will model the results of this known chemopreventor, which heretofore has been demonstrated to be an effective radiation countermeasure only for photons. Molecular and genetic changes measured in other projects will be modeled as well to establish correlations with carcinogenesis for eventually quantifying individual levels of risk. Finally, these in vivo and other results will be used to derive a response function and to normalize that response function for humans in order to improve risk assessment accuracy.

This project will 1) perform all in vivo and in vitro irradiations with protons and HZE particles at the accelerator facilities in collaboration with the investigators from the various projects; 2) perform the biostatistics and dosimetry preparations for the biological irradiations; 3 ) coordinate and correlate the biological data from this project and all others within the Radiation Effects program and then model the results; 5) determine response functions as a function of particle type and energy; 6) extrapolate and normalize these response functions to human response; and 7) improve estimations of risk based on new data from this program and other sources.

By combining the animal irradiations into a single core, we have been able to reduce the number of animal irradiations in the Radiation Effects program to a minimum, with a corresponding reduction in the number of shams and controls. Simultaneously, in collaboration with other projects, we will effectively examine the novel use of relatively mild pharmaceuticals to countermeasure observed effects of radiation exposures. Finally, two other studies originating from this work and the interactions of the investigators of this program with two other groups are related to the goals of the overall program: Dr. Dicello is a co-investigator on studies proposed in the Technology Program (R. Mauer) to develop a new approach for characterizing the doses in space from secondary neutrons; and Dr. Dicello and colleagues with Dr. Jay Shapiro, the Lead from the Bone Loss Program, are considering experimental methods to document changes in bone marrow cell radiation sensitivity in astronauts. 


\begin{tabular}{|ll|}
\hline RESEARCH AREA: & Radiation Effects: DNA Damage and Repair \\
PRINCIPAL INVESTIGATOR: John F. Dicello, Ph.D. \\
ORGANIZATION: & Johns Hopkins Oncology Center \\
PROJECT TITLE: & Chemoprevention of Radiation Induced Rat Mammary Neoplasms \\
FUNDING: & $\$ 139,900$ (FY1998) \\
\hline
\end{tabular}

PROJECT SUMMARY

The carcinogenic effects of low-LET radiations such as x-rays, $\gamma$-rays, or electrons are relatively well established environmental Earth exposures in experiments using the Sprague-Dawley rat mammary tumor model, the antiestrogen tamoxifen has been shown to inhibit initiation and progression of radiation-induced mammary tumors. Tamoxifen has also been shown to reduce the incidence of contralateral secondary breast cancers in woman undergoing therapy for primary breast cancer. Tamoxifen has thus been shown to be an effective chemopreventive agent in both animal models and in humans, suggesting that, at least in the case of breast cancer, effective counter measures can reduce the incidence of overt tumors.

This project seeks to evaluate the potential chemopreventive effects of tamoxifen for radiations to which travelers may be exposed in space. As carcinogenic low-level radiation effects for space travel remain unknown, we propose to mimic space radiations using energetic protons and iron nuclei. We will determine whether the chemopreventive effects in mammary tumor formation observed for tamoxifen in the Sprague-Dawley rat model following photon exposure can be duplicated for these radiations. 


\begin{tabular}{|ll|}
\hline RESEARCH AREA: & Radiation Effects: DNA Damage and Repair \\
PRINCIPAL INVESTIGATOR: Jerry R. Williams, Sc.D. \\
ORGANIZATION: & Johns Hopkins Oncology Center \\
PROJECT TITLE: & Radiation-Induced Cytogenetic Damage as a Predictor of Cancer \\
& $\begin{array}{l}\text { Risk for Protons and Fe Ions } \\
\text { FUNDING: }\end{array}$ \\
\hline 200,000 (FY1998)
\end{tabular}

\section{PROJECT SUMMARY}

This project will define the RBE for the induction of cytogenetic damage in relevant human and rat cells as they respond to $\mathrm{Fe}$ ions and energetic protons compared to photons. Specifically, we seek to determine whether cytogenetic response is a predictor of cancer induction in a rat model, and if so, to use similar endpoints in human cells as a parameter to set exposure limits to these radiations. In an analytic structure focusing on low dose and low dose-rate irradiation, we will measure multiple cytogenetic endpoints induced in vitro in three important human cell types: the peripheral lymphocyte, the hematopoietic stem cell and the mammary epithelial cell. We will determine in each of these human cell types an RBE for in vitro induction of selected cytogenetic endpoints by $\mathrm{Fe}$ ions and by energetic protons. We will perform parallel radiation studies in the same cell types in Sprague-Dawley rats, the selected animal model, for both in vivo and in vitro irradiation. Thus, this project will derive RBE values for three same cell types for both $\mathrm{Fe}$ ions and energetic protons for both humans and for the Sprague-Dawley rat. These data will demonstrate whether there is comparable response between cell types (lymphocyte versus bone marrow versus mammary epithelium), between species (human versus rat) and between in vitro and in vivo irradiation. We will compare the RBE for the induction of different cytogenetic endpoints with the RBE for induction of cancer in the animal model. If the RBE in rat cells correlates with the RBE for cancer induction, it will increase confidence that RBEs in human cells can be used to predict astronaut cancer risk when exposed to radiation represented by $\mathrm{Fe}$ nuclei and energetic protons.

Finally, we will address an important question relating to mechanisms in radiation- induced breast cancer. We have demonstrated that lymphocytes and mammary epithelial cells from some women at high risk for breast cancer are hypersusceptible to photon-induced damage, and hypothesize that this radiosensitivity is a marker for increased cancer risk. Since the animal model that the research team has chosen, the Sprague-Dawley rat is known to be hypersusceptible to radiation carcinogenesis, it will be important to ask whether human cells that are hypersusceptible to photon induced chromosomal damage are also more sensitive to the representative space radiations. Therefore, we will determine RBEs for $\mathrm{Fe}$ ions and energetic protons for induction of chromosomal damage in cells from women with elevated cancer risk that are sensitive to photon radiation.

In summary, this project will determine RBE values for the induction of chromosomal damage in a series of relevant human and rat cells from humans and from the Sprague-Dawley rat. The intercomparison of these values should lead to answers of several important questions:

(1) What is the RBE for the induction of different forms of chromosomal damage induced in relevant cells by $\mathrm{Fe}$ ions and by energetic protons?

(2) In comparing carcinogenesis to induction of chromosomal damage, is the RBE for response of the target cells (mammary epithelial cells) closer to the value for breast cancer induction than the RBE measured in other somatic cells (lymphocytes or hematopoietic stem cells) 
(3) Do cells that reside close to bony matrix (hematopoietic stem cells) experience more chromosomal damage for space radiations when irradiated in situ than when irradiated in vitro?

(4) Is there a systematic difference in RBE values between human cells and the same cells from the selected animal model?

(5) Are photon-sensitive cells from women who are at elevated risk of breast cancer equally sensitive to $\mathrm{Fe}$ ions and energetic protons? 


\begin{tabular}{|ll|}
\hline RESEARCH AREA: & Radiation Effects: DNA Damage and Repair \\
PRINCIPAL INVESTIGATOR: Richard R. Sinden, Ph.D. \\
ORGANIZATION: & Texas A\&M University \\
PROJECT TITLE: & Quantitation of Radiation Induced Deletion and Recombination \\
& Events Associated with Repeated DNA Sequences \\
FUNDING: & $\$ 50,000 \quad$ (FY1998) \\
\hline
\end{tabular}

PROJECT SUMMARY

The goal of this proposal is to develop data on the relationship between gene mutations, including deletions and recombination associated with direct repeats, and the quantity and quality of the radiation that interacts with the biological system so that countermeasures designed to minimize the health risks of radiation exposure in space can be devised. We will accomplish this by quantifying the rate of deletions between direct repeats, which may involve primer-template misalignment, recombination, or gene conversion in human cells following exposure to radiations which reproduce the energy deposition patterns produced in individual cells by the radiation environment in space. Using cell lines developed in the Sinden Lab that provide sensitive reporters of mutations involving deletions between direct repeats and recombination events, we will quantitate the rate of mutations in irradiated cells and in progeny of irradiated cells following exposure. In addition, we will develop additional reporter constructs to increase the sensitivity of measuring recombination events mediated by long direct repeats. The hypothesis driving this proposal is that DNA damage introduced by high-energy (HZE) particles induces aberrant DNA repair events, involving repeated DNA sequences that lead to recombination, gene conversion, or other mutation, that initiate the sequence of cytogenetic and functional changes which manifest themselves as the long term health effects of radiation exposure in space, including cancer. Knowing the types of mutational events induced by different radiations will contribute to sound decisions for optimizing shielding and reducing biological consequences through use of radioprotective drugs. The cell lines and procedures utilized in this proposal will be directly applicable to studies of the effect of radioprotective drugs. 


\section{NSBRI RESEARCH PROGRAM \\ TECHNOLOGY DEVELOPMENT}

Team Leader: $\quad$ Pisacane, V. L. Hopkins/APL

Charles, H. K. Jr. PI Hopkins/APL Compact, High Precision, Multiple B-50

Beck, T. J. CO-I Hopkins/SOM

Projection DEXA Scanner

Feldmesser, H. S. CO-I Hopkins/APL

Pisacane, V. L. CO-I Hopkins/APL

Cohen, R. J. $\quad$ PI $\quad$ MIT $\quad$ Instrumentation for Non-Invasive $\quad$ B-51

Mullen, T. J. CO-I Harvard Assessment of Cardiovascular Regulation

Potember, R. S. PI Hopkins/APL Miniature Time-of-Flight Mass $\quad$ B-52

Bryden, W. A. CO-I Hopkins/APL Spectrometer

Cotter, R. J. CO-I Hopkins/SOM

Pierson, D. L. CO-I NASA JSC

Pisacane, V. L. CO-I Hopkins/APL

Risby, T. H. CO-I Hopkins/SOM

Maurer, R. H. $\quad$ PI Hopkins/APL In-Situ Spectrometry of Neutrons $\quad$ B-53

Dicello, J. F. CO-I Hopkins/SOM

Fainchtein, R. CO-I Hopkins/APL

Gold, R. E. CO-I Hopkins/APL

Goldsten, J. O. CO-I Hopkins/APL

Kinnison, J. D. CO-I Hopkins/APL

Roth, D. R. CO-I Hopkins/APL 


\section{RESEARCH AREA: Technology Development PRINCIPAL INVESTIGATOR: Harry K. Charles, Jr., Ph.D. ORGANIZATION: Johns Hopkins University Applied Physics Laboratory PROJECT TITLE: Compact, High Precision, Multiple Projection DEXA Scanner FUNDING:}

\section{PROJECT SUMMARY}

The atrophy of bone and muscle in microgravity is well known, and the mitigation of this problem is an inevitable issue for long-term manned space flight. In order to gauge the magnitude of the problem, and the efficacy of countermeasures, suitable means for assessing status of the musculoskeletal system must be available to the astronauts during space flight. Such means of assessment must provide measurements of both muscle and bone with a high degree of precision. We propose to build and test a scanning system based on the principles of dual energy $x$-ray absorptiometry. The device will be a logical extension of commercial bone mineral scanning systems but it will differ in several ways. First, the scanner will be designed not only to measure conventional bone mass and to decompose soft tissue into measurements of fat and lean mass, but to use those measurements to derive structural properties permitting an assessment of the biomechanical consequences of a microgravity on bone or muscle mass. Multiple projection fan beam technology together with axial translation will be employed to provide geometric properties in three dimensions, suitable for a three dimensional structural analysis of the scanned region. Second, advanced fabrication techniques will be employed to optimize the volume and mass of the scanner as appropriate for the space environment, while maintaining required mechanical rigidity. Advanced electronic fabrication technologies such as chip-on-board and multichip modules will be utilized to minimize size and weight while maintaining overall system reliability. Commercial (off the shelf) parts will be incorporated whenever possible to minimize system cost. Power, heat dissipation, and mechanical properties will be optimized for the space environment. 


\begin{tabular}{|ll|}
\hline RESEARCH AREA: & Technology Development \\
PRINCIPAL INVESTIGATOR: & Richard J. Cohen, M.D., Ph.D. \\
ORGANIZATION: & Massachusetts Institute of Technology \\
PROJECT TITLE: & Instrumentation for Non-Invasive Assessment of Cardiovascular \\
& $\begin{array}{l}\text { Regulation } \\
\text { FUNDING: }\end{array}$ \\
\hline $110,000 \quad$ (FY1998) \\
\hline
\end{tabular}

\section{PROJECT SUMMARY}

It is critically important to be able to assess alterations in cardiovascular regulation during and after space flight. We propose to develop an instrument for the non-invasive assessment of such alterations that can be used on the ground and potentially during space flight. This instrumentation would be used by the Cardiovascular Alterations Team at multiple sites for the study of the effects of space flight on the cardiovascular system and the evaluation of countermeasures. In particular, the Cardiovascular Alterations Team will use this instrumentation in conjunction with ground-based human bed-rest studies and during application of acute stressors (e.g., tilt, lower body negative pressure, exercise) as well as in animal studies. In future studies, the Cardiovascular Alterations Team anticipates using this instrumentation to study astronauts before and after space flight and ultimately, during space flight. The instrumentation may also be used by the Neurovestibular Team and the Human Performance Factors, Sleep and Chronobiology Team to measure changes in autonomic nervous function.

The instrumentation will be based on a powerful new technology -- cardiovascular system identification (CSI) -- which has been developed in our laboratory. CSI provides a non-invasive approach for the study of alterations in cardiovascular regulation. This approach involves the analysis of second-to-second fluctuations in physiologic signals such as heart rate and noninvasively measured arterial blood pressure in order to characterize quantitatively the physiologic mechanisms responsible for the couplings between these signals. Through the characterization of multiple physiologic mechanisms, CSI provides a closed-loop model of the cardiovascular regulatory state in an individual subject.

The application of CSI currently requires off-line computerized analysis of recorded physiologic signals by an expert user. The user interacts iteratively with the computer to preprocess the data, select data segments for analysis, run the CSI analyses, and evaluate and interpret the results. In this project, we will develop integrated instrumentation capable of acquiring the physiologic signals, performing the CSI analysis in a fully automated fashion, and displaying the results online. The design of this instrumentation will be such that users with minimal training (including astronauts and other NSBRI investigators) can perform CSI conveniently and effectively.

The availability of this instrumentation is essential for effectively studying the cardiovascular effects of space flight and for the subsequent development and evaluation of appropriate countermeasures. The development of such instrumentation may also have significant clinical impact on the diagnosis and treatment of patients with a variety of cardiovascular and neurologic disorders. 


\section{RESEARCH AREA: Technology Development PRINCIPAL INVESTIGATOR: Richard S. Potember, Ph.D. ORGANIZATION: Johns Hopkins University Applied Physics Laboratory PROJECT TITLE: FUNDING:}

\section{PROJECT SUMMARY}

A small, high resolution, time-of-flight mass spectrometer (TOFMS) will be designed, fabricated and tested for long duration space flight. This instrument can be used to identify solids, liquids and gases of both chemical and biological origins to quantify the habitat environment and support biomedical research and medical care. Several miniature TOF mass spectrometers for military use are presently under development at The Johns Hopkins University Applied Physics Laboratory (JHU/APL) using unique multi-electrode TOF analyzers to characterize biological and chemical compounds. The use of TOFMS in space varies from the analysis of chemicals and microorganisms in the spacecraft environment to the analysis of microorganisms in body fluids, breath, and space bioreactors. The virtue of the JHU/APL TOFMS technologies resides in the promise for a small (less than one cubic $\mathrm{ft}$ ), lightweight (less than $5 \mathrm{~kg}$ ), low power (less than 50 watts), device that can be used continuously with advanced signal processing diagnostics. Further, the quantitative and electronic nature of the TOFMS output makes it ideal for telemetry to Earth.

The TOFMS system could use either laser desorption and ionization methods, or electron impact methods to ionize compounds for analysis in near-real time with sensitivities down to the attomole $\left(10^{-18}\right.$ mole). The JHU/APL approach is to design the instrument for both wide mass range and fine mass resolution by the use of electronic control in a tandem mass spectrometer instrument. The tandem approach will provide both mass separation and exquisite mass resolution for the precise characterization of many compounds. To date, the JHU/APL approach for military application has demonstrated mass capability beyond 10,000 atomic mass units $(\mathrm{amu})$ in a very small, low power prototype for biological analysis.

This space instrument should be of value to the Hematology, Immunology, and Infection and Muscle Alterations and Atrophy Research Teams, as well as being useful for gathering data on other NASA experiments, such as in the Space Bio-reactor Systems. In addition to its low size, weight, and power, the TOFMS offers tremendous savings in requirements for the transport and stowage of materials. Therefore, this three-year project will work closely with collaborators in the other NSBRI research teams and NASA Johnson Space Center investigations to develop TOFMS system sampling, ionization, and analysis tools for high priority compounds and microorganisms. The identification of analysis requirements and sample collection procedures will lead to the focused development of a prototype TOFMS system for long duration space flight. 


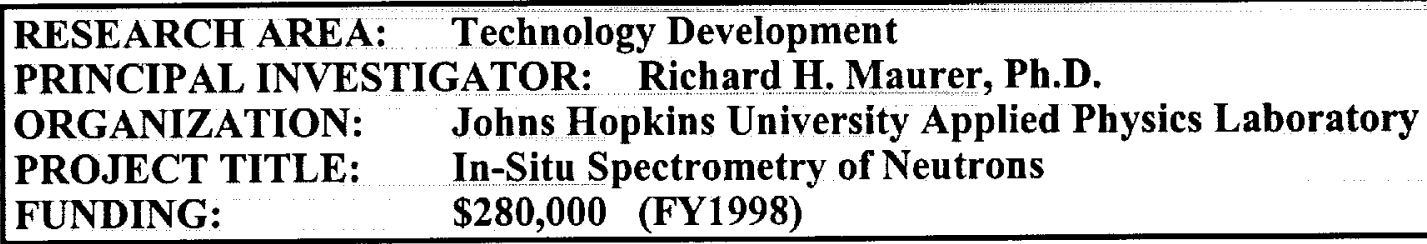

\section{PROJECT SUMMARY}

This project proposes to build an in situ portable neutron spectrometer to monitor the neutron environment produced by collisions of high energy charged primary cosmic rays with space structures, with planetary atmospheres and surfaces. The instrument will combine two detection systems - a proportional counter to detect low energy neutrons between $100 \mathrm{eV}$ and $500 \mathrm{keV}$, as well as counting neutrons with energies less than $100 \mathrm{eV}$, and a silicon solid state detector array to detect neutrons between several hundred $\mathrm{keV}$ and $500 \mathrm{MeV}$.

Standard pulse height analysis techniques and instrument data handling electronics will be employed to produce energy spectra from charge deposited by the secondaries created in the neutron-silicon collision. Data processing will produce consequent neutron energy spectra and will also calculate equivalent dose by converting energy deposited in silicon to that deposited in tissue using the appropriate quality factors for damage. The instrument will be less than $10 \mathrm{~kg}$ to insure portability. No animal or human testing is involved in this project.

This proposal responds to the need for such an instrument as indicated by both Johnson Space Center experts and the chairman of the NSBRI Radiation Effects Team who is a co-investigator on this project. It utilizes the substantial experience of the Applied Physics Laboratory in the development of space instrumentation, will address the concerns and requirements established by our colleague from the Johns Hopkins School of Medicine and builds upon the expertise of the Clemson University group gained in radiation effects experiments and modeling during their study of single event effects in electronics over the past fifteen years. 


\section{NSBRI RESEARCH PROGRAM SYNERGY PROJECTS}

Note: These projects, selected in April $\mathbf{1 9 9 8}$, are limited to one year of funding at $\mathbf{\$ 5 0 , 0 0 0}$ (Total Cost). They are designed to integrate the research activities of two or more teams and stimulate the development of multi-team research activities.

$\begin{array}{lll}\text { Cohen, R. J. } & \text { PI } & \text { MIT } \\ & & \\ \text { LeBlanc, A. } & \text { CO-I } & \text { Baylor } \\ \text { Mullen, T. J. } & \text { CO-I } & \text { Harvard } \\ \text { Ramsdell, C. R. } & \text { CO-I } & \text { Harvard } \\ \text { Shackelford, L. } & \text { CO-I } & \text { NASA JSC } \\ \text { Yelle, J. M. } & \text { CO-I } & \text { NASA JSC }\end{array}$

Alterations in Cardiovascular

B-55

Regulation and Function During

Long-Term Simulated Microgravity

(Cardiovascular Alterations - Bone Loss)

Dijk, D. $\quad$ PI Harvard

$\begin{array}{lll}\text { Cajochen, C. } & \text { CO-I } & \text { Harvard } \\ \text { Williams, G. H. } & \text { CO-I } & \text { Harvard }\end{array}$

Mullen, T. J. $\quad$ PI $\quad$ Harvard

Visual- and Vestibular-Autonomic

B-58

Influence on Short-Term Cardio-

vascular Regulatory Mechanisms

(Cardiovascular Alterations - Neuro-

vestibular Adaptation)

$\begin{array}{lll}\text { Beall, A. C. } & \text { CO-I } & \text { MIT } \\ \text { Oman, C. M. } & \text { CO-I } & \text { MIT } \\ \text { Paloski, W. } & \text { CO-I } & \text { NASA JSC } \\ \text { Wood, S. } & \text { CO-I } & \text { Baylor } \\ \text { Yelle, J. M. } & \text { CO-I } & \text { NASA JSC }\end{array}$

Mullington, J. M. PI Harvard

Sustained Partial Sleep

B-59

Deprivation: Effects on Immune

Modulation \& Growth Factors

(Human Performance - Immunology,

$\begin{array}{lll}\text { Butel, J. S. } & \text { CO-I } & \text { Baylor } \\ \text { Dinges, D. F. } & \text { CO-I } & \text { Penn } \\ \text { Schwartz, R. J. } & \text { CO-I } & \text { Baylor }\end{array}$

Infection \& Hematology - Muscle Alterations) 
SYNERGY AREA: Cardiovascular Alterations - Bone Loss

PRINCIPAL INVESTIGATOR: Richard J. Cohen, M.D., Ph.D.

ORGANIZATION: Harvard Medical School/MIT

PROJECT TITLE: Alterations in Cardiovascular Regulation and Function During Long-

Term Simulated Microgravity

FUNDING: $\$ 50,000(\$ 25,000$ FY1998)

\section{PROJECT SUMMARY}

The Cardiovascular Alterations Team is already conducting studies of hemodynamic regulation and susceptibility to arrhythmias resulting from ten days of simulated microgravity exposure. In these studies very intensive measurements are made during a short duration of bed rest. In the collaborative effort described in this proposal we will make many of the same measurements, however much less frequently, on subjects who are exposed to a much longer duration of simulated microgravity. It is anticipated that this will provide valuable additional data on the time course of cardiovascular deconditioning, especially with respect to susceptibility to cardiac arrhythmias as is detailed below.

Alterations in cardiovascular regulation and function that occur during and after space flight have been reported. These alterations are manifested, for example, by reduced orthostatic tolerance upon reentry to the Earth's gravity from space [Charles et al., 1994, Buckey et al., 1996]. However, the precise physiologic mechanisms responsible for these alterations remain to be fully elucidated. Perhaps, as a result, effective countermeasures have yet to be developed. In addition, numerous reports from the past 30 years suggest that the incidence of ventricular arrythmias among astronauts is increased during space flight [Charles et al., 1994, Yelle, in press]. However, the effects of space flight and the associated physiologic stresses on cardiac conduction processes are not known, and an increase in cardiac susceptibility to arrythmias has never been quantified.

The objective of this proposal is to apply the most powerful technologies available to determine, in a ground-based study of long duration space flight, the mechanisms by which space flight affects cardiovascular function, and then on the basis of an understanding of these mechanisms to develop rational and specific countermeasures. To this end we propose a collaborative project with the Bone Demineralization/Calcium Metabolism Team of the National Space Biomedical Research Institute (NSBRI). The Bone Team plans to conduct bed-rest studies in human subjects lasting 17 weeks, which will provide a unique opportunity to study the effects of long duration microgravity exposure on the human cardiovascular system. We will apply a number of powerful new methods to these long term bed-rest subjects, including cardiovascular system identification (CSI), microvolt level T wave alternans analysis, and cardiac magnetic resonance imaging to assess non-invasively the effects of simulated long duration space flight on the cardiovascular system.

CSI involves the mathematical analysis of second-to-second fluctuations in non-invasively measured heart rate, arterial blood pressure (ABP), and instantaneous lung volume (ILV respiratory activity) in order to characterize quantitatively the physiologic mechanisms responsible for the couplings between these signals. Through the characterization of all the physiologic mechanisms coupling these signals, CSI provides a model of the closed-loop cardiovascular regulatory state in an individual subject. The model includes quantitative descriptions of the heart rate baroreflex as well as other important physiologic mechanisms. With an additional non-invasive measurement of stroke volume (SV - ultrasound Doppler 
method), the model may be extended to also include the characterization of the peripheral resistance baroreflex - which may play a central role in the development of orthostatic intolerance - and measures of systolic and diastolic function.

To determine whether simulated long term space flight increases the risk of developing lifethreatening heart rhythm disturbances such as sustained ventricular tachycardia (defined as ventricular tachycardia lasting at least 30 seconds or resulting in hemodynamic collapse) and ventricular fibrillation, we will apply a powerful new non-invasive technology, developed in Professor Cohen's laboratory at MIT, for the quantitative assessment of the risk of lifethreatening ventricular arrhythmias. This technology involves the measurement of microvolt levels of $T$ wave alternans during exercise stress. In addition, we will obtain other non-invasive markers of susceptibility to ventricular arrhythmias based on signal averaged electrocardiography (SAECG), QT dispersion, and 24 hour Holter monitoring (to detect non-sustained ventricular tachycardia and to assess heart rate variability). Finally, in order to investigate the effect of long duration microgravity on cardiac mass, cardiac magnetic resonance images will be obtained before and after the bed-rest period. 


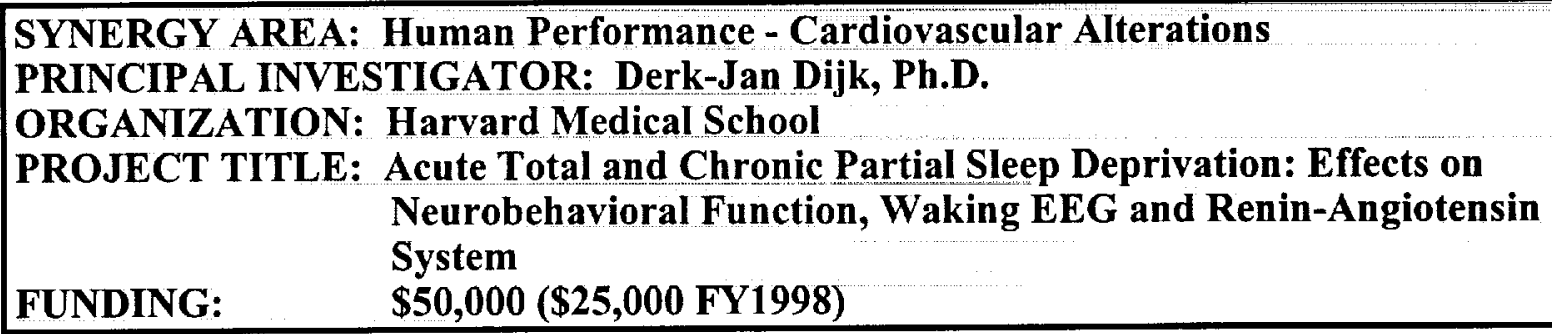

\section{PROJECT SUMMARY}

Exposure to the microgravity environment leads to changes in sleep and associated deterioration of waking neurobehavioral function as well as changes in sodium and volume homeostasis and associated renal and cardio-endocrine responses. We propose integration of research tools and research projects to enhance the fidelity of the simulated conditions of space flight which are characterized by complexity and mutual interactions. The effectiveness of countermeasures and physiologic mechanisms underlying neurobehavioral changes and renal-cardio endocrine changes are investigated in Project 3 of the Human Performance Team and Project 3 of the Cardiovascular Alterations Team respectively. Although the specific aims of these two projects are very different, they employ very similar research protocols. Thus, both projects investigate the effects of posture/bedrest ( 2 days and 10 days) and sleep deprivation (total or partial) on outcome measures relevant to their specific aims. The main aim of this enhancement grant is to exploit the similarities in research protocols by including the assessment of outcome variables relevant to the Renal-Cardio project in the research protocol of Project 3 of the Human Performance Team and by including the assessment of outcome variables relevant to the Quantitative EEG and Sleep Deprivation Project in the research protocols of Project 3 of the Cardiovascular Alterations team. In particular we will assess Neurobehavioral Function and Waking EEG in the research protocols of the renal-cardio endocrine project and renin-angiotensin and cardiac function in the research protocol of the Quantitative EEG and Waking Neurobehavioral Function project.

This will allow us to investigate two additional specific aims:

1) Test the hypothesis that chronic partial sleep deprivation during a 10 day bedrest experiment results in deterioration of neurobehavioral function during waking and increases in EEG power density in the theta frequencies, especially in frontal areas of the brain, as well as the nonREM-REM cycle dependent modulation of heart-rate variability.

2) Test the hypothesis that acute total sleep deprivation modifies the circadian rhythm of the renin-angiotensin system, changes the acute responsiveness of this system to posture beyond what a microgravity environment alone does and affects the nonREM-REM cycle dependent modulation of heart-rate variability.

The data obtained on the waking EEG and neurobehavioral function in the chronic partial sleep deprivation experiment will complement the data obtained on the effects of total sleep deprivation which will be collected in project 3 of the Human Performance Team. The data obtained on the renin-angiotensin levels in the acute total sleep deprivation experiment will complement data obtained on the effects of chronic partial sleep deprivation which will be collected in project 3 of the Cardiovascular Alterations team. The application of identical research tools and outcome measures in research protocols across the Cardiovascular and Human Performance team will greatly enhance the overall science return of these projects and emphasizes the synergistic nature of this application. 


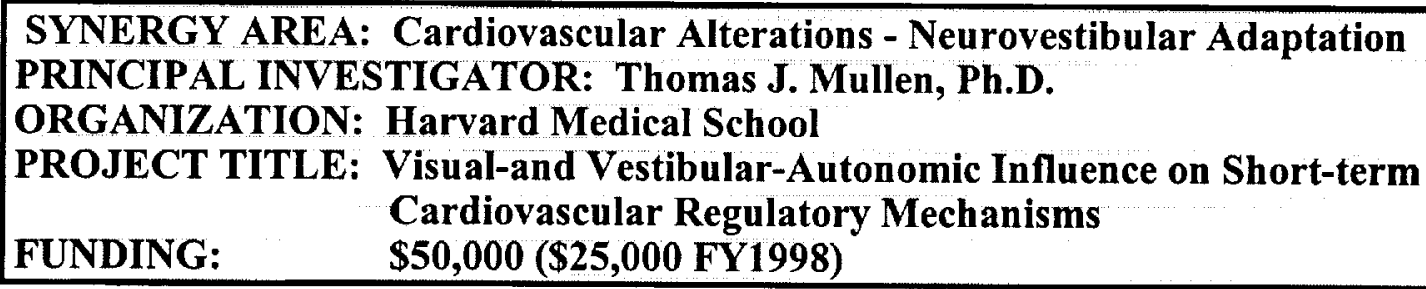

\section{PROJECT SUMMARY}

This synergy proposal describes a one-year effort to be conducted cooperatively by members of the NSBRI Cardiovascular Alterations and Neurovestibular Adaptation Teams in collaboration with NASA- Johnson Space Center (JSC) colleagues. The objectives of the proposed research are:

1. to investigate vestibular and visual influences on autonomic modulation of cardiovascular regulatory mechanisms, and

2. to compare baroreflex changes as measured with a new Cardiovascular System Identification (CSI) technique with those measured using a neck barocuff.

Blunting of the carotid-cardiac baroreflex has been observed during and after space flight and prolonged bed rest using the neck barocuff technique (Fritsch et al., 1992; Fritsch-Yell et al., 1994). Comparable barocuff response changes have recently been reported during yaw axis vestibular stimulation and eye movements (Convertino et al., 1997; Convertino, 1998). It has been suggested that vestibular pathways could play a significant role in changing the orthostatic competence of astronauts and bedridden patients by inhibition of vagal withdrawal and elevation of parasympathetic outflow. However, functional interpretation of neck barocuff data is complicated because this method stimulates only the carotid baroreceptors. Interpretation would be more straightforward if blunting during whole body rotation could be demonstrated using a method like Cardiovascular System Identification (CSI) which provides a measure of overall baroreflex responsiveness. Also, it is important to understand how the vestibular system contributes to cardiovascular control during body tilt, as opposed to yaw rotation. This cannot easily be done using actual body tilt, since the body's non-vestibular gravireceptors (e.g. baroreceptors) are also stimulated. However, we have recently found compelling static tilt and tumbling illusions in a majority of human subjects tested using a virtual reality head mounted display system. We propose to look for baroreflex changes during real and illusory body rotation and tilt using both the neck barocuff and CSI techniques. 


SYNERGY AREA: Human Performance - Immunology, Infection and Hematology -
Muscle Alterations
PRINCIPAL INVESTIGATOR: Janet M. Mullington, Ph.D.
ORGANIZATION: Harvard Medical School
PROJECT TITLE: Sustained Partial Sleep Deprivation: Effects on Immune Modulation
\& Growth Factors
FUNDING: $\quad$ \$50,000 (\$25,000 FY1998)

\section{PROJECT SUMMARY}

While the endurance of public health maintenance and safety are important goals for governments of advanced societies, these aims are prerequisite for the success of prolonged space missions. The vulnerability to human performance errors or medical emergencies are greatest in space where there are real limits to the availability or effectiveness of ground based assistance. The Human Performance Factors, Sleep and Chronobiology Team (Dr. Czeisler, Leader) has approached the problems associated with performance failure from the perspective of optimizing performance capacity. They have developed integrated research projects aimed at understanding the mechanisms involved in human adaptation to the space environment and the associated behavioral factors lead to certain performance failure, notably insufficient sleep and circadian rhythm disruption.

In long term space flight, the issue of immune suppression and possible reactivation of latent viruses are risks that cannot be prevented by preflight quarantine. The possibility of reactivation of latent viruses is a serious potential hazard for the success of long term space missions where confined conditions increase the possibility of transmitting disease. Medical complications which would not pose a serious problem on Earth may be disastrous if they emerged in space. The Hematology, Immunology and Infection Team (Dr. Rudolph, Leader) is addressing issues of immune regulation in space, to alterations in function produced by weightlessness and the stresses associated with space flight and living in confined spaces. In addition to stress modulation of immune function, recent research suggests that sleep is also involved. While we all have the common experience of being sleepy when suffering from infection, and being susceptible to infection when not getting enough sleep, the mechanisms involved in this process are not understood and until recently have gone largely overlooked. We believe that the immune function changes seen in spaceflight may also be related to the effects of partial cumulative sleep deprivation.

The Human Performance Factors, Sleep and Chronobiology team project "Countermeasures to Neurobehavioral Deficits from Cumulative Partial Sleep Deprivation During Space Flight" was designed not only to test the efficacy of sleep-wake scheduling for the maintenance of optimal performance during long term space flight but also to investigate the possible augmentation of growth hormone by providing supplemental sleep episodes, or naps, positioned half way through the waking period. The underlying hypothesis is that since $>70 \%$ of total GH secretion occurs during the nocturnal sleep period, that reduction of sleep time for prolonged periods may result in a curtailment of 24 hour GH production, which may translate to reduced availability at the level of the tissues. The Muscle Alterations and Atrophy team (Dr. Schwartz, Leader) are conducting a series of studies to investigate the genetic expression of GH and insulin-like growth factors at the level of the muscle, with a view to developing countermeasures for the known problems associated with muscle fiber degeneration during prolonged space travel. It is anticipated that the investigation of the GH-IGF-I axis during conditions of prolonged partial sleep deprivation will help to develop countermeasures that can contribute to health maintenance and preventative 
strategies for use in space travel, and also to provide behavioral strategies that will be useful in promoting GH and perhaps IGF-I availability to counteract degenerative processes in aging and illness on Earth.

In order to synergize the aims of these three research teams we have chosen to investigate the neuroendocrine and neuroimmune modulation of sustained partial sleep deprivation and furthermore to test the influence of cumulative sleep loss on the reactivation of latent viruses, and the delayed hypersensitivity response to cutaneously applied antigen testing. The results of this research will integrate the teams and give them the opportunity to examine data using technologies and methodologies that come from separate and distinct scientific methodologies, and bring them together in a common protocol with a view to enhancing the potential of each team to take back information which will help in the development and implementation of countermeasure strategies and future scientific developmental plans. 


\section{BIOGRAPHICAL SKETCH}

Provide the following information for the key personnel in the order listed on Form Page 2. Photocopy this page or follow this format for each person.

\begin{tabular}{|l|l|l|l|}
\hline NAME & \multicolumn{3}{|l|}{ POSITION TITLE } \\
\hline William T. Shearer, M.D., Ph.D. & Professor \\
\hline \multicolumn{1}{|c|}{ CATIONTRAINING (Begin with baccalaureate or other initial professional education, such as nursing, and include postdoctoral training). } \\
\hline \multicolumn{1}{|c|}{ INSTITUTION AND LOCATION } & DEGREE & YEAR(s) & \\
\hline University of Detroit, Detroit, MI & B.S. & 1960 & Chemicable) \\
Wayne State University, Detroit, MI & Ph.D. & 1966 & Biochemistry \\
Washington University, St. Louis, MO & M.D. & 1970 & Medicine \\
\hline
\end{tabular}

RESEARCH AND PROFESSIONAL EXPERIENCE: Concluding with present position, list, in chronological order, previous employment, experience, and honors. Include present membership on any Federal Government public advisory committee. List, in chronological order, the titles, all authors, and complete references to all publications during the past three years and to representative earlier publications pertinent to this application. If the list of publications in the last three years exceeds two pages, select the most pertinent publications. DO NOT EXCEED TWO PAGES.

\section{Training:}

63-66: Pre-doctoral Fellow in Biochemistry, Dept. Biochem., Wayne State Univ., Detroit, MI; 66-67: Post-doctoral Fellow in Chemistry, Dept. Chem., Indiana Univ., Bloomington, IN; 70-71: Intern in Peds., St. Louis Children's Hosp., St. Louis, MO; 71-72: Resident in Peds., St. Louis Children's Hosp.; 72-74: Resident in Immunol. in Peds., Barnes \& St. Louis Children's Hospital, Washington University Medical Center.

\section{Honors:}

B.S. (Magna Cum Laude), Senior Biochemistry Award, Phi Lambda Upsilon, Detroit News Fellowship, Sigma Xi, St. Louis Pediatric Society Award, Alexander Berg Award, USPHS Special Fellowship, Research Scholar Award of the Cystic Fibrosis Foundation, Faculty Research Award of the American Cancer Society, American Society for Clinical Investigation, Myrtle Wreath Award of Hadassah, Special Recognition Award, American Academy of Allergy and Immunology.

\section{Certification:}

National Board of Medical Examiners, 70; American Board of Pediatrics, 75, 81, 86; American Board of Allergy and Immunology 75, 77, 80, 83, 87, 89; Diagnostic Laboratory Immunology, American Boards of Internal Medicine, Pediatrics, Allergy and Immunology, 86.

\section{Appointments:}

66-67: Research Associate in Chemistry, Dept. Chem., Indiana Univ., Bloomington, IN; 72-74: Special U.S. Public Health Science Research Fellow in Medicine (Immunology) awarded by Natl. Inst. of Allergy \& Infect. Dis., Dept. Med., Washington Univ.; 74-78: Director of Div. of Allergy and Immunology, St. Louis Children's Hosp.; 76-78: Associate Prof. of Peds., Washington Univ., St. Louis, MO; 78-78: Prof. of Peds., Washington Univ., St. Louis, MO; 78-: Chief, Allergy \& Immunol. Service, Texas Children's Hosp., Houston, TX; 78-: Head, Sect. of Allergy \& Immunol., Dept. Peds., Baylor Col. of Med., Houston, TX; 78-: Prof. of Peds., Microbiol. \& Immunol., Baylor Col. of Med., Houston, TX; 91 -: Director, Pediatric HIV Research Center, Baylor Col., of Med., Houston, TX.

Consultant:

AIDS Committee, St. Luke's and Texas Children's Hosp., Houston, TX; AIDS Committee, Houston Independent School District, Houston, TX; Ad Hoc Reviewer National Cooperative Drug Discovery Groups for AIDS; Review Committee, Specialized Centers of Research in Transfusion Medicine, National Heart, Lung, and Blood Institute; Consultant, Central Nervous System Aspects of HIV Infection and AIDS in Infants and Children, National Institute of Mental Health; Review Committee, AIDS Related Research; Section Chair, NICHD Workshop, Early Diagnosis of HIV Infection in Infants: Other Methods for HIV Detection; Consultant and Site Visitor, NHLBI Study of Heart and Lung Complications of Pediatric HIV Infection; Ad Hoc Reviewer, AIDS and Related Research Study Section; Member, Special Review Committee, Persons Affected by Chronic Granulomatous Disease, National Institutes of Health; Chairman, Executive Committee of NICHD IVIG Trial in HIV-infected Children; member, Pediatric Core Committee and Pediatric ACTG, Chair, Pediatric Immunology Committee and B2 Immunology Laboratory Subcommittee, NIAID Pediatric ACTG; Vice-Chair, Pediatric Executive Committee, Pediatric ACTG; Chairman, 


\section{Appendix C}

Population Committee, NHLBI Study of Heart and Lung Complications of Pediatric AIDS; Member, AIDS Ad Hoc Working Group; Member, Therapeutics Subcommittee, AIDS Advisory Research Committee, NIAID; Director and Chair, American Board of Allergy and Immunology; Editorial Board, Journal of Allergy and Clinical Immunology, Pediatric Asthma, Allergy and Immunology.

\section{Publications (selected from over 215 full papers):}

Kuruvilla A, Putcha G, Poulos E, Shearer WT. Tyrosine phosphorylation of phospholipase $C$ is essential for its activation by platelet-activating factor in a human B cell line. J Immunol 151:637-648, 1993.

Dorenbaum A, Shearer WT, Abramson SL. Phagocytic cell superoxide production in children with HIV infection. Pediatr AIDS HIV Infect 4:215-221, 1993.

Kline MW, Lewis DE, Hollinger FB, Reuben JM, Hanson IC, Kozinetz CA, Dimitrov DH, Rosenblatt HM, Shearer WT. A comparative study of human immunodeficiency virus (HIV) culture, polymerase chain reaction, and antiHIV immunoglobulin A antibody detection in the diagnosis during early infancy of vertically acquired HIV infection. Pediatr Infec Dis J 13:90-94, 1994.

Smith C, Shearer WT. Activation of NF- B and immunoglobulin expression in response to platelet activating factor in a human B cell line. Cellular Immunology 155:292-303, 1994.

Morgan J, Landers D, Williams-Herman D, Wara D, Viscarello R, Hammill H, Kline M, Shearer WT, Charlebois E, Kohl S. Association between anti-HIV antibody-dependent cellular cytotoxicity antibody titers at birth and vertical transmission of human immunodeficiency virus. J Infect Dis 170:308-312, 1994.

Patke CL, Green CG, Shearer W.T. Immunomodulatory role of platelet-activating factor on human B cells: Differential effect of interleukin-2 and interleukin-4. Clin Diag Lab Immunol 1(4):424-432, 1994.

Smith CS, Parker L, Shearer, W.T. Cytokine regulation by platelet-activating factor in a human B cell line. J Immunol 153:3997-4005, 1994.

Smith CS, Ortega G, Parker L, Shearer WT. Cyclosporin A blocks induction of tumor necrosis factor-alpha in human B lymphocytes. Biochem Biophys Res Commun 204:383-390, 1994.

Lewis DE, Adu-Oppong A, Kline MW, Hollinger FB, Kozinetz CA, Shearer WT. Sensitivity of immune-complexdissociated p24 antigen testing for early detection of HIV in neonates Clin Diag Lab Immunol 2(1): 87-90, 1995.

Kuruvilla A, Pielop C, Shearer WT. Platelet-activating factor induces the tyrosine phosphorylation and activation of phspholipase $\mathrm{C}-1$, fyn and lyn kinases, and phosphatidylinositol 3-kinase in a human B cell line. J Immunol 153:5433- 5442, 1994.

Shearer WT, Duliege AM, Kline MW, Hammill H, Minkoff $H$, Mordenti J, Chen S, Izu A, Ammann AJ. Transport of recombinant human CD4-immunoglobulin $G$ (rCD4-lgG) across the human placenta: pharmacokinetics and safety in six mother:infant pairs. Clin Diag Lab Immunol 2:281-285, 1995.

Langston C, Lewis DE, Hammill HA, Popek EJ, Kozinetz CA, Kline MW, Hanson IC, Shearer WT. Excess intrauterine fetal demise associated with maternal HIV infection. $J$ Infect Dis 172:1451-1460, 1995.

Lee B-N, Lu J-G, Kline MW, Paul M, Doyle M, Kozinetz C, Shearer WT, Reuben JM. Type 1 and Type 2 cytokine profiles in children exposed to or infected with vertically transmitted human immunodeficiency virus. Clin Diag Lab Immunol 3:493-499, 1996.

O'Neal KD, Chari MV, McDonald CH, Cook RG, Yu-Lee L-Y, Morrisett JD, Shearer WT. Multiple Cis-trans conformers of the prolactin receptor proline-rich motif (PRM) peptide by RP-HPLC and NMR spectroscopy. Biochem J 315:833-844, 1996.

Kline MW, Fletcher CV, Federici ME, Harris AT, Evans KD, Rutkiewicz VL, Shearer WT, Dunkle LM. Combination therapy with stavudine (d4T) and didanosine (dd) in children with advanced human immunodeficiency virus infection: pharmacokinetic properties, safety, and immunologic and virologic effects. Pediatrics 97:886-890, 1996.

Shearer WT, Quinn TC, La Russa P, Lew JF, Mofenson L, Almy S, Rich K, Handelsman E, Diaz C, Pagano M, Smeriglio V, and Kalish LS, for the Women and Infants Transmission Study Group. Viral load and disease progression in infants infected with HIV-1. N Eng J Med 336:1337-1342, 1997.

Lee B-N, Ordonez N, Popek EJ, Lu J-G, Helfgott A, Eriksen N, Hammill H, Kozinetz C, Doyle M, Kline M, Langston C. Shearer WT, Reuben JM. Inflammatory cytokine expression is correlated with the level of HIV transcripts in HIV-infected placental trophoblastic cells. J Virol 71:3628-3635, 1997.

Shearer WT, Langston C, Lewis DE, Pham EL, Hammill HH, Kozinetz CA, Kline MW, Hanson IC, Popek EJ. Early spontaneous abortions and fetal thymic abnormalities in maternal-to-fetal HIV infection. Acta Paediatr Suppl 421:60-4, 1997. 
Tuomala RE, Kalish LA, Zorilla C, Fox H, Shearer W, Landay A, Vermund SH, Landesman S, Burns D, for the Women and Infants Transmission Study (WITS). Changes in total, CD4+ and CD8+ lymphocytes during pregnancy and one year postpartum in HIV-infected women. Obstet Gynecol 89:967-74, 1997.

Chinen J, and Shearer WT. Gene therapy for pediatric HIV infection. The Immunologist 5/3;93-97, 1997.

Shearer WT, Kalish LA, Zimmerman PA. Letter to the editor: CCR5 HIV-1 vertical transmission. J AIDS Hum Retrovirol 17;180-181, 1998.

Shearer WT. Editorial: Monitoring cellular immune function in HIV infection by the delayed hypersensitivity skin test: alternative to the CD4 ${ }^{+}$T-cell count? J Allergy Clin Immunol, 1998 (in press). 


\section{AGREEMENT OF AFFILIATION BETWEEN THE INSTITUTE OF AEROSPACE MEDICINE OF THE GERMAN AEROSPACE CENTER AND THE NATIONAL SPACE BIOMEDICAL RESEARCH INSTITUTE}

This agreement is between the INSTITUTE OF AEROSPACE MEDICINE of the German Aerospace Center (Deutsches Zentrum für Luft- und Raumfahrt e.V., DLR) and the NATIONAL SPACE BIOMEDICAL RESEARCH INSTITUTE (NSBRI) and is effective as of the date set forth herein.

WHEREAS the INSTITUTE OF AEROSPACE MEDICINE of the German Aerospace Center, Linder Höhe, $51147 \mathrm{Köln}$, Germany, and the NATIONAL SPACE BIOMEDICAL RESEARCH INSTITUTE, One Baylor Plaza, NA-425, Houston, Texas 77030-3498, U.S.A, share a common interest in the human exploration and development of space and similar scientific, academic and professional objectives; and

WHEREAS both institutions are desirous of increasing the human and scientific relations which would contribute to the achievement of aims which both pursue.

NOW, THEREFORE, the parties do agree as follows:

1) Because of their joint interest in the human exploration and development of space, the parties agree to undertake specific activities from time to time aimed at furthering the following general objectives:

(a) joint projects involving research, technological development, or education and outreach;

(b) exchange of life scientists;

(c) joint or coordinated organization of seminars, meetings and lectures on subjects of mutual interest;

(d) reciprocal use of research and other published information;

(e) exchange of research and teaching materials and use of facilities;

(f) exchange of publications; and

(g) development of life-scientist related postgraduate, graduate and undergraduate student exchange programs according to academic rules jointly adopted, but subject to legislation in force in each country.

All such activities shall be subject to the budgetary resources available to, and any legal restrictions applicable to the activities of, the parties. 


\section{Appendix D}

2) Each project created under this agreement must be reduced to a separate, formal, written agreement which must be signed by authorized representatives of the parties before such a project can be deemed in effect and, accordingly, binding on either party.

3) By means of the special agreements reduced to writing and signed by authorized persons, the parties shall determine specific areas and programs of cooperation, as well as the terms, methods, financial conditions and procedures of specific projects. As a governing principle for all such agreements, and unless otherwise agreed to in writing, all costs and expenses related to implementation of a project - direct or indirect costs and expenses, costs of equipment and supplies, travel, etc. - and all expenses as are created pursuant to said agreements - travel, housing, living expenses, stipends, benefits (including, but not limited to, health and life insurance), licensure, malpractice insurance, etc. - will be paid by the sending party. Neither party will be responsible for any costs and expenses incurred in any respect by the other party or its students, residents or faculty unless expressly agreed to by separate written agreement signed by authorized representatives of the parties.

4) The parties agree that, within the scope of this instrument and upon approval of the parties, other qualified institutions may be invited to participate in the various projects envisioned by this agreement.

5) The parties agree that, as an essential proposition to any cooperative endeavor, all individual participants in projects created pursuant to this agreement will be selected with full respect for equal opportunity for all persons in accordance with the policies of each party and without regard to the race, sex, age, national origin or religious affiliation of participants or candidates for participation.

6) The parties acknowledge that, due to the unique professional, institutional, and legal requirements for registration, enrollment and certification applicable to each party, student participants in the various projects envisioned by this agreement will be registered and/or enrolled in and will receive certification and/or degrees from only the sending party. Accordingly, project participants will not automatically be registered and/or enrolled in, nor will they receive degrees from the receiving party, unless specifically accepted by the receiving institution and meeting their requirements.

7) While it is not contemplated that any projects implemented pursuant to this agreement will involve the rendition of health care services by professionals out of their country, the parties acknowledge that all physicians or other health care professionals who wish to participate in the rendition of patient care shall be solely responsible, at their expense or the expense of the sending party, for securing requisite licensure and all other authorization and any malpractice or other insurance coverage as may be required by law or applicable institutional and hospital policies and procedures.

8) This agreement will enter into force on January 21, 1998 and will continue in effect for five (5) years from that date. It shall be renewed for equal periods, unless one of the parties notifies the other in writing of its desire to terminate such agreement at least three (3) months prior to the date of termination.

9) Entered into in the City of Köln, Germany, by means of the execution of two counterpart originals. 
FOR THE INSTITUTE OF AEROSPACE MEDICINE, DLR, KÖLN, GERMANY

By:

Rupert Gerzer, Prof. Dr. med Date

Director, Institute of Aerospace Medicine, DLR

Approval:

By:

Walter Kröll, Prof. Dr. rer. nat

Date

Chairman, Executive Board, DLR

FOR THE NATIONAL SPACE BIOMEDICAL RESEARCH INSTITUTE, HOUSTON, TEXAS, U.S.A.

By:

Laurence R. Young, Sc.D. Date

Director, NSBRI

Approval:

By:

Bobby R. Alford, M.D.

Date

Chairman of the Board and Chief Executive Officer, NSBRI 


\title{
National Space Biomedical Research Institute
}

\author{
RETREAT \\ June 8-11, 1998
}

Del Lago Conference Center

Montgomery, Texas

Monday, June 8

AGENDA

PLENARY SESSION - TEJAS BALLROOM I

8:00 a.m. Welcome

B. Alford

8:10 Purposes \& Objectives of Retreat

L. Young

NSBRI Activities: March 1997-June 1998

June-October 1998

$\begin{array}{lll}\text { 8:45 } & \text { NASA Greetings } & \text { J. Rummel } \\ \text { 9:00 } & \begin{array}{l}\text { Critical Path Roadmap for Human } \\ \text { Exploration Missions - Overview }\end{array} & \text { C. Sawin }\end{array}$

10:00 BREAK

10:30 Team Report: Bone Loss J. Shapiro

11:30 Team Report: Immunology, Infection \& Hematology W. Shearer

12:30 p.m. LUNCH

POSTER SESSION: TEJAS BALLROOM II

1:30 Bone Loss \& Immunology Team Posters Project Investigators

3:00 FREE DISCUSSION TIME

6:00 BUFFET DINNER

PLENARY SESSION - TEJAS BALLROOM I

8:00 Critical Path Roadmap for Human $\quad$ C. Sawin

Exploration Missions

J. Charles

- Reports from Risk Area Teams

L. Leveton

- Assignment for Workshop 


\section{PLENARY SESSION - TEJAS BALLROOM I}

8:00 a.m. Team Report: Cardiovascular Alterations

R. Cohen

9:00

Team Report: Radiation Effects

J. Dicello

10:00

BREAK

$10: 30$

Team Report: Muscle Alterations \& Atrophy

R. Schwartz/F. Booth

$11: 30$

Team Report: Neurovestibular Adaptation

C. Oman

12:30 p.m. LUNCH

POSTER SESSION: TEJAS BALLROOM II

$1: 30$

Cardiovascular, Radiation, Muscle \& Neurovestibular Team Posters

FREE DISCUSSION TIME

PLENARY SESSION - TEJAS BALLROOM I

M. MacLeish

6:00

BUFFET DINNER

8:00

ROUND TABLE DISCUSSIONS

- TEJAS BALLROOM I

NASA Flight Opportunities \&

C. Sawin

Experiment Integration

- SAM HOUSTON I

Education \& Outreach: Connecting

NSBRI to Communities \& Schools

- SAM HOUSTON II

Use of Crescendo (MK0677) and Growth R. Schwartz

Hormone Releasing Factor

- MONTGOMERY I

Remote and In Situ Biomedicine H. Pien

- MONTGOMERY II

M. MacLeish

Stem Cells in Space

W. Shearer 
Wednesday, June 10

PLENARY SESSION - TEJAS BALLROOM I

8:00 a.m. Team Report: Human Performance

C. Czeisler

9:00

Team Report: Technology Development

V. Pisacane

10:00 BREAK

10:30 International Space Station Capability

J. Buchli

and Industry Partnership

12:30 p.m. LUNCH

POSTER SESSION: TEJAS BALLROOM II

$1: 30$

Human Performance \& Technology Development Team Posters

Project Investigators

FREE DISCUSSION TIME

PLENARY SESSION - TEJAS BALLROOM I

5:00

NSBRI Data Archive Project

L. Suther

6:00

BUFFET DINNER

8:00

ROUND TABLE DISCUSSIONS

- TEJAS BALLROOM I

Microbiological Characterization of

M. Wilson

Closed Systems: Potential Impacts \&

Countermeasures

- SAM HOUSTON I

Technology Development: How Industry

And Academia Collaborate

J. Kerwin

SPECIAL INTEREST GROUP MEETING

- SAM HOUSTON II

Institute Data Archive System

V. Pisacane 
Thursday, June 11

PLENARY SESSION - TEJAS BALLROOM I

8:00 a.m. Critical Path Roadmap for Human J. Charles

Exploration Missions

- Final Reports from Risk Area Teams - Discussion by All

10:30 BREAK

10:45 FINAL REMARKS

B. Alford \& L. Young

11:15 ADJOURN

11:30 LUNCH

\author{
TEAM LEADERS ONLY \\ MEETING ROOM: LONGHORN
}

12:00 p.m. Team Leaders Meeting - Post Retreat Discussions

Where Do We Go From Here?

1:00

ADJOURN 


\title{
NATIONAL SPACE BIOMEDICAL RESEARCH INSTITUTE INDUSTRY FORUM CHARTER
}

\author{
Establishment and Authority
}

The National Space Biomedical Research Institute (NSBRI) Administration, having determined that it is in the public interest in connection with the accomplishment of the major mission of the Institute, as well as to foster strong interaction between Industry and the Institute, hereby establishes the NSBRI Industry Forum.

\section{Membership}

The Industry Forum membership will consist of representatives from 11 charter companies, including: Boeing Space Systems; Veridian; Merck Pharmaceuticals; Lockheed-Martin; Draper Labs; Wyle Laboratories; Payload Systems; Raytheon; Southwestern Bell Communications; Silicon Graphics; and Information Dynamics. This ensures the inclusion of consensus leaders in the aerospace industry who have experience in partnering with NASA in the commercial development of technologies adapted from the space program.

\section{Purpose and Duties}

The Industry Forum will strive to partner with the Institute by:

- identifying technologies in development by research teams that have the potential for commercialization;

- providing new technologies for use by the research teams and through direct financial support to the research teams;

- identifying operational problems of space flight that have relevance to space-based research enterprises;

- contributing to cost-sharing; and

- assisting in leveraging Federal support to the Institute through cooperative activities.

\section{Meetings}

The Industry Forum will convene at least semi-annually, with teleconferences offset 3 months from each of these meetings. NSBRI Administration will be notified well in advance of upcoming Industry Forum activities.

\section{Administrative Provisions}

The Industry Forum will be an independent body that will interact with, but not be governed by, NSBRI. Leadership of the forum is by majority election of a member company representative to a one year term as Executive Secretary. Administrative support for the Executive Secretary will be provided by the elected individual's company, and will be considered in-kind support. The forum will receive no operating budget from NSBRI, with the exception of use of the NSBRI headquarters conference room facility for semi-annual meetings as deemed appropriate by the forum representatives. Representatives to the forum will serve at the discretion of the member companies who employ them; NSBRI administration will play no role in the selection of representatives. Member companies may use the Institute logo at their discretion, and may identify themselves as NSBRI Forum members in correspondence. 


\section{APPLICATION FOR MEMBERSHIP IN THE NATIONAL SPACE BIOMEDICAL RESEARCH INSTITUTE INDUSTRY FORUM}

\section{Introduction}

As a preamble to this document it should be clearly stated that the aim of the Industry Forum is to expand by only a few members companies, since the intended purpose of this group is to form a limited number of productive partnerships with Institute research teams. Were the Industry Forum to become a large group, any competitive advantage gained by member companies as a result of having invested resources into partnering would be diluted, likely to a level that would not justify continued participation.

\section{Mission Statement for the Industry Forum}

The mission of the NSBRI Industry Forum is to work together with the administration and research teams of the Institute to make possible the transfer and dissemination of biomedical advances in knowledge and technology acquired through living and working in space to the benefit of mankind in space and on Earth.

\section{Application Procedure}

Companies interested in membership in the Industry Forum should prepare a letter addressed to the Executive Secretary. This document should include the following:

- Identification of the management level at which approval for application for membership has received written approval;

- A brief description of the company;

- Identification of the individual within the company who will serve as the point of contact with the Industry Forum, together with a brief discussion of the role played by that person within the company;

- A statement identifying how the company, through membership in the Industry Forum, can contribute to accomplishing the missions of both the Industry Forum and the Institute; and

- A quantitative per annum estimate of the direct and/or in-kind support to be provided by the company to the Industry Forum and to the Institute

\section{Industry Forum Consideration of Applications}

A simple majority vote of the Industry Forum companies is required in order to recommend an applicant company for membership. This recommendation is forwarded to the Institute's Board of Directors for approval. It is expected that applications will be handled expeditiously by the Industry Forum, however applicant companies should be aware that the Institute Board of Directors may consider such matters infrequently (once or twice per year). 


\section{PROPOSAL FOR PARTNERING AND INITIATIVES \\ NATIONAL SPACE BIOMEDICAL RESEARCH INSTITUTE INDUSTRY FORUM}

\section{INTRODUCTION}

The National Space Biomedical Research Institute (NSBRI) Industry Forum (IF) held an Executive Session meeting on June 9, 1998 during the NSBRI Workshop at Del Lago Conference Center in Conroe, Texas. All Industry Forum members present expressed the need to develop partnering and initiatives with NSBRI research programs to successfully fulfill the IF mission, increase Institute impact, and improve Industry's return on investment in the Institute.

As stated in the NSBRI Industry Forum mission statement, and as detailed in the Industry Forum Charter, the Industry Forum will strive to partner with the Institute in a variety of ways (See Industry Forum Charter). It is our belief that Industry Forum involvement in the development of critical path technology roadmaps and research directions, development of research proposals, and peer review of Institute research proposals is critical to mission implementation and success.

\section{PLAN FOR PARTNERING}

We believe that the first step for improved interaction between the IF and Institute is to develop a formal process to solicit and integrate critical path technologies from industry engineers and scientists and Institute research teams. The Industry Forum membership includes companies with expertise in aerospace, biomedicine, pharmaceuticals, biotechnology, and telemedicine, to name several. The integration of applied industrial research with basic academic research will ensure quantitative critical path research prioritization, improve technology transfer, and leverage government and industry co-funding. Information concerning critical path technologies should be updated annually and provided to researchers prior to requests for proposals.

Secondly, Industry participation in the development of research proposals for the Institute is one of the most important criteria for improving industry interaction between forum scientists and engineers and Institute research teams. Members of the Industry Forum should be included on distribution lists for NSBRI research announcements and requests for proposals. Industry has had limited success coordinating and communicating with research teams through roundtables and other means at NSBRI meetings. Incentives should be developed to encourage teaming of industry and academic scientists. We suggest the establishment of experience tours or sabbaticals for professors, postdoctoral fellows and/or graduate students to utilize industry facilities to further the Institute research effort. Also, Industry co-investigators could spend a sabbatical at the associated university performing basic and applied research on critical projects benefiting both Industry and the Institute. Cooperative research will provide a greater return on investment for the Institute and Industry by: supporting cost sharing; facilitating educational outreach; and improving technology transfer.

Last, the Industry Forum requests input into the peer review process for Institute proposal selection and research progress reports. We are not suggesting that industry should be involved in evaluating the quality of research: rather we feel that the $t$ he Industry Forum could play an important role in assessing whether ongoing and proposed research projects satisfy the 
requirements of the critical path technologies and NASA requirements. The membership of the Industry Forum possesses the knowledge and experience to relate operational problems of space flight to research needs.

\section{SUMMARY}

We, the members of the Industry Forum of the National Space Biomedical Research Institute, look forward to increased involvement with and support of, the Institute in 1999. In this document, we have made suggestions designed to assist the Institute in: development of critical path technology roadmaps and research directions: formulation of new research proposals: and review Institute research proposals. Our unanimous opinion is that adding these responsibilities will be critical to improving the functionality of the Industry Forum. We request that NSBRI Administration work together with us to develop these formal processes in order to assist the Institute in meeting its future goals, increase cost sharing for critical path research projects, and better transition technologies for use in space and on Earth. 
Appendix G

\section{NATIONAL SPACE BIOMEDICAL RESEARCH INSTITUTE}

\section{Investigator List}

Andersen Consulting: Carpenter-Smith, T. R.; Australian Antarctic Division: Lugg, D. J.; Baylor College of Medicine: Abdellatif, M. M., Alfrey, C. P., Appel, S. H., Butel, J. S., Cohen, H. S., Conner, M. E., Demayo, F. J., Epstein, H. F., Goldberg, J., Hamilton, S. L., LeBlanc, A., Lednickey, J. A., Ling, P. D., Medina, D., Mosier, D. R., O'Malley, B. W., Overbeek, P. A., Reid, M. B., Rice, L., Rosenblatt, H. M., Schneider, M. D., Schwartz, R. J., Shearer, W. T., Smith, C. L., Smith, C. W., Smith, E. O., Smolen, J. E., Trial, J., Weigel, N. L., and Wood, S.; Brookhaven National Laboratory: Sutherland, B. M.; Brooklyn College: Raphan, T.; Dartmouth College: Taube, J. S.; Harvard Medical School: Bonventre, J. V., Brown, E. M., Brown, E. N., Cajochen, C., Czeisler, C. A., Dijk, D., Goldberg, A. L., Jewett, M. E., Khalsa, S. B., Krebs, D. E., Kronauer, R. E., Lorell, B. H., Luithardt, H. H., Mullen, T. J., Mullington, J. M., Oden, Z. M., Ramsdell, C. R., Ronda, J. M., Rosenthal, N. A., Wall, C. C., Williams, G. H., and Wright, K. P.; Loma Linda University Medical Center: Gridley, D. S.; Massachusetts Institute of Technology: Beall, A. C., Cohen, R. J., Kamm, R. D., Mark, R. G., Natapoff, A., Newman, D. J., Oman, C. M., Szolovits, P., and Young, L. R.; Mayo Clinic: Turner, R. T.; Morehouse School of Medicine: Ofili, Elizabeth, and Thierry-Palmer, M; NASA Johnson Space Center: Bloomberg, J. J., Cucinotta, F. A., Paloski, W. H., Pierson, D. L., Sams, C., Shackelford, L., Yang, T., and Yelle, J. M.; SmithKline Beecham Pharmaceuticals: Suva, L. J.; Texas A\&M University: Armstrong, R. B., Bloomfield, S. A., Braby, L. A., Delp, M. D., Hogan, H. A., Shebilske, W. L., and Sinden, R. R.; The Johns Hopkins University: Beck, T. J., Berkowitz, D., Bryden, W. A., Charles, H. K. Jr., Cotter, R. J., Dicello, J. F., Fainchtein, R., Fedarko, N. S., Feldmesser, H. S., Gold, R. E., Goldsten, J. O., Griffin, C. A., Helzlsouer, K. J., Huso, D. L., Jones, R. J., Kessler, P., Kinnison, J. D., Maurer, R. H., Minor, L. B., Novak, G. R., O'Malley, B. W. Jr., Piantadosi, S., Pisacane, V. L., Potember, R. S., Risby, T. H., Roth, D. R., Ruff, C. B., Schultheis, L. W., Shelhamer, M. J., Shoukas, A. A., Strandberg, J. D., Williams, J. R., Zee, D. S., and Zhang, Y.; Uniformed Services University of the Health Sciences: Shapiro, J. R.; University of Caifornia, Irvine: Baldwin, K. M.; University of Florida: Byrne, B. J.; University of Houston: Fox, G. E., and Willson, R. C.; University of Pennsylvania: Dinges, D. F., Maislin, G., and Van Dongen, H. P.; University of Texas Health Science Center at Houston: Booth, F. W.; University of Texas M. D. Anderson Cancer Center: Reuben, J. M.; University of Washington: Ochs, H. D.; University of Wisconsin: Howard, S. P.; York University: Howard, I. P. 


\title{
NIDCD-NSBRI PROGRAM FOR THE SUPPORT OF VESTIBULAR RESEARCH
}

\author{
Release Date: June 16, 1998
}

PA NUMBER: PAS-98-081

P.T.

National Institute on Deafness and Other Communication Disorders

National Space Biomedical Research Institute

Application Receipt Date: September 28, 1998

PURPOSE

The National Institute on Deafness and Other Communication Disorders (NIDCD) of the National Institutes of Health (NIH) and the National Space Biomedical Research Institute (NSBRI) invite research project applications for the support of ground-based research on the dynamic adaptation of central vestibular functions. The purpose of this initiative is to promote the application of cellular and molecular biologic approaches and advanced systems-level approaches to the understanding of vestibular adaptation. This research shall contribute to one or both of the following goals: 1) understand the neural basis of the autonomic responses that accompany acute vestibular dysfunction, motion sickness and responses to altered gravitational environments, and 2) facilitate the development of targeted approaches for the management of balance and vestibular disorders, motion sickness and adaptation to altered gravitational environments.

\section{HEALTHY PEOPLE 2000}

The Public Health Service (PHS) is committed to achieving the health promotion and disease prevention objectives of "Healthy People 2000," a PHS-led national activity for setting priority areas. This Program Announcement (PA), NIDCD-NSBRI Program for the Support of Vestibular Research, is related to the priority areas of physical activity fitness, educational and community-based programs, unintentional injuries, occupational safety and health, diabetes and chronic disabling diseases, clinical prevention services and human resource development. Potential applicants may obtain a copy of "Healthy People 2000" (Full Report: Stock No. 017001-00474-0 or Summary Report: Stock No. 017-001-00473-1) through the Superintendent of Documents, Government Printing Office, Washington, DC 20402-9325 (telephone 202-5121800).

\section{ELIGIBILITY REQUIREMENTS}

Applications may be submitted by domestic and foreign, for-profit and non-profit organizations, public and private, such as universities, colleges, hospitals, laboratories, units of state and local governments, and eligible agencies of the Federal government. Applications from minority individuals, women and individuals with disabilities are encouraged. 


\section{MECHANISM OF SUPPORT}

The mechanism of support shall be the individual investigator-initiated research grant (R01) award. Although a scored application responsive to this initiative may be awarded by either the NIDCD or the NSBRI, individual grant awards will not be cofunded. Hence, the grant awards made by the NIDCD and the NSBRI will be separate and mutually exclusive. Upon authorization from the applicant investigator and the applicant institution (see "SPECIAL REQUIREMENTS"), the grant application, the summary statement and related materials will be released to the NSBRI. The NIDCD and the NSBRI will both employ the same criteria in the award of applications for this program (see "AWARD CRITERIA") and confer during this process to ensure that there is no overlap in funding.

\section{FUNDS AVAILABLE}

The NIDCD has committed up to $\$ 400,000$ total costs [direct cost plus facilities and administrative allowance (indirect cost)] to this initiative for FY99 (Year One). The NSBRI has committed up to $\$ 400,000$ total costs for FY99, as well. It is anticipated that a total of three to six awards of up to five years each will be made in FY99. Those awards made by the NIDCD shall be administered according to current NIH policy.

\section{RESEARCH OBJECTIVES}

\section{Background}

Changes in vestibular function play a key role in numerous clinical disorders of balance and spatial orientation on Earth and in the spatial orientation and motor performance of space travelers during and after flight. However, the mechanisms responsible for vestibular adaptive changes are not well understood. The cellular and subcellular properties of many neurons within the vestibular system have been characterized anatomically and physiologically, and there is evidence implicating the involvement of both excitatory amino acid and peptide neurotransmitters in vestibular function. However, there have been no comprehensive studies of the neurochemical organization of the vestibular nuclear complex and the central vestibular pathways, nor has there been sufficient application of systems approaches and models to relate stimulus parameters and behavior to vestibular adaptation. These studies are needed in order to understand the recovery of vestibular function following injury (vestibular compensation) and the adaptation of the vestibular system to altered gravitational environments, including microgravity and centrifugation.

The NIDCD signed a Memorandum of Understanding with the NSBRI on June 6, 1997 for the joint support of ground-based research in the vestibular system relevant to the research missions of both the NIDCD and the NSBRI. This research shall be applicable to the health of space travelers and to vestibular disorders on Earth. The NSBRI was established by the National Aeronautics and Space Administration at the Baylor College of Medicine in April 1997 as a consortium of seven institutions for the conduct of biomedical research necessary to support human health in the exploration and development of space. Further information on the mission and the research components of the NSBRI is available on the World Wide Web at http://www.nsbri.org. 
Scope

Changes in vestibular function, through modifications of the processes of learning and adaptive plasticity, underlie both treatment approaches to vestibular disorders and adaptation to altered gravitational environments. These changes take place through a combination of cellular and integrated neural network modifications. Very little is known about the cellular- and molecularlevel processing of signals from the vestibular and nonvestibular motion sensors in the central vestibular pathways, about the changing roles of neural circuits during and following adaptation, and about the integrated neural network modifications that lead to a new adapted state. It is now possible to identify specific relay neurons in vitro and to determine how their cellular properties contribute to the processing of vestibular and visual information and how this processing is modified by cerebellar or brain stem inhibitory mechanisms. It is also possible to use advanced systems approaches to model integrated neural network responses. Knowledge of the key cellular- and systems-level events underlying vestibular compensation and dynamic adaptation will provide a solid basis for the improved rehabilitation of patients with balance disorders and for management of the sensorimotor and perceptual difficulties associated with space travel, particularly during long-duration space missions.

The purpose of this initiative is to promote the application of cellular and molecular biologic approaches and advanced systems-level approaches to the understanding of adaptive functions (e.g., learning and adaptive plasticity) within the central vestibular pathways. This will afford the opportunity to merge and maximize the efforts of cellular and systems neuroscience.

Applications submitted in response to this PA may either encompass a continuum of approaches from reductionistic to systems-level and integrated systems-levels, or may focus on one level of analysis. Applicants shall define how their proposed research will contribute to one or both of the following goals: 1 ) understand the neural basis of the autonomic manifestations that accompany acute vestibular dysfunction, motion sickness and responses to altered gravitational environments, and 2) facilitate the development of targeted pharmacotherapeutic, physical rehabilitative and/or behavioral approaches for the management of balance and vestibular disorders, motion sickness and adaptation to altered gravitational environments.

\section{SPECIAL REQUIREMENTS}

\section{Annual Meetings}

The principal investigators (PIs) supported through this initiative shall meet annually for one day with the Neurovestibular Adaptation Team of the NSBRI and with program officials of the NSBRI and the NIDCD to review the progress and to discuss the future plans of their research projects. The Neurovestibular Adaptation Team is headquartered in the Boston area at the present time. In addition, the PIs shall participate in an annual three- to four-day NSBRI-sponsored workshop/retreat or symposium which will usually be held in the Houston, TX area. These events will facilitate communication and collaborative interactions among the investigators supported through this initiative and the investigators comprising the Neurovestibular Adaptation Team and the other research teams of the NSBRI. Budget requests for travel should reflect the costs associated with these two annual meetings and should include a statement indicating that this travel is a special requirement of this PA. 


\section{Letter of Authorization}

In order for an application to be considered for funding by the NSBRI, the applicant must submit a brief letter of authorization, co-signed by the Principal Investigator and the official signing for the applicant institution, authorizing the NIDCD to release the application, the summary statement and all related materials to the NSBRI. These materials will be shared with the NSBRI when available. Applications without such authorization will not be considered for funding by the NSBRI.

\section{INCLUSION OF WOMEN AND MINORITIES IN RESEARCH INVOLVING HUMAN SUBJECTS}

It is the policy of NIH that women and members of minority groups and their subpopulations must be included in all NIH supported biomedical and behavioral research projects involving human subjects, unless a clear and compelling rationale and justification is provided that inclusion is inappropriate with respect to the health of the subjects or the purpose of the research. This policy results from the NIH Revitalization Act of 1993 (Section 492B of Public Law 10343). All investigators proposing research involving human subjects should read the "NIH Guidelines For Inclusion of Women and Minorities as Subjects in Clinical Research", which have been published in the Federal Register of March 28, 1994 (FR 59 14508-14513), and in the NIH Guide for Grants and Contracts, Volume 23, Number 11, March 18, 1994. Investigators may obtain copies from these sources or from the program staff or contact person listed under INQUTRIES. Program staff will, on request, provide additional relevant information concerning the policy.

\section{APPLICATION PROCEDURES}

Applications are to be submitted on the grant application form PHS 398 (rev. 5/95). These forms are available at most institutional offices of sponsored research, from the NIDCD program administrator listed under INQUIRIES, as well as from the Office of Extramural Outreach and Information Resources, National Institutes of Health, 6701 Rockledge Drive, MSC 7910, Bethesda, MD 20892-7910, telephone 301/435-0714, FAX 301/480-0525, email: ASKNIH@ODROCKM1.OD.NIH.GOV. The PHS 398 form is also available electronically on the NIH Home Page at http://www.nih.gov/grants/phs398.

The PA title and number (NIDCD-NSBRI Program for the Support of Vestibular Research, PAS98-081) must be typed in Section 2 of the face page of the application form and the "Yes" box must be checked. Instructions for completing the application are found in the PHS 398 form.

Submit the signed, original application and five exact photocopies and five collated sets of appendix materials, in one package to:

CENTER FOR SCIENTIFIC REVIEW

NATIONAL INSTITUTES OF HEALTH

6701 ROCKLEDGE DRIVE, ROOM 1040 - MSC 7710

BETHESDA, MD 20892-7710

BETHESDA, MD 20817 (for express/courier service)

There will be only one receipt date for this PA. Applications must be postmarked by the receipt date of September 28, 1998. 
If the application submitted in response to this PA is substantially similar to a grant application already submitted to the $\mathrm{NIH}$ for review, but not yet reviewed, the applicant will be asked to withdraw either the pending application or the new one. Simultaneous submission of identical applications will not be allowed, nor will essentially identical applications be reviewed by different review committees. This does not preclude the submission of substantial revisions of applications already reviewed, but such applications must include an introduction addressing the previous critique.

\section{REVIEW CONSIDERATIONS}

Applications will be evaluated for scientific and technical merit by an appropriate peer review group convened by the Center for Scientific Review in accordance with NIH peer review procedures. As part of the initial merit review, all applications will receive a written critique and undergo a process in which only those applications deemed to have the highest scientific merit, generally the top half of applications under review, will be discussed, assigned a priority score and receive a second-level review by the National Deafness and Other Communication Disorders Advisory Council and the NSBRI.

\section{Review Criteria}

o Significance: Does this study address an important problem relevant to this PA? If the aims of the application are achieved, how will scientific knowledge be advanced? What will be the effect of these studies on the concepts or methods that drive this field?

o Approach: Are the conceptual framework, design, methods, and analyses adequately developed, well-integrated, and appropriate to the aims of the project? Does the applicant acknowledge potential problem areas and consider alternative tactics?

o Innovation: Does the project employ novel concepts, approaches or method? Are the aims original and innovative? Does the project challenge existing paradigms or develop new methodologies or technologies?

o Investigator: Is the investigator appropriately trained and well suited to carry out this work? Is the work proposed appropriate to the experience level of the principal investigator and other researchers (if any)?

o Environment: Does the scientific environment in which the work will be done contribute to the probability of success? Do the proposed experiments take advantage of unique features of the scientific environment or employ useful collaborative arrangements? Is there evidence of institutional support?

o Appropriateness of the proposed budget and duration in relation to the proposed research.

o For Studies Involving Human Subjects: Adequacy of plans to include both genders and minorities and their subgroups as appropriate for the scientific goals of the research. Plans for the recruitment and retention of subjects will also be evaluated.

The initial review group will also examine the provisions for the protection of human and animal subjects, and the safety of the research environment. 


\section{AWARD CRITERIA}

Up to a total of six research grants will be awarded separately by NIDCD and NSBRI in response to this PA. The anticipated date of award is August 1, 1999. The following criteria will be considered by both the NIDCD and the NSBRI in making their funding decisions:

o Responsiveness of the proposed project to the purpose of this PA;

o Quality of the proposed project, as determined by peer review;

o Program priorities of the NIDCD and the NSBRI within the research purview of this PA; and

o Availability of funds for this initiative.

\section{INQUIRIES}

Inquiries concerning this PA are encouraged. The opportunity to clarify any issues and to respond to questions from potential applicants is welcome.

Direct inquiries regarding programmatic issues to:

Daniel A. Sklare, Ph.D.

Health Scientist Administrator

Hearing and Balance/Vestibular Sciences Branch

Division of Human Communication

National Institute on Deafness and Other Communication Disorders

6120 Executive Boulevard, Room 400-C - MSC 7180

Bethesda, MD 20892-7180

Rockville, MD 20852 (for express/courier service)

Telephone: (301) 496-1804

FAX: (301) 402-6251

Email: daniel_sklare@nih.gov

or to:

Ronald J. White, Ph.D.

Associate Director

National Space Biomedical Research Institute

One Baylor Plaza, NA-425

Houston, TX 77030

Telephone: (713) 798-7412

FAX: (713) 798-7413

Email: rwhite@bcm.tmc.edu

Direct inquiries regarding fiscal matters to:

Sharon Hunt

Chief, Grants Management Branch

Division of Extramural Activities

National Institute on Deafness and Other Communication Disorders

Executive Plaza South

6120 Executive Boulevard, Room 400-B - MSC 7180 
Bethesda, MD 20892-7180

Rockville, MD 20852 (for express/courier service)

Telephone: (301) 402-0909

FAX: (301) 402-1758

Email: sh79f@nih.gov

\section{AUTHORITY AND REGULATIONS}

This program is described in the Catalog of Federal Domestic Assistance No. 93.173. Awards are made under the authority of the Public Health Service Act, Title IV, Part A (Public Law 78410, as amended by Public Law 99-158, 42 USC 241 and 285) and administered under PHS grant policies and Federal Regulations at 42 CFR 52 and 45 CFR Part 74. This program is not subject to the intergovernmental review requirements of Executive Order 12372 or Health Systems Agency review.

The PHS strongly encourages all grant and contract recipients to provide a smoke-free workplace and promote the non-use of all tobacco products. In addition, Public Law 103-227, the ProChildren Act of 1994, prohibits smoking in certain facilities (or in some cases, any portion of a facility) in which regular or routine education, library, day care, health care or early childhood development services are provided to children. This is consistent with the PHS mission to protect and advance the physical and mental health of the American people. 